(Aus dem Res.-Lazarett Kunstgewerbemuseum Berlin und dem Res.-Lazarett Bad Altheide.)

\title{
Die Wirkung natürlicher und künstlicher Kohlensäurebäder sowie der Hochfrequenzbehandlung bei Herzkranken, kontrolliert durch die ,plethysmographische Arbeitskurve ${ }^{66 *}$ )
}

\author{
Von
}

Prof. Ernst Weber (Universität Berlin).

Mit 47 Textabbildungen.

(Eingegangen am 6. Dezember 1918.)

In der Zeitschr. f. experim. Pathol. u. Ther. habe ich unter dem Titel „Eine neue Untersuchungsmethode bei Herzkranken“ im Jahre 1916 an der Hand von 26 Kurven die erste ausführliche Beschreibung der physiologischen und pathologischen Grundlagen meiner Methode der ,plethysmographischen Arbeitskurve“" und ihrer Anwendung bei Herzkranken veröffentlicht. Inzwischen sind meine Angaben von mehreren Klinikern nachgeprüft und bestätigt worden. (L. Dünner, „,Die Funktionsprüfung des Herzens mittels der Plethysmographie nach Weber", Zeitschr. f. klin. Medizin 1917; H. Schirokauer, ,Die klinische Bewertung der Plethysmographie bei Herzkrankheiten", Zeitschr. f. phys. u. diät. Ther. 1918.)

Die von beiden erwähnten Herren Kollegen und von mir ausführlich beschriebene Technik der Methode, die man erst nach mehrmonatiger, täglicher Ubung beherrschen lernt, lasse ich hier völlig beiseite, ebenso jede eingehende Erläuterung der physiologischen Grundlagen der Methode, die ich in der früheren Abhandlung ausführlich behandelt habe. Die früheren Untersuchungsergebnisse an Kranken und meine Deutung der pathologischen Kurvenformen bei Herzkranken, die sich als vollkommen richtig erwiesen hat, will ich zunächst nochmals kurz zusammenfassen, zumal ich in mehreren Punkten nach den neu hinzugekommenen Erfahrungen einige, wenn auch unwesentliche, theoretische Ergänzungen hinzuzufügen habe, die das Verständnis klären und neue Beweise für die Richtigkeit meiner Erklärungen darstellen. Ganz besonders betrifft das die eine, für die hier erörterte Untersuchung wich tigste, pathologische Form der plethysmographischen Arbeitskurve, nämlich die von mir ,nachträglich ansteigend" genannte Kurve. Auch

*) Diese Abhandlung erscheint gleichzeitig im Verlag von Julius Springer in Berlin als Broschüre. 
hierbei muß ich aber betreffs zahlreicher Einzelheiten auf die frühere Abhandlung verweisen, wenn auch das Wichtigste hier erwähnt wird.

Die seit 12 Jahren von mir ausgebildete Methode besteht darin, daß die untersuchte Person, die nur den Vorderarm zu entblößen braucht, entweder sitzend, wie es Abb. 1 veranschaulicht, mit dem frei herabhängenden Fuß, oder auf einem Bett liegend bei unterstütztem Unterschenkel, eine 10-15 Sekunden lang dauernde kräftige Fußbewegung ausführt (die in schnell abwechselnder Dorsal- und Plantarflexion oder in dauernder Dorsalflexion besteht), während gleichzeitig die Änderung des Volumens des Armes und der Atmungsgröße, aus

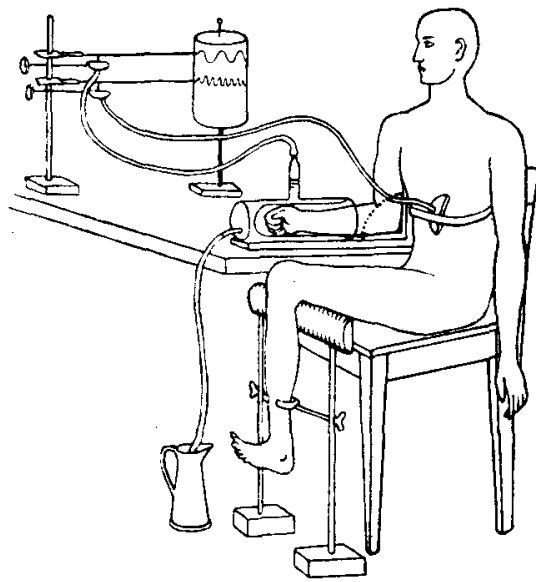

Abb. 1. Schema der Versuchsanordnung bei sitzender Person.

Alle folgenden Kurven sind (im Gegensatz zu den Verhăltnissen obiger Abbildung) von links nach rechts zu lesen. denen man die Änderungen der Blutfülle des Armes erkennt, auf einer rotierenden Trommel registriert werden, wie dies gleichfalls aus $A b b .1$ zu ersehen ist.

Nach meinen Feststellungen an Tausenden von Gesunden tritt während der völlig lokalisierten Muskelarbeit des Fußes (wie bei jeder anderen kräftigen Muskelarbeit) eine Zunahme der arteriellen Blutfülle aller äußeren Körperteile (ausgenommen die des Kopfes) ein unter gleichzeitiger Abnahme der Blutfülle der Bauchorgane. Der Vorgang stellt ein überaus zweckmäBiges Hilfsmittel zur Ausdauer bei anstrengender Muskelarbeit dar, da durch ihn die Beseitigung der in den arbeitenden Muskeln entstehenden Ermüdungsstoffe erleichtert und durch verstärkte Sauerstoffzufuhr die verbrauchten Stoffe schneller ersetzt werden. Zur Erkennung des normalen Eintretens dieses Vorgangs ist die von mir vorgenommene gleichzeitige Registrierung der Änderung der Blutfülle der Bauchorgane und des Gesichts unnötig, es genügt die des Armes, bei der es sich durch ein Ansteigen der Volumkurve während der 10-15 Sekunden dauernden Muskelarbeit des Fußes kennzeichnet. Beim Gesunden sinkt sofort nach Aufhören der Muskelarbeit die Volumkurve wieder vollkommen auf die anfängliche Höhe zurück.

Der Vorgang wird bewirkt erstens durch aktive Erweiterung der äußeren Blutgefäße (neben aktiver Verengerung der Bauchgefäße) infolge der während der Muskelarbeit eintretenden Erregung der motorischen Zonen der Hirnrinde, die zum Gefäßzentrum der Medulla weitergeleitet 
wird und zweitens durch die während der Muskelarbeit verstärkte Arbeit des Herzens, das das Blut aus den Bauchorganen schöpft und in verstärkter Menge in die erweiterten Blutgefäße der Peripherie wirft.

Störungen in der Funktion jeder dieser beiden Komponenten können nun Änderungen in dem Eintreten des Vorgangs und den Kurven, in denen er sich selbst registriert, verursachen.

Bei jedem Gesunden entsteht nach vollkommen erschöpfender Muskelarbeit (lange Märsche usw.) während dann vorgenommener Fußarbeit anstatt der Steigung eine Senkung der Kurve des Armvolumens, da die in diesem erschöpften Zustand des Körpers in großer Menge im Blut zirkulierenden Ermüdungsstoffe auch die motorìschen Hirnrindenteile umspülen und dabei in der Weise schädigen, daß sie die bei der Intention der Muskelarbeit in ihnen entstehenden Reize in derart veränderter Weise zum Gefäßzentrum weiterleiten, daß von dort aus gerade die entgegengesetzten Veränderungen in der Weite der Blutgefäße bewirkt werden, wie im normalen Zustand, so daß also Verengerung der äußeren Gefäße während der Muskelarbeit entsteht, mit allen ihren physiologischen Nachteilen. Ein solches Verhalten der Gefäßreaktion wird nach etwa 2 Stunden wieder normal, da die schädlichen Beimischungen des Blutes im Ruhezustand allmählich wieder beseitigt werden. Sind derartige Beimischungen bei Kranken aber dauernd vorhanden, so sehen wir, wenn ihre Stärke im Verhältnis zur Empfindlichkeit der Hirnzentren des Patienten eine genügende ist, schon im ganz frischen Zustand der Patienten, und zwar dauernd, die umgekehrte, auch als negative bezeichnete, Gefäßreaktion bei Muskelarbeit eintreten. Das ist der Fall bei schwerer Chlorose, Diabetes, nach gewissen Infektionskrankheiten, Blutvergiftungen durch Gas usw., besonders aber auch bei solcher Insuffizienz der Herzfunktion, bei der das Blut nicht mehr genügend durch den kleinen Kreislauf arterialisiert werden kann, so daß die Anwesenheit einer zu großen Menge Kohlensäure oder anderer schädlicher Stoffe im Blut die obenerwähnte Schädigung der Hirnrinde herbeiführt.

Man muß also bei Herzkranken jedesmal zunächst die oben genannten anderen Möglichkeiten der Schädigung der Blutzusammensetzung ausscheiden, was praktisch niemals Schwierigkeiten macht. Uberdies kann, wie wir später sehen werden, eine umgekehrte (negative) Gefäßreaktion bei Herzinsuffizienz meist durch solche Eingriffe, die vorübergehend eine bessere Arterialisierung des Blutes herbeiführen, wie durch Inhalation von Sauerstoff, Herzmassage usw., für eine kurze Zeit in eine positive Gefäßreaktion verwandelt werden, während diese Maßnahmen bei Zuständen, in denen die schädlichen Beimischungen zum Blut, wie z. B. Zucker oder bakterielle Gifte, nicht zeitweilig entfernt werden können, wirkungslos bleiben. 
Die zwingenden Beweise dafür, daß das Auftreten der umgekehrten (negativen) Volumkurve des Armes bei Herzinsuffizienz nur durch die Änderung der Funktionsrichtung der Gefäßzentren im Gehirn bewirkt wird, also nur eine indirekte Folge der mangelhaften Herzfunktion ist (vermittels der ungenügenden Arterialisierung des Blutes), keinesfalls seine direkte Folge, habe ich, wie auch die anderen Grundlagen der Methode, in der früheren Abhandlung ausführlich erörtert, und verweise dahin.

Neben dieser indirekten Wirkung kann es aber auch zu direkter Wirkung der mangelhaften Herzfunktion auf die Form der Arbeitskurve kommen.

Normalerweise kommt es nach dem Ansteigen der Volumkurve während der Muskelarbeit (also nach dem verstärkten Zuströmen des

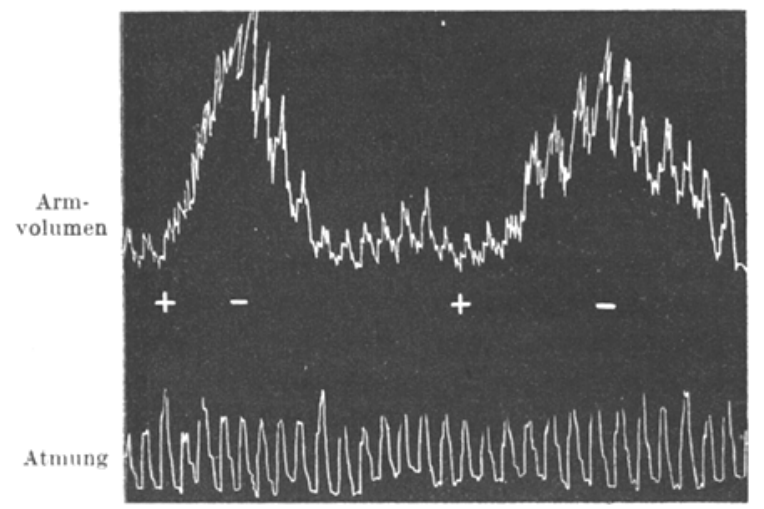

Abb. 2. Normale plethysmographische Arbeitskurven eines an Muskelarbeit gewöhnten gesunảen Mannes. (Die Muskelarbeit des Fußes dauert jedesmal vom Zeichen + bis zum Zeichen -.)

arteriellen Blutes zu allen für Arbeit und Fortbewegung in Betracht kommenden Muskeln), sogleich nach der Beendigung der Muskelarbeit wieder zum Absinken der Kurve, das heißt, der während der Arbeit in die Peripherie geworfene UtberschuB an Blut strömt sogleich wieder zum Herzen und weiter zu den Bauchorganen zurück, wobei der absteigende Schenkel der Kurve ungefähr dieselbe Länge wie der aufsteigende hat, wie dies in der Kurve von Abb. 2 der Fall ist. (Bei den Kurven dauert die Fußarbeit jedesmal vom Zeichen + bis zum Zeichen-.) Oft ist nun der absteigende Schenkel der Kurve doppelt, oder um ein Vielfaches länger, als der aufsteigende, das heißt der Rückfluß des Blutes von der Peripherie ist stark verlangsamt, und das findet sich zunächst im stärksten Maße bei Funktionsschwäche besonders des rechten Herzens, das die von der Peripherie zurückströmende überschüssige Blut- 
menge aufnehmen muß. Rückwirkend kann das Hindernis natürlich auch im kleinen Kreislauf und in der Funktionsschwäche des linken Herzens liegen, oder auch der Widerstand in den Bauchgefäßen kann die Ursache der venösen Stauung sein. Die Möglichkeit der Unterscheidung des letzteren Zustands von den anderen wird an anderer Stelle behandelt werden. Bei vorzugsweiser Schwäche des rechten Herzens und noch gutem, reaktionsfähigem linken Ventrikel wird eine solche ,träge a bfallende" Kurve nach Anregung des linken Ventrikels durch ca. 1/2 Minute danerndes kräftiges Armstoßen des Patienten, durch Herzmassage, oder andere geeignete Mittel oft für einige Zeit in eine normal abfallende verwandelt, da die Staung zeitweilig behoben wird. Ist der linke Herzmuskel dagegen von schlechterer Qualität, oder der Vagus des Patienten besonders reizempfindlich (darüber später Näheres), so kann es danach zu einer negativen Kurve kommen, weil durch die infolge der Vagusreizung verminderte Herzaktion die Arterialisierung des Blutes verschlechtert und dadurch der oben erörterte schädliche Einfluß auf die Gefäßzentren im Gehirn ausgeübt wird, der die Umkehrung der GefäBreaktion bei Muskelarbeit zur Folge hat.

Diese kurzen Andeutungen sollen nur darauf hinweisen, daß derselbe Kranke keineswegs immer bei dieser Funktionsprüfung des Kreislaufs dieselbe Arbeitskurve aufweisen muß, sondern je nach dem Grade der vorhandenen Ermüdung oder Anregung eine verschiedene, während der Gesunde nur nach einer außergewöhnlich erschöpfenden Muskelanstrengung, wie sie ein' 6-8stündiger Marsch darstellt, vorübergehend derartige Änderungen der Kurve zeigt. Um ein Urteil über den Gesamtzustand der Kreislauffunktion eines Herzkranken zu erhalten, muß man daher immer nach der ersten Kurvenaufnahme der Wiederholung eine leicht anstrengende Arbeit anderer Muskeln (nicht des während der Untersuchung arbeitenden Fußes) vorausgehen lassen, am besten das etwa eine Minute lang dauernde kräftige Stoßen des freien Armes, und dann zwischen spätere Kurvenaufnahmen probeweise eine Herz- oder Bauchmassage, oder andere therapeutische Maßnahmen einschalten. In zweifelhaften Fällen kann man diese durch das Armstoßen experimentell herbeigeführte leichte Ermüdung, nach der die Kurve eines Gesunden besser als vorher ist, etwas verlängern, oder besser eine ermüdende Arbeit noch anderer Muskelgruppen (nur nicht des während des Versuchs arbeitenden Fußes) hinzufügen. Ganz besonders ist dies bisweilen bei träg abfallenden Kurven nötig, da diese Form der Kurve zunächst sowohl eine leichte, als auch eine schwerere Störung der Zirkulationsverhältnisse bedeuten kann, was sich nach experimenteller Herbeiführung von Ermüdung des Patienten völlig klärt.

Eine andere Kurvenform ist die ,nachträglich ansteigende“ 
Kurve, an deren Formbildung die pathologische Herzfunktion sowohl direkt beteiligt ist, als auch indirekt mittels der Beeinflussung der Gefäßzentren. Zum Zustandekommen einer solchen Kurve ist zunächst unbedingt erforderlich, daß eine ungenügende Arterialisierung des Blutes, also eine absolute Insuffizienz des Kreislaufs in dieser Beziehung früher vorhanden gewesen ist, und solange wir die nachträglich ansteigende Kurve eintreten sehen, wissen wir, daß eine relative Insuffizienz des Kreislaufs noch besteht, der Zustand ist also keineswegs als ein günstiger aufzufassen. (Ưber diesen Punkt siehe auch die Erörterungen auf S. 12 unten.)

Immerhin hat der in dieser Kurve sich ausdrückende Zustand der Kreislaufsfunktion gewisse Vorzüge vor dem oben erwähnten Zustand, bei dem wir eine-negative Volumkurve eintreten sehen.

Im letzteren Falle ist gleichfalls die Arterialisierung des Blutes eine ungenügende, also die Funktion des kleinen Kreislaufs versagt, dazu kommt aber auch noch ein völliges Versagen derjenigen Funktion des großen Kreislaufs, der während der Muskelarbeit die Versorgung der Muskeln mit einer größeren Menge von Sauerstoff und die Ausspülung der entstehenden Ermüdungsstoffe obliegt, denn die Kurvensenkung während der Muskelarbeit bedeutet, daß in dieser Zeit nicht eine größere, sondern infolge der starken Gefäßverengerung in der Peripherie (gegen die die während der Muskelarbeit verstärkte Herzarbeit nicht aufkommt), sogar eine geringere Blutmenge zu den arbeitenden Muskeln kommt, als im Ruhezustand. Die Folge ist die Unmöglichkeit der Ausdauer bei jeder anstrengenden Muskelarbeit.

Im Zustand der nachträglich ansteigenden Kurve dagegen versucht das Herz durch Entwicklung einer größeren Aktionskraft seiner Systole die durch die Verengerung der Gefäße in der Peripherie geschaffenen Widerstände zu überwinden, sie durch die mit entsprechend größerer Kraft in die Peripherie geworfene Blutwelle passiv auszudehnen und auf diese Weise den arbeitenden Muskeln den dringend nötigen Sauerstoff doch noch zuzuführen, also wenigstens diesen Teil der Funktion des Kreislaufs nach Möglichkeit zu erfüllen. Da das dabei in Betracht kommende Blut sich im Zustand der ungenügenden Arterialisierung befindet, muß die Zuführung einer größeren Menge von Blut in die Peripherie diesen Schaden einigermaßen auszugleichen suchen. Dazu kommt noch, daß dies an sich nützliche Hilfsmittel des Kreislaufs durch thertreibung der Entwieklung der Hilfsaktion zu einer ,Überkorrektion“ des Schadens führt, die ihrerseits wieder neue Schädlichkeiten in der Funktion des Kreislaufs herbeiführen kann, wobei allerdings immer zu berücksichtigen ist, daß der ganze Hilfsmechanismus sich dem schlechtesten, zuerst bestehenden Zustand anzupassen sucht und dem Untersucher in einem späteren Zustand, bei dem die äußeren Widerstände sich vielleicht vermindert haben, als Überkorrektion erscheint, während 
er doch bei einer späteren größeren Anforderung an die Aktionskraft des Herzmuskels, wie etwa während einer Infektionskrankheit, wieder voll ausgenutzt werden und sehr wertvoll sein kann.

Diese Entwicklung der verstärkten Herzaktion ist also die Reaktion des Herzens auf den erhöhten Widerstand, den die in die Peripherie geworfene Blutmenge, besonders während der Ausführung von Muskelarbeit, dort findet, aber zweifellos besteht in solchen Fällen ein gesteigerter Tonus der peripheren Gefäße in geringerem Grade anch dauernd, da die Schädigung der Gefäßzentren im Gehirn durch das ungenügend arterialisierte Blut dauernd vorhanden ist. Es zeigt sich dies auch an den besonders kleinen Volumpulsen (nicht Radialpulsen) solcher Kranker, die bei Muskelarbeit eine negative Kurve aufweisen, auch in Ruhezustand. (Dieser Nachweis ist nur unter Einhaltung bebonderer Vorsichtsmaßregeln zu führen.) Dieser dauernde, durch die peripheren Widerstände bewirkte Reiz trägt zur Entwicklung der Verstärkung der Herzaktion bei.

Rein theoretisch ist es vorstellbar, daß zunächst eine kurze Zeit hindurch diese verstärkte Herzarbeit auch vom Herzmuskel normaler Größe geleistet werden kann, unter Zuhilfenahme besonderer Anregung durch die auf die Systole verstärkend wirkenden Fasern des Accelerans, es muß sogar in jedem Fall für eine kurze Periode ein solches Utbergangsstadium eintreten, aber schon nach sehr kurzer Zeit wird, wie bei jedem Muskel, der dauernd stärker als vorher arbeiten muß, eine Verdickung der Muskulatur, also Hypertrophie des linken Herzens, eintreten. Da aber der Zeitraum, der der Entwicklung der Hypertrophie vorausgeht, nur kurz sein kann und wohl nur in seltenen Fällen zur Untersuchung kommt, ist wohl in fast allen Fällen, in denen man eine nachträglich ansteigende Kurve findet, das Vorhandensein einer linksseitigen Hypertrophie anzunehmen, auch wenn man sie mit anderen, weniger empfindlichen Untersuchungsmethoden nicht nachweisen kann, denn sie kann zunächst nur gering und auch konzentrisch sein. Diese Frage ist praktisch jedenfalls unwesentlich, da bei einem infolge von Insuffizienz des Kreislaufs während der Muskelarbeit übermäßig arbeitenden Herzen, das eine nachträglich ansteigende Kurve aufweist, nach kurzer Zeit in jedem Falle eine Hypertrophie sich entwickelt, die in den meisten Fällen später auch mit anderen Untersuchungsmethoden nachzuweisen ist.

$\mathrm{Da} B$ beim Auftreten der nachträglich ansteigenden Kurve, deren allmähliche Entwicklung aus negativer "Kurve im Laufe einer Reihe von Monaten ich oft verfolgen konnte, immer noch eine ungenügende Arterialisierung des Blutes vorhanden ist, geht außer den erwähnten theoretischen Utberlegungen auch aus folgendem hervor.

Es wäre völlig falsch, nach dem oben Gesagten zu denken, daß die 
Notwendigkeit, durch eine größere Menge des ungenügend arterialisierten Blutes, das während der Muskelarbeit in die Peripherie geworfen werden muß, eine genügende Versorgung der arbeitenden Muskeln mit Sauerstoff zu bewirken, die Ursache davon sei, daß der Herzmuskel nach der Beendigung der Muskelarbeit noch einige Zeit weiter verstärkt arbeite, und daß dies die Ursache des nachträglichen Anstiegs der Kurve sei.

Zunächst könnte eine bloße Verlängerung der verstärkten Herzarbeit über das Ende der Fußarbeit hinaus keineswegs ein noch weiteres Ansteigen der Kurve erklären, es müßte dazu die Herzarbeit nach dem Ende der Fußarbeit noch bedeutend stärker werden als vorher. Bisweilen ist aber bei derartigen Kurven (siehe Abb. 6b, 8b, 8c, 11 a, 11 b) der Anstieg während der Fußarbeit selbst nur unbedeutend, auch wenn die Fußarbeit lange andauert, und erst nach dem Ende dieser Arbeit kommt es dann zu sehr starkem, nachträglichem Anstieg, dessen Nutzen für die Ausdauer bei der dann schon beendeten Muskelarbeit nicht mehr in Betracht kommt. Es deutet schon dies darauf hin, daß in diesen Fällen während der Dauer der Muskelarbeit selbst noch ein Hindernis in der Peripherie zu überwinden ist. Da die Verstärkung der Herzaktion vor allem während der Muskelarbeit selbst wichtig ist, und zweifellos während der Erregung der motorischen Rindenzone infolge der Intention der Muskelarbeit die stärksten Reize von dort aus für die Verstärkung der Herzaktion ausgegeben werden, ist es physiologisch nicht denkbar, daß erst nach Beendigung dieser Vorgänge, auch wenn diese Beendigung durch Verlängerung der Fußarbeit noch so weit. hinausgeschoben wird, die volle Verstärkung der Herzaktion eintreten solle.

Nicht dadurch, daß das Herz nach der Beendigung der Muskelarbeit noch weiter eine sich immer vermehrende Menge von Blut in die Peripherie wirft, wird den arbeitenden Muskeln trotz der ungenügenden Arterialisierung des Blutes die nötige Menge von Sauerstoff zugeführt (das ist eine unerwünschte Nebenerscheinung bei noch unvollkommener Entwicklung dieser Korrektionsversuche des Kreislaufs), sondern der Mechanismus dieser Entwicklung strebt darauf hin (wie wir später noch genauer sehen werden), den Zweck durch Zuführung einer die normale bedeutend übertreffende Blutmenge zur Peripherie während der Dauer der Muskelarbeit selbst zu erreichen. Das Erreichen dieses Zieles drückt sich dadurch aus, daß die Arbeitskurve schon während der Dauer der Muskelarbeit selbst besonders schnell und bedeutend höher, als bei der normalen Kurve, ansteigt, und daß hei späterer Besserung des Allgemeinzustandes der nachträgliche Anstieg der Kurve in eine träge abfallende Kurve übergeht, wie es sich in Abb. 9a auf S. 35 zeigt. Deshalb ist jede besonders schnell und 
hoch während der Muskelarbeit ansteigende Kurve, wenn sie außerdem noch einen verzögerten Abfall zeigt, auf einen alten hypertrophischen Prozeß verdächtig, bei dem die bestmögliche Korrektion der Kreislaufsfunktion erreicht ist und der Widerstand in der Peripherie infolge besserer Arterialisierung des Blutes bedeutend nachgelassen hat. Die Hypertrophie des linken Herzens braucht in solchen Fällen keineswegs anatomisch zurückgegangen zu sein, sie ist mit dem größten Teile ihrer Funktion, der nicht mehr gebraucht wird, und für dessen Ausnutzung daher die Reize fehlen, funktionell latent geworden und kann in diesen Fällen durch künstliche Reizmittel des Herzmuskels, wie Herzmassage, kurze anstrengende Muskelarbeit, Bauchmassage oder andere therapeutische Maßnahmen, wieder zum Vorschein gebracht werden, so daß dann wieder eine deutlich nachträglich ansteigende Kurve entsteht. Die Wichtigkeit dieses Umstandes für die Erklärung der Wirkung der Kohlensäurebäder usw. wird sich später zeigen.

Da bei den träge abfallenden, oben erwähnten Sta u ungskurven nach Herzanregung die Kurve nur normal oder negativ werden kann, aber nicht nachträglich ansteigend, ist ihre Verwechslung mit den hier besprochenen Kurven unmöglich.

In diesem besten Korrektionszustand der früher nachträglich ansteigenden Kurve deutet sich der frühere Zustand noch dadurch an, daß der absteigende Schenkel der Kurve einen geringen, bei jedem Versuch wiederkehrenden nachträglichen Anstiegshöcker zeigt, wie z. B. in der Kurve von Abb. 9a auf S. 35, oder die Kurve fällt träge ab, weil die während der Muskelarbeit verstärkte Arbeit des hypertrophischen Herzmuskels etwas langsamer abklingt als im normalen Zustand, eine Eigenschaft, die für die Reaktion der hypertrophischen Muskelfaser auf Reize charakteristisch ist. Bei der ersten Kurve von Abb. 2 oben könnte man wegen des schnellen, hohen Anstiegs an eine derartige Kurve denken, aber es fehlten alle anderen Anzeichen am absteigenden Schenkel der Kurve, und die völlig normale folgende Kurve zeigt (im Verein mit der Wirkungslosigkeit experimenteller Herzreize), daß es sich hier nur um einen an Muskelarbeit oder Sport gewöhnten gesunden Organismus handelt, bei dem der ganze Mechanismus der Blutverschiebung kräftiger ausgebildet zu sein pflegt, als bei anderen.

Die physiologische Erklärung des nachträglichen Ansteigens einer Arbeitskurve ist, wie oben schon angedeutet, nur darin zu suchen, daß infolge der schlechten Arterialisierung des Blutes bei Beginn der Intention der Fußarbeit von der motorischen Rindenzone aus Reize zur Verengerung der peripheren Gefäße ausgehen, und diese durch die mit größerer Gewalt in die Peripherie geworfene Blutwelle nur mühsam passiv ausgedehnt werden können. Die Reize zur Gefäßverengerung verschwinden in den allermeisten Fällen (nicht immer) 
fast gleichzeitig mit der Beendigung der Intention der Fußarbeit von der Hirnrinde aus, während die verstärkte Herzarbeit zwar auch mit dem Ende der Fußarbeit etwas schwächer wird, aber viel langsamer abklingt, also nach Ende der Fußarbeit noch einige Zeit verstärkt (gegenüber dem Zustand vor der Fußarbeit) fortwirkt, wenn auch schwächer als während der Dauer der Fußarbeit selbst. Da also der Widerstand in der Peripherie schneller verschwindet, als die Verstärkung der Herzaktion, so ist die notwendige Folge, daß die Blutwelle dann den peripheren Widerstand viel leichter überwinden kann, als vorher, und es zum nachträglichen Ansteigen der Kurve kommt.

Alles dies wird deutlich durch die Formen dieser Kurven im einzelnen In manchen Fällen von nachträglich ansteigender Kurve ist deutlich zu erkennen, daß kurze Zeit nach der Beendigung der Fußarbeit das Ansteigen der Kurve (das dadurch also zum nachträglichen Ansteigen wird) plötzlich in bedeutend stärkerer und offenbar in mehr ungehemmter Weise sich fortsetzt, als es während der Fußarbeit selbst eintrat. (Siehe darüber die Kurven 3c, 8b, 8c, 11 a.) Es fehlt eben dann die noch unmittelbar vorher der Herzkraft entgegenwirkende Verengerung der peripheren Gefäße, und erst das spätere Sinken der nachträglich angestiegenen Kurve zur Anfangshöhe ist das Anzeichen dafür, daß die vorher noch andauernde Verstärkung der Herzaktion allmählich zur Norm zurückkehrt. In vielen Fällen (siehe Kurve 7c, 8c, 11 b, 12b) kommt es sogar unmittelbar nach Ende der Fußarbeit vor dem plötzlich verstärkten nach träglichen Anstieg zu einer schnell vorübergehenden, meist geringen Kurvensqnkung, als Ausdruck dafür, daß die beim Ende der Intention der Fußarbeit in der motorischen Rindenzoneeintretende oben erwähnte relative Verminderung der verstärkten Herzaktion an der Kurve etwas eher zum Ausdruck kommt, als das Nachlassen der peripheren Gefäßverengerung, weil die plötzlich eintretende relative Verminderung der Blutdrucksteigerung infolge der physiologischen Verhältnisse sich um etwa eine Sekunde eher an der Volumkurve bemerkbar macht, als die gleichzeitig vom Gehirn intendierte Verminderung des Widerstands der peripheren Gefäße.

In den bisher besprochenen Fällen hat sich die früher negative Kurve schon vollkommen in eine nachträglich ansteigende umgewandelt, es kommen aber ebensoviel Fälle zur Untersuchung (und ihr Vorkommen vor allem beweist die Richtigkeit der erörterten theoretischen Erklärung), die einen früheren Zeitpunkt der unvollständigen Entwicklung dieses Zustands darstellen, und andererseits können Krankheitszustände, bei denen in einer früheren Periode die reine nachträglich ansteigende Kurve gefunden wurde, bei späterer Verschlechterung der Zirkulationsverhältnisse infolge von Ubberanstrengung usw. sich wieder in einen Zustand des früheren Úbergangsstadiums zurückbilden, sei es nur für Stunden, oder für längere Zeit. 
Wenn die Arterialisierung des Blutes eine schlechtere ist, als in den oben behandelten Fällen, oder die Entwicklung, oder funktionelle Ausnutzung der Hypertrophie des linken Herzens eine geringere ist, so kommt die Wirkung des vom Gehirn ausgehenden Reizes zur peripheren Gefäßverengerung auf der Arbeitskurve stärker zum Ausdruck, und besonders bei sehr schlechter Arterialisierung des Blutes dauert der Reiz zur Gefäßverengerung oft bedeutend länger, als bis zum Ende der Fußarbeit und überwindet in seiner Endwirkung die nach dem Ende der Fußarbeit sich abschwächende Herzaktion, die nur bei ihrer stärksten Kraftentfaltung während der Fußarbeit selbst, gerade genügte, die Gefäße passiv auszudehnen. Es kommt dann zu einer ,nach träglich sinkenden" Kurve, die außerordentlich häufig ist, eine Kurve, die nach dem Ansteigen während der Fußarbeit infolge der noch länger anhaltenden Gefäßkontraktion schnell bis tief unter die Anfangshöhe der Kurve absinkt und erst beim Nachlassen des Reizes für die Gefäßkontraktion wieder allmählich zur Anfangshöhe ansteigt (siehe Kurve 4 b, 8 a). Bisweilen tritt bei solchen Zuständen der unvollkommenen Korrektion einer negativen Kurve durch Hypertrophie des linken Herzens sogleich nach Beginn der Muskelarbeit zunächst eine leichte Senkung vor dem Ansteigen während der weiteren Fußarbeit ein, als Zeichen-dafür, daß die Herzaktion sich erst allmählich während der fortschreitenden Fußarbeit so weit verstärkt, daß sie die zunächst an der Kurve in Erscheinung tretende periphere Gefäßverengerung überwinden kann. Wenn die Kurve dann nach Ende der Fußarbeit wieder unter die Anfangshöhe sinkt, so erkennt man deutlich darin die ursprüngliche rein negative Kurve, in die mittenhinein ein Kurvenberg gesetzt ist, der bei besserer Ausbildung der Korrektion das ganze Tąl ausfüllen soll. (Wie wir wissen, ist das Endziel der Korrektion aber:die Umbildung der nachträglich ansteigenden Kurve in eine träg abfallende.)

Durch das Wechselspiel der gesteigerten Herzaktion und der peripheren Gefäßkontraktion kommt es zu noch anderen Arten von Kurvenformen, auf die ich hier nicht eingehen kann. Jedenfalls kann man daran die Veränderungen eines Krankheitsbildes in allen Einzelheiten im Laufe der Monate genau verfolgen.

Wie schon angedeutet, kann eine vorher nachträglich ansteigende Kurve in vielen Fällen durch eine kurze anstrengende Muskelarbeit (ca. 1 Minute Armstoßen) in eine nachträglich sinkende Kurve und weiterhin sogar in eine völlig negative Kurve verwandelt werden, wenn die Hypertrophie, oder die funktionelle Ausnutzung der Hypertrophie, im Verhältnis zur vorhandenen Insuffizienz entweder noch zu gering ist, oder wenn die Insuffizienz so angewachsen ist, daß die vorhandene, 
völlig entwickelte und funktionell ausgenutzte Hypertrophie nicht mehr genügt.

Im letzteren Falle muß natürlich immer die beträchtliche Hypertrophie auch mit anderen Methoden deutlich nachzuweisen sein, und meistens wird es sich dann auch um eine hinzukommende Dilatation handeln. Die denkbar schlechteste Kurve braucht nicht immer eine rein negative Kurve zu sein, denn bei negativen Kurven ist es möglich, daß das Hilfsmittel der Hypertrophie des linken Herzens noch nicht entwickelt ist, oder daß, wie wir sehen werden, aus bestimmten Gründen eine vorhandene Hypertrophie zeitweilig unbenutzt bleibt, bis eine neue Anregung des Accelerans hinzukommt, aber wenn bei der Untersuchung während der Fußarbeit eine tiefe und langdauernde Kurvensenkung eintritt; die erst nach Ende der langdauernden Fußarbeit in einen beträchtlichen nachträglichen Anstieg übergeht, so geht daraus hervor, da $B$ alle Hilfsmittel zur Korrektion der Kreislaufinsuffizienz schon entwickelt und im Gebrauch sind, daß sie aber wegen der schlechten Qualität des Herzmuskels so vollkommen versagen, daß sich die Kurve während der Zeit, bei der allein das Gegenteil von Wert wäre, nämlich während der Dauer der Fußarbeit selbst, wie eine völlig negative verhält (siehe Abb. 10, S. 39).

In keinem Falle sollte man bei der Untersuchung von nachträglich ansteigenden Kurven es versäumen, die Widerstandsfähigkeit der damit geschaffenen Kreislaufskorrektion durch Ausführung von ermüdender Muskelarbeit und durch Anwendung von Anregungsmitteln für den Herzmūskel zu prüfen. Tritt danach ein noch stärkeres nachträgliches Ánsteigen der Kurve ein, als vorher, so ist dies der Beweis dafür, daß tatsächlich ein Zustand von Uberkorrektion eingetreten ist, die für die betreffende Insuffizienz zu groß ist und daher gedämpft werden muß, denn die nachträgliche Steigung an sich ist, wie schon hervorgehoben, kein wünschenswerter Zustand, da eine unangemessene und unnötige Menge von Herzarbeit dabei geleistet wird, sie ist nur ein notwendiges t'bergangsstadium. Wie sehr ein starker nachträglicher Anstieg den Herzmuskel ermüdet, geht unzweifelhaft daraus hervor, daß bei vielen Patienten, bei denen der Herzmuskel nicht von guter Qualität ist, nach einem sehr hohen und langdauernden nachträglichen Anstieg der Kurve schon bei der nächsten Wiederholung des Versuchs nach einigen Minuten sich an Stelle des allzu hohen nachträglichen Anstiegs eine völlig negative Kurve zeigt. Es ist daher sicher empfehlenswert, auch bei Patienten mit gutem Herzmuskel, bei denen sich bei Wiederholung des Versuchs immer wieder ein hoher und langdauernder nachträglicher Anstieg der Kurve zeigt, und die anscheinend durch die abnorme Inanspruchnahme des Herzmuskels dabei nicht belästigt werden, den übertriebenen hohen 
und langdauernden Anstieg der Kurve durch bestimmte therapeutische Maßnahmen abzudämpfen. Die Mittel, durch die solche Dämpfung erzielt werden kann, werden später behandelt.

Tritt aber nach Einschaltung der Belastungsproben bei abermaliger Fußarbeit anstatt einer noch höheren nachträglichen Ansteigung eine nachträglich sinkende Kurve ein, so ist die Korrektion noch ungenügend, und man muß durch Behandlung mit Anregungsmitteln für die Herzaktion, wie Kohlensäurebäder (unter gewissen Kautelen), Bauchmassage, Medikamente, diese herbeizuführen suchen und darf ein dämpfendes Mittel höchstens damit kombinieren. Der Ausfall dieser Untersuchung ist also in solchen Fällen für die Art der Behandlung ganz besonders wichtig und gänzlich unersetzlich.

Ein bemerkenswertes Ergebnis der Untersuchungen ist weiterhin die Feststellung, daß bei rein neurasthenischen Herzbeschwerden, mögen sie noch so stark sein, eine völlig normale Arbeitskurve auftritt, so daß man diese von anderen Herzkrankheiten auf solche Weise unterscheiden kann. Ebenso kann man mittels dieser Methode objektiv bei Herzkranken das Maß von Anstrengungen, oder auch das von einmalig zugeführten Genußmitteln genau bestimmen, das noch von dem Herzen vertragen wird, wozu man nur eine Untersuchung vor und eine nach der betreffenden Anstrengung vornehmen muß.

Besonders wichtig erscheint mir aber, daß man mittels einer doppelten Untersuchung durch diese Methode objektiv den Einfluß einer einzelnen therapeutisehen Maßnahme bei jedem Herzkranken in genauester Weise feststellen kann. Die subjektiven Angaben der Herzkranken über die gute oder schlechte Wirkung einer therapeutischen Maßnahme sind oft nicht maßgebend, werden doch oft sogar unwichtige Nebenbefunde, wie Intercostalneuralgien, in den Vordergrund gerückt und sind besonders auch deshalb oft irreführend, weil in manchen Fällen, wie wir sehen werden, der gute Dauererfolg erst stundenlang später eintritt und ebenso bisweilen die üble Wirkung.

In meiner oben erwähnten Abhandlung von 1916 habe ich an Hand von Kurven zeigen können, wie bei Herzkranken, die dauernd negative Arbeitskurven aufwiesen, nach Injektion von Strophantin, nach Bauchmassage oder nach künstlichem Kohlensäurebad eine ansteigende, positive Kurve eintrat, und ebenso durch Herz- oder besser manuelle oder Saugdruck-Bauchmassage die träge abfallenden, oder nachträglich ansteigenden Kurven oft in normale verwandelt werden konnten. In diesen Fällen hielt die gute Wirkung zunächst nur wenige Stunden an, bei fortgesetztem Gebrauch der betreffenden wirksamen therapeutischen Maßnahme aber immer länger.

Besonders interessant war dabei, daß die Kurven bewiesen, daß bei den einzelnen Patienten eine dieser Maßnahmen günstig wirken 
konnte, während andere, auch solche, die hier nicht erwähnt werden, vollkommen versagten, oder sogar ungünstig wirken konnten, so daß zweifellos bisweilen erst durch die plethysmographische Arbeitskurve die für den betreffenden Kranken heilsame Behandlungsmethode gefunden werden konnte. Bei gewissen Fällen zeigte sich nach keiner Art von Behandlung Besserung der Kurven, außer nach langer Bettruhe. War eine gute Wirkung nach einer therapeutischen Maßnahme überhaupt vorhanden, so zeigte sich zum mindesten eine Teilwirkung in jedem Falle schon nach der ersten Behandlung, wenn sie auch zunächst nur stundenlang anhielt. Nach Kohlensäurebädern trat sie allerdings bisweilen erst nach einer Reihe von Stunden ein, hielt dann aber auch länger vor. Bei künstlichen Kohlensäurebädern zeigte sich, nebenbei bemerkt, eine deutliche Utberlegenheit der Sandowbäder über die Zeobäder. Seit Mitte des Jahres 1916 kontrollierte ich mit meiner Untersuchungsmethode besonders oft die Wirkung von Kohlensäurebädern und der Hochfrequenzbehandlung, von der hier ausführlich die Rede sein soll ${ }^{1}$ ).

Die Hochfrequenzbehandlung und ein großer Teil der Bäder mußten den Patienten außerhalb des Lazaretts, in dem ich in Berlin arbeite, verabfolgt werden, doch konnten die Kranken bequem nach der nötigen Ruhezeit in 15 Minuten das Lazarett wieder erreichen und wurden sowohl vorher, als nachher, in Zwischenräumen von mehreren Stunden und ebenso an den folgenden Tagen von mir untersucht. Ein Teil der Bäder wurde im Lazarett selbst gegeben.

Am meisten war ich dabei überrascht durch den unerwartet guten und regelmäßigen Erfolg der allgemeinen Hochfrequenzbehandlung, die in dieser Beziehung zweifellos bisher sehr unterschätzt worden ist, und den häufig mangelnden, bisweilen sogar ungünstigen Erfolg der künstlichen Kohlensäurebäder. In einer Reihe von Fällen konnte ich völlig sicher beobachten, daß die fehlende, oder ungünstige Wirkung der unverdeckt verabreichten Bäder bei Verhinderung der Einatmung der Kohlensäure durch völlige Verdeckung der Bäder in eine regelmäßig günstige Wirkung der Bäder umgewandelt werden konnte. Immerhin blieb auch dann oft die Wirkung aus, während andererseits bisweilen auch bei unverdeckten Bädern vortreffliche und von einem einzelnen Bad mehrere Tage anhaltende Wirkung eintrat. Im übrigen will ich die damals und später in Berlin gemachten Erfahrungen zusammen mit den in Altheide gewonnenen Ergebnissen behandeln. Nach den

1) In Berlin bin ich für Behandlung meiner Patienten mit Hochfrequenz und Kondensatorströmen Herrn Kollegen Bohn zu Dank verpflichtet und für Behandlung mit Kohlensäurebädern und Hochfrequenz Herrn Kollegen Tobias, dem ich auch den ersten Hinweis auf die Vorzüge der völlig verdeckten Bäder verdanke. 
zwölfmonatigen Vorversuchen in Berlin war es für die Untersuchungen besonders wertvoll, daß ich im Sommer 1917 vom Sanitätsamt des Gardekorps zur Vervollständigung der Ergebnisse auf 5 Wochen nach Reservelazarett Bad Altheide kommandiert wurde, zumal dort sowohl künstliche (Sandow) als natürliche (Altheider Quelle) Kohlensäurebäder wie auch Hochfrequenz- und Vierzellenbad-Behandlung in demselben Haus verabfolgt werden konnten, in dem ich die Kranken untersuchte, außerdem aber ein überaus reiches Material an Herzkranken jeder Art zur Verfügung stand ${ }^{1}$ ).

Außer der Wirkung der Bäder auf die verschiedenen Arten von Herzkrankheiten untersuchte ich besonders auch den Unterschied in der Wirkung künstlicher und natürlicher (Altheider) Bäder, sowie den Unterschied in der Wirkung völlig offener und völlig verdeckter Bäder bei denselben Patienten. Bei allen Bädern wurde eine Temperatur von $32^{\circ}$ und eine Dauer von 10 Minuten innegehalten. Die vergleichende Untersuchung der Wirkung anderer Temperaturen und anderer Badezeiten konnte ich vorläufig nicht berücksichtigen, wie ich auch in vielen Fällen auf Blutdruckmessungen, deren häufig normaler Ausfall bei den schwersten Fällen ihre sehr beschränkte Bedeutung beweist, und die schon häufig nach $\mathrm{CO}_{2}$-Bädern ausgeführt wurden, verzichtete.

Der einzelne Patient wurde z. B. zunächst früh $9 \mathrm{Uhr}$ plethysmographisch von mir untersucht, erhielt unmittelbar darauf ein völlig verdecktes, natürliches (Altheider) Bad, wobei Vorsorge getroffen war, daß während des Einlassens des Bades und während des Hineinsteigens und Heraussteigens des Patienten keine wesentliche Menge Kohlensäure sich in dem gut gelüfteten Zimmer verbreitete. Nach dem Anziehen ruhte der Patient, so daß er genau 40 Minuten nach Verlassen des Bades zur zweiten plethysmographischen Untersuchung kam. Dann. ruhte der Patient wieder und kam nach etwa 6 Stunden (nachmittags $4 \mathrm{Uhr}$ ) wieder zur Untersuchung, ebenso dann am anderen Morgen usw. Waren die durch das Bad bewirkten Veränderungen der Kurve völlig abgeklungen, so erhielt der Kranke zur gleichen Zeit ein verdecktes, künstliches (Sandow-) Bad unter genau den gleichen Bedingungen und mit denselben Nachuntersuchungen. Hierauf folgte wieder ein verdecktes natürliches und wiedèr ein verdecktes künstliches Bad, so daß Zufälligkeiten ausgeschaltet wurden. Bei anderen Patienten wurde mit dem künstlichen Bad begonnen. Dann wurden auch vergleichende Versuche mit unverdeckten natürlichen und künstlichen Bädern vorgenommen, und ferner wurden im weiteren Verlauf der Untersuchungen

1) Der Verwaltung des Bades Altheide und insbesondere Herrn Kollegen Karfunkel bin ich für bedeutende Erleichterung meiner Arbeiten dort und wertvolle Ratschläge zu Dank verpflichtet, die es mir ermöglichten, in kurzer Zeit eine unverhältnismäßig große Anzahl von Unterstuchungen vorzunehmen. 
die Wirkungen von Hochfrequenz und Vierzellenbädern festgestellt. An jedem Tag wurden 3-4 Bäder und eine Reihe anderer Behandlungsarten verabfolgt, und ich konnte täglich 15-20 verschiedene Untersuchungen vornehmen, da ich vortreffliche Assistenz hatte und bei dem großen Herzmaterial die Auswahl der Patienten nicht nur von dem Gesichtspunkt der Verschiedenartigkeit der Fälle, sondern auch von dem der leichteren Untersuchungsmöglichkeit abhängig sein lassen konnte, da bei manchen unruhigen Patienten die einzelne Untersuchung stundenlang dauert.

Natürlich untersuchte ich auch bei mehreren Herzgesunden die Wirkung der Bäder, verdeckt und unverdeckt, und fand dabei als unwesentliche Einwirkung bisweilen nur eine kräftigere Ausdrucksform der vorher normalen Kurve. Ferner konnte ich feststellen, daß der für die Erklärung der Wirkung der Kohlensäurebäder häufig in den Vordergrund gerückte erweiternde Einfluß dieser Bäder auf die peripheren Blutgefäße tatsächlich bedeutungslos ist. Bei Herzkranken, bei denen nach Kohlensäurebädern starke Veränderungen an der Arbeitskurve in günstigem Sinne festgestellt wurden, fehlten sie völlig, wenn bei ihnen eine gleich starke periphere GefäBerweiterung unter Fortlassung der Kohlensäure durch starke Salzbäder úsw. herbeigeführt wurde. Es muß sich daher um eine spezifische Wirkung der Kohlensäure selbst handeln, die in ganz bestimmter Weise erregend auf gewisse Nervenendigungen in der Haut und weiterhin reflektorisch auf die Funktion des Herzmuskels wirkt. Ich komme am Schlusse ausführlicher darauf zurück. Die Gesamtergebnisse aller meiner Untersuchungen über Wirkung der Kohlensäurebäder und Hochfrequenzbehandlung bei Herzkranken werden am klarsten zutage treten, wenn ich an Hand der Kurven die durch diese Behandlungsarten bei einer Auswahl der von mir beobachteten Krankheitsfälle bewirkten Veränderungen beschreibe.

Bei dem Falle, auf den sich die Kurven von Abb. 3 beziehen, handelte es sich um einen älteren Fall von Mitralstenose mit schwacher Verbreiterung des rechten, stärkerer des linken Herzens und normalem Blutdruck. Patient hatte $1^{1 / 2}$ Jahre vorher schon 20 unverdeckte natürliche Kohlensäurebäder ohne bedeutenden Erfolg genommen. Es zeigte sich bei ihm bei Untersuchung an verschiedenen aufeinander folgenden Tagen regelmäßig die stark negative und noch nach Ende der Arbeit weitersinkende Kurve von $\mathrm{Abb}$. $3 \mathrm{a}$, es bestand also eine vollkommene Insuffizienz des Kreislaufs. Die infolge der schlechten Arterialisierung des Blutes vom Gehirn ausgehenden Reize zur Verengerung der peripheren Gefäße während der Muskelarbeit dauerten sogar einige Zeit über das Ende der Fußarbeit hinaus. Die subjektiven Erscheinungen waren entsprechend schwer. 
Nach Verabfolgung eines verdeckten künstlichen Bades war sowohl bei Untersuchung nach 40 Minuten, als nach 6 und 24 und nach 48 Stunden. die Kurve eher schlechter als vorher, dagegen zeigte sich nach einem verdeckten Altheider Bad zwar nach 40 Minuten auch noch die gleiche negative Kurve wie vorher, aber nach 6 Stunden zeigte sich die nur noch leicht sinkende Kurve von Abb. $3 \mathrm{~b}$ und am nächsten Morgen die gut ansteigende Kurve von Abb. 3c, die mehrere Tage bestehen blieb, bevor sie wieder negativ wurde. Dasselbe versehiedene Ergebnis wiederholte sich mehrere Male, und es zeigte sich ferner, daß auch unverdeckt verabfolgte Altheider Bäder wirkungslos waren, daß also allein nach verdeckten, natürlichen Bädern die gute Reizwirkung für den Herzmuskel eintrat, die zwar übers Ziel hinausgehend eine nachträgliche Ansteigung bewirkte, aber zunächst als sehr vorteilhaft gegenüber dem früheren Zustand anzusehen ist. Dieser Fall zeigt auch die oft bei schwereren Fällen vorhandene Empfindlichkeit gegen die Einatmung der Kohlensäure, durch welche die gute Wirkung des Bades vollständig verhindert werden kann, wie ich schon früher erwähnte. Daneben zeigt dieser Fall auch, daß bisweilen die gute Wirkung eines Bades nach 40 Minuten noch gar nicht, in vollem Maße sogar erst nach 24 Stunden hervortreten kann, um dann aber auch schon nach einem einzelnẹn Bade tagelang anzudauern.

Der Umstand, daß die gute Wirkung dieses Bades erst nach Stunden einzusetzen begann, läßt es als völlig berechtigt erscheinen, daß sich die absolute Ruhe derartiger Patienten nach einem Kohlensäurebad auf eine Reihe von Stunden erstreckt und möglichst den ganzen Tag über andauert.

Am meisten überraschte mich, wie ich gestehe, der prinzipielle Unterschied in der Wirkung der natürlichen (Altheider) und der künstlichen Kohlensäurebäder, obwohl der oben erwähnte Unterschied in der Wirkung der verschiedenen Arten der künstlichen (Zeo- und Sandowbäder) bei denselben Patienten mich darauf hätte vorbereiten können. Die hier zum Vergleich mit den natürlichen herangezogenen künstlichen Bäder waren die nach meinen Kurven neben den Flaschenbädern am besten wirkenden Sandowbäder.

Es handelt sich also in diesem Falle, wie in vielen anderen, nicht nur um eine Úberlegenheit der natürlichen (Altheider) Bäder über die besten künstlichen, sondern sogar um eine alleinige Wirkung der natürlichen, bei völligem Versagen der künstlichen Bäder. Da dieser Unterschied auch bei völlig verdeckten Bädern vorhanden war, können nicht etwa Verschiedenheiten, die etwa durch stärkere Einatmung der Kohlensäure bei den künstlichen Bädern geschaffen werden, dabei eine Rolle spielen. (Davon, daß die verschiedenen Bäder unter völlig gleichen anderen äußeren Bedingungen verabfolgt wurden, habe ich 
mich natürlich selbst überzeugt, auch schließt das gleiche Ergebnis bei Wiederholung der Versuche Versehen nach dieser Richtung hin aus.)

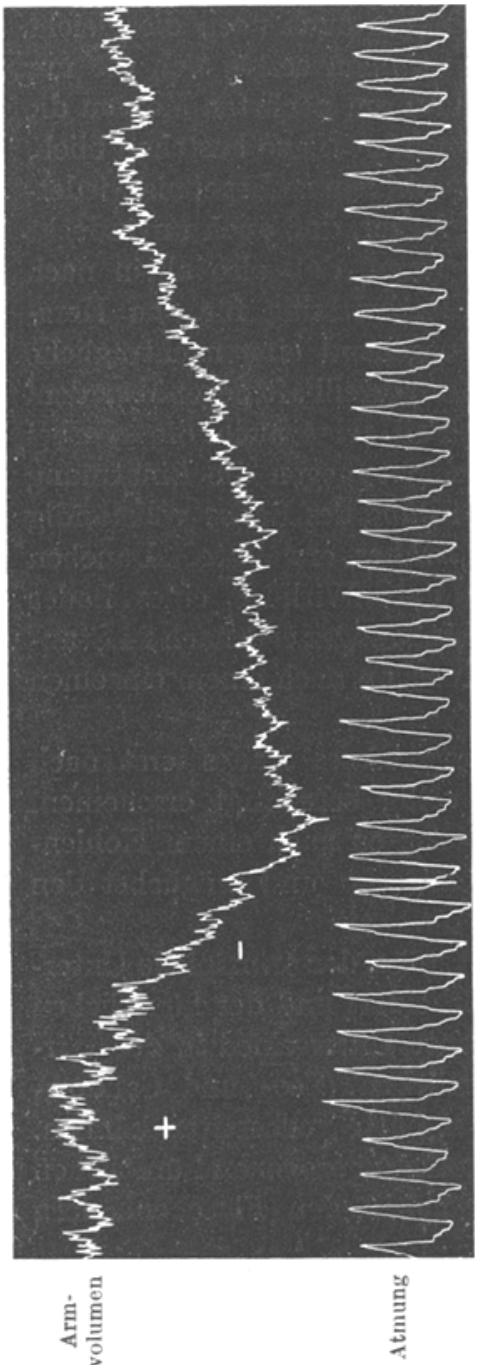

Wie wir später sehen werden, tritt nicht nur die beschriebene Reizwirkung, sondern auch die dämpfende Wirkung für den Herzmuskel bisweilen nur nach den natürlichen und nicht nach den künstlichen Bädern ein, während niemals die umgekehrte Erscheinung zu beobachten war. Es deutet dies alles darauf hin, daß zwischen den natürlichen (Altheider) Bädern und den besten künstlichen nicht

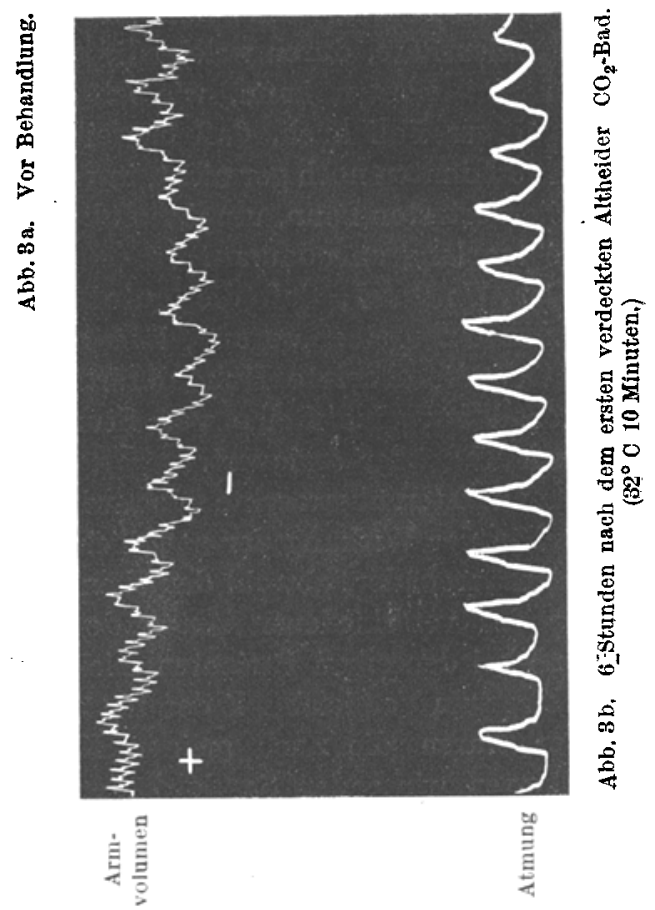

nur ein gradweiser Unterschied in der Stärke der Wirkung besteht, sondern auch ein sachlicher Unterschied in der Angriffsweise der Kohlensäure an den von ihr beeinflußten Nervenendigungen in der Haut vorhanden sein muß. Das Ergebnis der Behandlung des Falles von Abb. 3 zeigt übrigens, daß trotz der vor der Behandlung dauernd völlig negativen Kurve eine funktionsfähige Hypertrophie des linken 
Herzens' vorhanden war, daß sie nur aus bestimmten, später zu erörternden Gründen völlig unausgenutzt war (denn sonst hätte eine nachträglich sinkende oder nach der Senkung nachträglich ansteigende Kurve [siehe oben] eintreten müssen), und daß erst der durch das natürliche Kohlensäurebad gesetzte reflektorische Reiz für den Herzmuskel den vorhandenen hypertrophischen Herzmuskel wieder aktionsfähig machte. Die nachträglich ansteigende Kurve von Abb. $3 \mathrm{c}$ beweist, daß dieser Muskel sogar zu einer t'berkorrektion fähig war, wenn er nur funktionell genügend ausgenutzt wurde, und das herbeizuführen, muß in solchen Fällen die Therapie erstreben.

Eine ähnlich gute Reizwirkung der Kohlensäurebäder mit etwas anderen Begleitumständen trat in dem Falle von Abb. 4a, b, c ein.

Es handelte sich um eine Mitralinsuffizienz mitVergrößerung des Herzens beiderseits, stärkster Pulsirregularität und Blutdruck 140. Zunächst trat dauernd die völlig negative Kurve vonAbb. 4 a auf. 40 Minuten nach der Beendigung eines unverdeckten, natürlichen (Altheider) Bades stellte ich noch die gleiche negative Kurve fest, aber bereits nach etwa 6 Stunden ergab sich die Kurve von Abb. 4 b mit schwacher Steigung während der Daner der Fußarbeit und nachträglich unter die Abszisse sinkender Kurve. Die vorher völlig

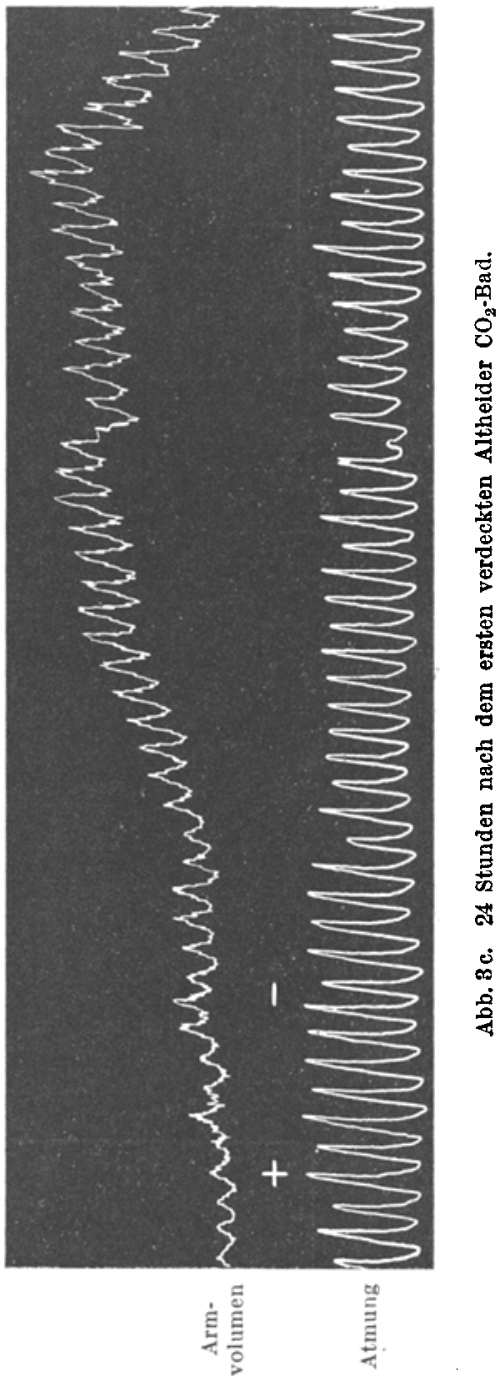
fehlende funktionelle Wirkung der vorhandenen Hypertrophie des linken Herzens ist also hier schon deutlich zu erkennen, sie genügt aber noch nicht, um die negative Kurve in eine völlig positive zu verwandeln, die Korrektion war noch ungenügend. Auch am nächsten Morgen war diese Wirkung noch in ähnlicher Weise festzustellen, am zweiten Morgen nach dem Bade aber war wieder die frühere negative Kurve 


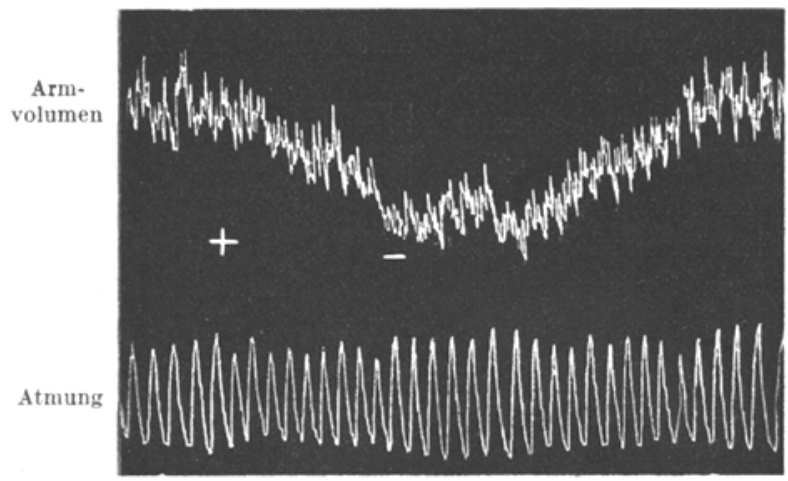

Abb. 4a. Vor Behandlung.

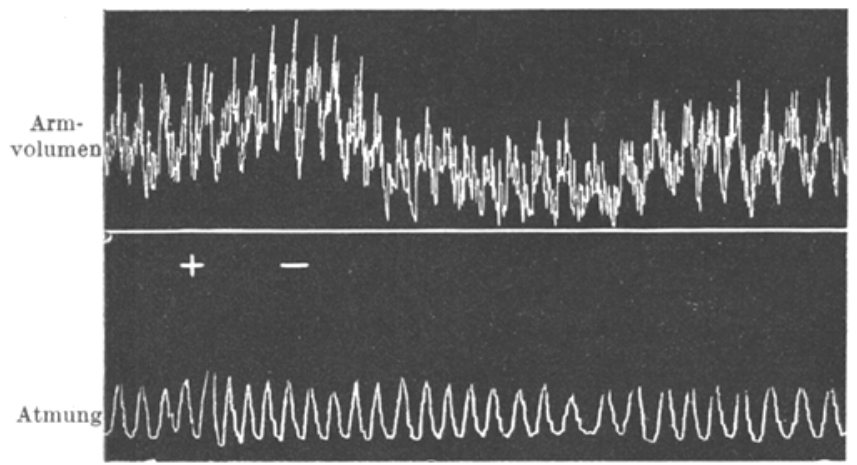

Abb, 4 b. 6 Stunden nach dem ersten inverdeckten Altheider $\mathrm{CO}_{2}$-Bad.

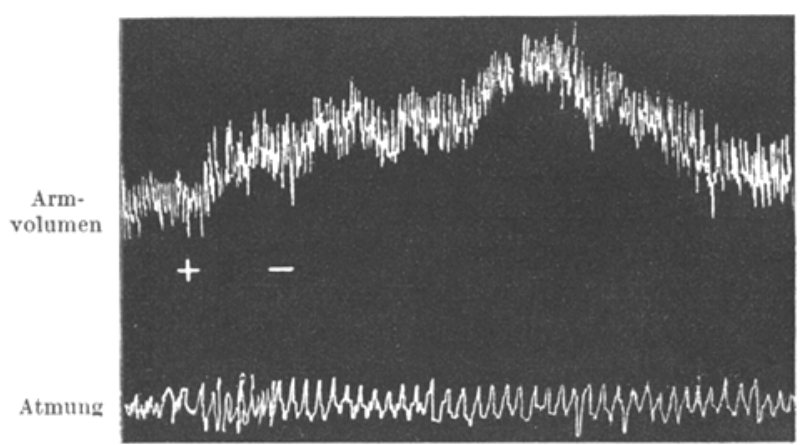

Abb. 4 c. 40 Minuten nach dem vierten Altheider $\mathrm{CO}_{2}$-Bad. 
vorhanden und wurde durch ein dann gegebenes unverdecktes künstliches $\mathrm{CO}_{2}$-Bad in keiner Weise gebessert, eher verschlechtert. 2 Tage darauf folgte ein verdecktes natürliches Bad, und die Wirkung war die gleiche wie nach dem ersten unverdeckten natürlichen Bad, während wiederum 2 Tage später ein künstliches, verdecktes Bad ebenso völlig versagte wie das unverdeckte künstliche. Es geht daraus deutlich hervor, daß in diesem Falle das Einatmen der Kohlensäure bei unverdeckten Bädern nicht schädigend wirkte, wie es bestimmt bei dem Patient von Abb. 3 oben der Fall war. Aber trotz dieses Unterschiedes trat eine günstige Wirkung gleichfalls nur nach den natürlichen, nicht nach den künstlichen Bädern ein. Es wurden danach dem betr. Patienten nur noch natürliche (Altheider) Bäder verabreicht, und nach dem $z$ weiten dann folgenden Bade trat schon 40 Minuten nach dem Bade die Kurve von Abb. 4c auf, die der von $3 \mathrm{c}$ gleicht und infolge der weiteren Heranziehung der Funktion des hypertrophischen Muskels zunächst sogar eine Ưberkorrektion der vorherigen Insuffizienz bedeutet, die einen bedeutenden Fortschritt gegen den vorherigen Zustand darstellt. Indessen hielt auch diese Wirkung, im Gegensatz zu der entsprechenden Wirkung im Falle von Abb. 3, zunächst nur tageweise vor. Ủbrigens konnte in diesem Falle auch mit allgemeiner Hochfrequenzbehandlung eine ähnliche, wenn auch schwächere, günstige Reizwirkung erzielt werden, die in diesem Falle also den künstlichen Kohlensäurebädern überlegen war. Vierzellenbäder (die allerdings immer nur mit galvanischem Strom 15 M.-A. 10 Minuten lang gegeben werden konnten) hatten gar keinen Erfolg. Daß die Reizwirkung der allgemeinen Hochfrequenzbehandlung in Ausnahmefällen auch stark sein kann (in solchen Fällen sind die natürlichen Kohlensäurebäder immer gleichfalls wirksam), zeigt Abb. 5 a und 5 b, die von einem Fall von Arteriosklerose mit mäßiger Hypertrophie des linken Ventrikels und normalem Blutdruck stammen.

Die vorher dauernd negative Kurve bei diesem Falle war schon am Tag vorher durch ein natürliches Kohlensäurebad in eine nachträglich ansteigende Kurve verwandelt worden, die Wirkung nach 24 Stunden aber völlig wieder verschwunden. Der Patient wurde nun zunächst in oben angegebener Weise mit Vierzellenbad behandelt und zeigte hierauf die unverändert negative Kurve von Abb. 5a, nach einer dann unmittelbar folgenden allgemeinen Hochfrequenzbehandlung aber die nachträglich ansteigende Kurve von $\mathrm{Abb} .5 \mathrm{~b}$. Die letztere Behandlungsart scheint also der ersteren überlegen zu sein. Die Reizwirkung ist aber fast immer schwächer als die der $\mathrm{CO}_{2}$-Bäder und dauert vor allem nicht länger als einige Stunden, während die eines $\mathrm{CO}_{2}$-Bades tagelang dauern kann. (In einem einzigen Falle von pathologischer Uberempfindlichkeit des Accelerans, der auf physi- 
kalische Einwirkungen jeder Art mit L̇berreizung des hypertrophischen linken Herzens reagierte, sah ich auch nach Hochfrequenz eine übertriebene Utberkorrektion eintreten.)

Bei einer Behandlung, die dauernd durch Anfnahme von Kurven kontrolliert wird, ist zweifellos aus den eingangs erörterten Gründen der Gesichtspunkt im Auge zu behalten, daß zunächst als Wichtigstes erstrebt werden muß, eine negative Kurve für die Dauer in eine positive zu verwandeln. Die in den hier besprochenen Fällen erkennbare zeitweilige Uberkorrektion infolge der Reizwirkung auf den

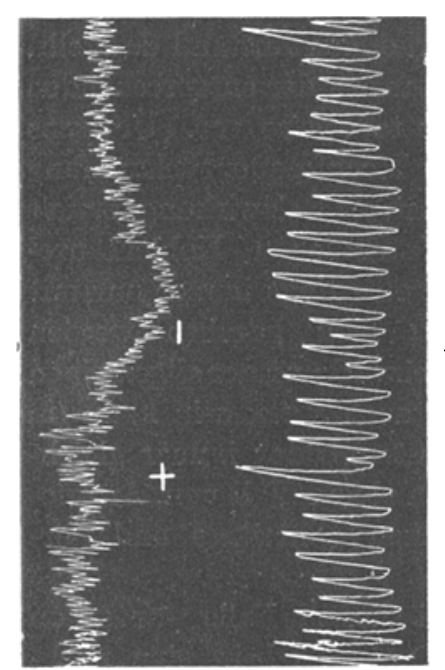

를

$\stackrel{\Xi}{\Xi}$
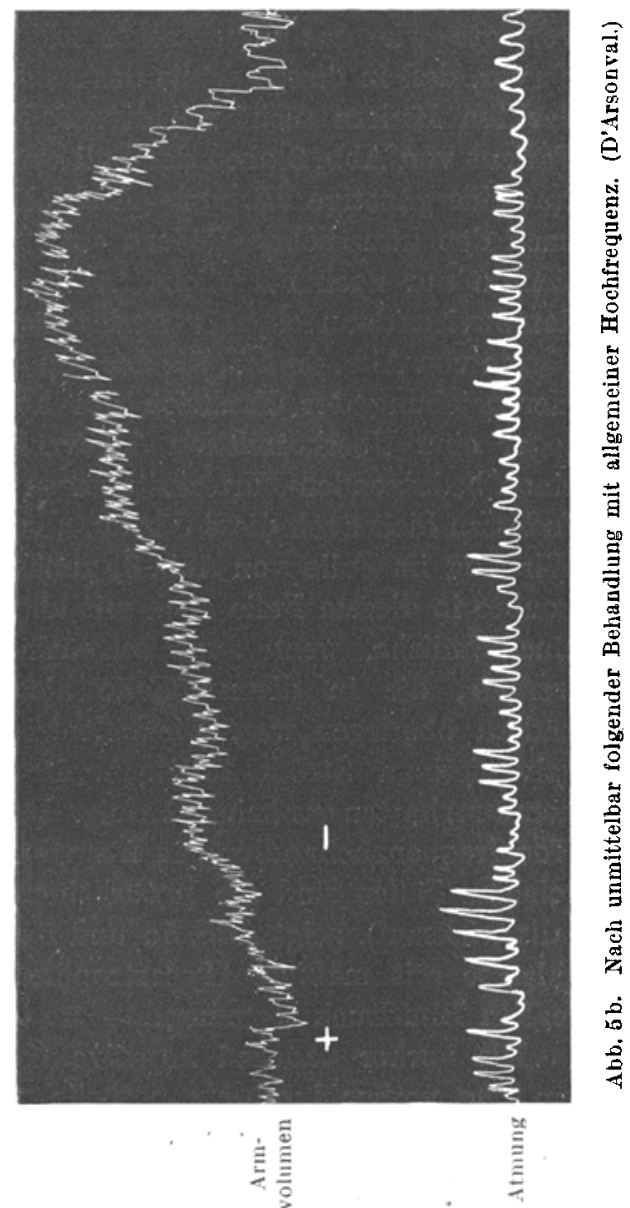

Herzmuskel ist so lange mit in Kauf zu nehmen, als die Gesamtwirkung einer Behandlung geneigt ist, nach $1-2$ oder mehr Tagen wieder zu verschwinden. Wenn die Heilwirkung allmählich eine haltbarere geworden ist, oder wenn der nachträgliche Anstieg einen gewissen mäßigen Grad übersteigt, muß man daran denken, diese übermäßige und überflüssige nachträgliche Herzarbeit durch äußere Einwirkungen abzudämpfen, wozu, wie wir sehen werden, allgemeine Hochfrequenzbehandlung ganz besonders geeignet ist. Die Notwendigkeit einer solchen Abdämpfung 
ergibt sich aus der fruchtlosen Utberanstrengung des Herzmuskels durch den sehr langdauernden nachträglichen Anstieg der Kurve, der einen schwachen Herzmuskel so erschöpfen kann, daß bei der Wiederholung der Muskelarbeit nach einer solchen Kurve eine negative Kurve auftritt.

Offenbar besitzen alle bei Herzkranken wirksamen therapeutischen Maßnahmen die Eigenschaft, gleichzeitig sowohl anregend, als auch hemmend auf die Herzaktion zu wirken, nur überwiegt bei dem einen Mittel prinzipiell die anregende Wirkung, bei dem anderen die hemmende Wirkung, und ferner kann die Wirkung desselben Mittels bei verschiedenen Patienten verschieden ausfallen, da offenbar bei den verschiedenen Patienten die beiden Nervensysteme, die die beiden Arten von Beeinflussung des Herzmuskels infolge ihrer reflektorischen Erregung vermitteln, sich in verschiedenem Erregbarkeitszustand befinden können, und daher zum Beispiel die neben den erregenden Reizen einwirkenden hemmenden Reize bei gewissen Patienten eine viel stärkere Wirkung am Erfolgsorgan haben und deshalb sich deutlicher an den Kurven ausdrücken können, als bei anderen.

Am meisten erwünscht ist es natürlich, wenn diese Verhältnisse so günstig liegen, daß schon ohne besondere Einwirkung die anregende Wirkung der Herzaktion neben der hemmenden so zur Geltung kommt, daß nach der therapeutischen Einwirkung eine völlig normale Kurve entsteht und das mindestens überflüssige nachträgliche Ansteigen der Kurve ganz vermieden wird. Einen solchen Fall illustrieren die Kurven von Abb. 6a, b, c, bei dem sich die Uberlegenheit der natürlichen Bäder über die künstlichen auch in dieser Beziehung erweist.

Es handelt sich um eine Miralinsuffizienz mit beiderseits stark vergrößertem Herzen und Blutdruck 125. Zunächst zeigte sich dauernd die negative und nachträglich noch sinkende Kurve von Abb. 6a.

Nach einem künstlichen verdeckten Kohlensäurebad (verdeckt oder unverdeckt machte bei diesem Fall keinen Unterschied) zeigte sich schon nach 40 Minuten die Kurve von $6 \mathrm{~b}$, also eine starke Utberreizung des hypertrophischen linken Herzmuskels. Diese Wirkung war noch nach 2 Tagen zu erkennen, bevor sie wieder verschwand. Hierauf wurde ein natürliches (Altheider) Bad gegeben und nach 40 Minuten die schöne, völlig normale Kurve von $\mathrm{Abb}$. 6c aufgenommen, bei der offenbar die anregende und dämpfende Wirkung des Bades sich gerade die richtige Wage halten. Daß wirklich eine dämpfende Wirkung hinzukam, und nicht etwa nur die Reizwirkung schwächer war, geht aus dem prompten Abfall der Kurve hervor und weiterhin daraus, daß diese dämpfende Wirkung eher nachließ, als die anregende Wirkung, denn schon nach 6 Stunden zeigte sich bei dem Patienten die Kurve von Abb.6d ınd am nächsten Tag eine ebenso hoch nachträglich ansteigende 
E. Weber: Die Wirkung natürlicher und künstlicher Kohlensäurebäder

Kurve, wie die von Abb. 6 b gewesen war. Es deutet dies offenbar darauf hin, daß die anregende Wirkung des natürlichen Bades ebenso stark gewesen war, wie die des künstlichen Bades, daß aber während

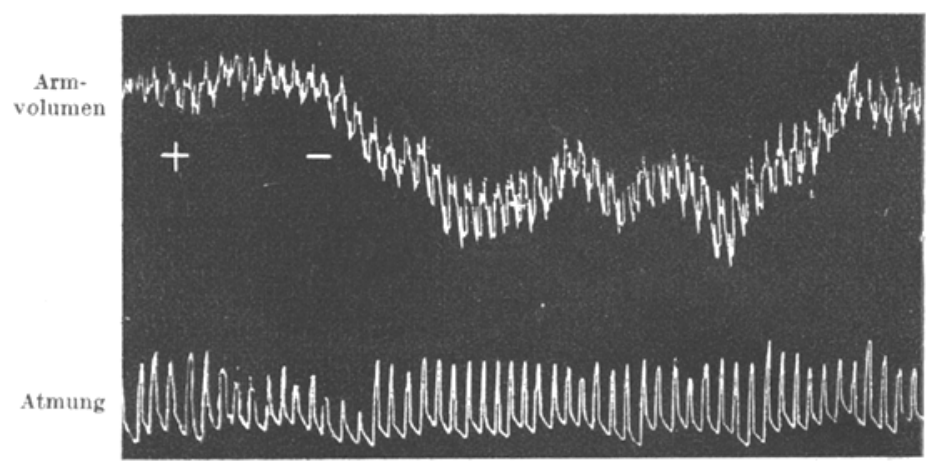

Abb. 6 a. Vor Behandlung.

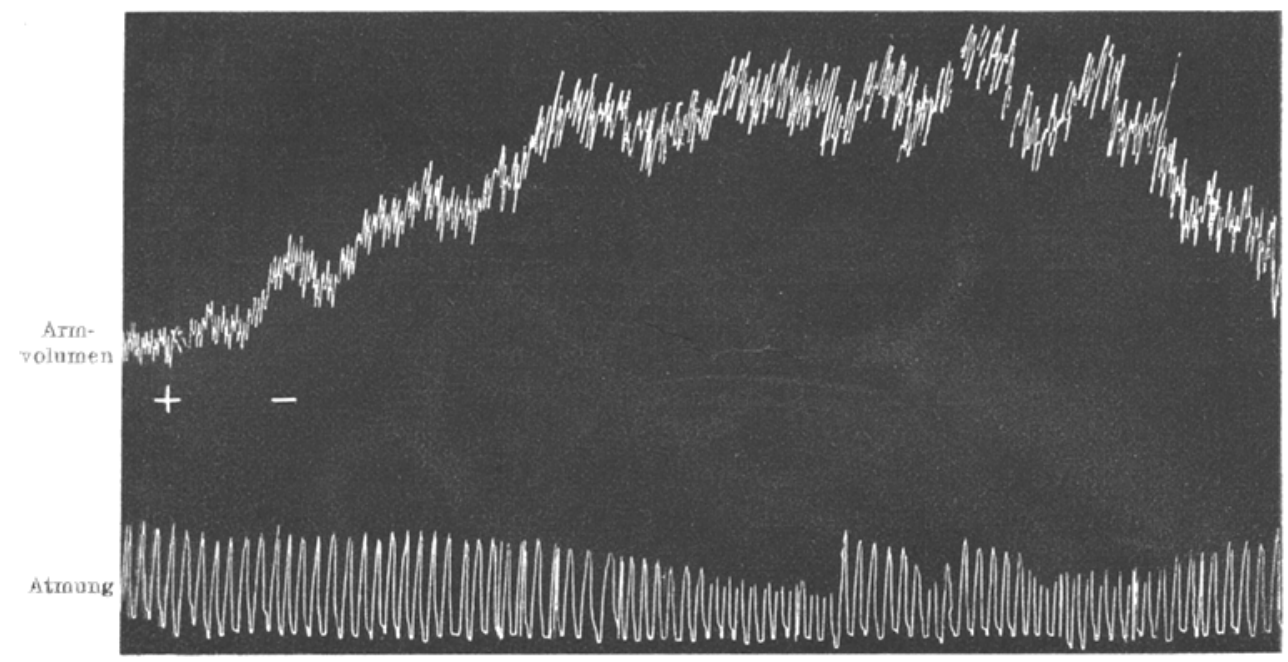

Abb. 6 b. 40 Minuten nach dem ersten künstlichen, verdeckten $\mathrm{CO}_{2}$-Bad.

des ersten halben Tages nach dem natürlichen Bade noch eine andere, hemmende Wirkung für die übermäßig angeregte Herzaktion hinzugekommen war, die für die kürzere Zeit ihrer Einwirkungsdauer eine Dämpfung der gesteigerten Herzaktion verursacht hatte, die in größter Stärke unmittelbar nach dem Bad wirkte und dann allmählich abnahm. Diese dämpfende Wirkung fehlte bei diesem Falle dem künstlichen Bad vollkommen. Auf diese dämpfende Wirkung der $\mathrm{CO}_{2}$-Bäder komme ich später ausführlicher zurück. 
Úbrigens konnte bei diesem letzten Patienten auch durch allgemeine Hochfrequenzbehandlung eine, wenn auch nur sehr schwache, Anregung des Herzens herbeigeführt werden, während Vierzellenbäder völlig ver-

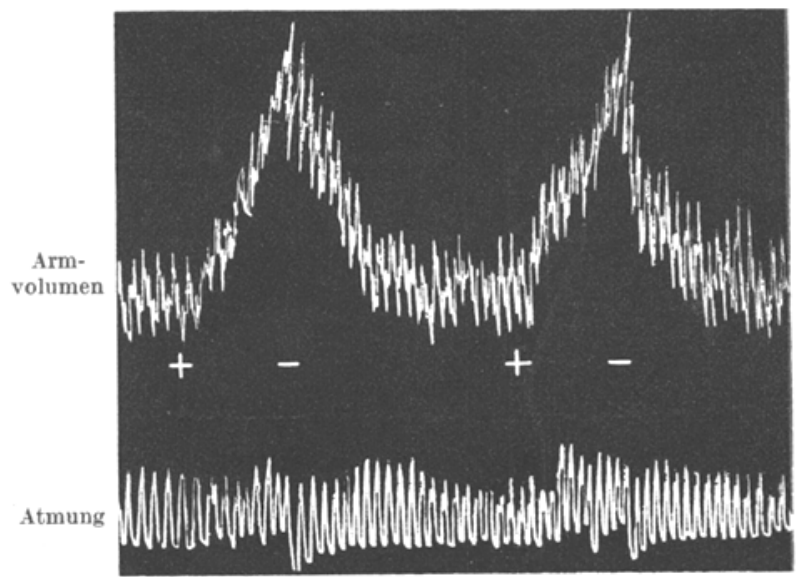

Abb. 6 c. 40 Minuten nach dem ersten Altheider $\mathrm{CO}_{2}$-Bad, dass 2 Tage nach der Aufnahme von $6 \mathrm{~b}$ gegeben wurde.

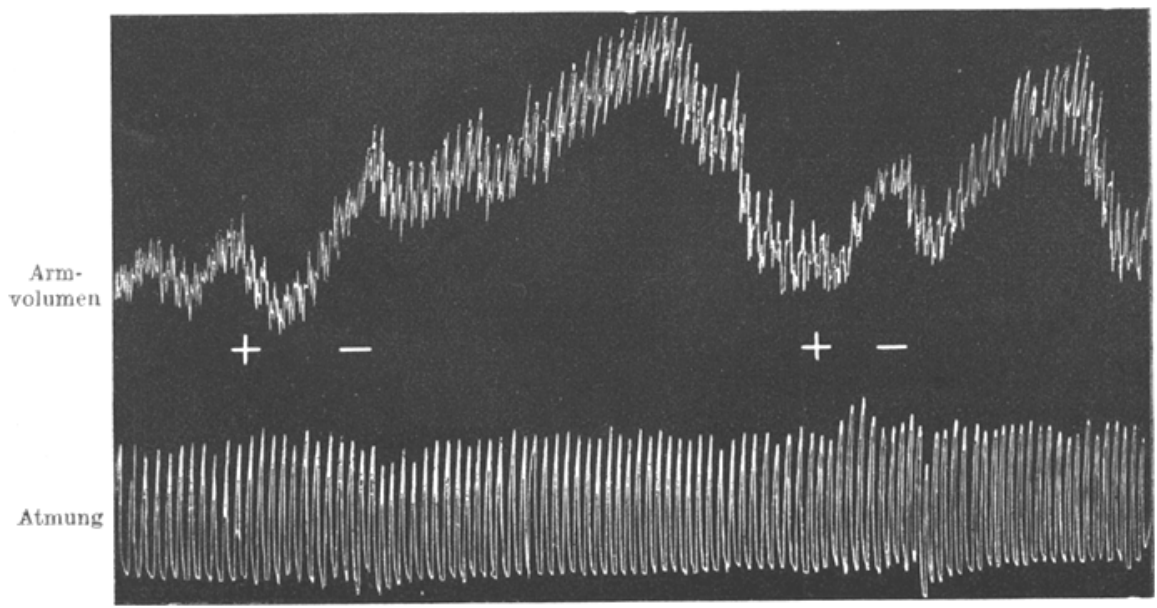

Abb. 6 d. 6 Stunden nach dem ersten Altheider $\cdot \mathrm{CO}_{2}-\mathrm{Bad}$.

sagten. Andererseits konnte durch allgemeine Hochfrequenzbehandlung die vorhandene übertriebene Reizwirkung sehr erfolgreich abgedämpft werden, wenn auch beides nur für einen halben Tag wirkte.

Wie schon erwähnt, ist trotz der kurzen Dauer die dämpfende Wirkung der Hochfrequenzbehandlung die brauchbarste und am regelmäßigsten wirksame, wenn die der Kohlensäurebäder, wie sehr̈ häufig, 
E. Weber: Die Wirkung natürlicher und künstlicher Kohlensäurebäder
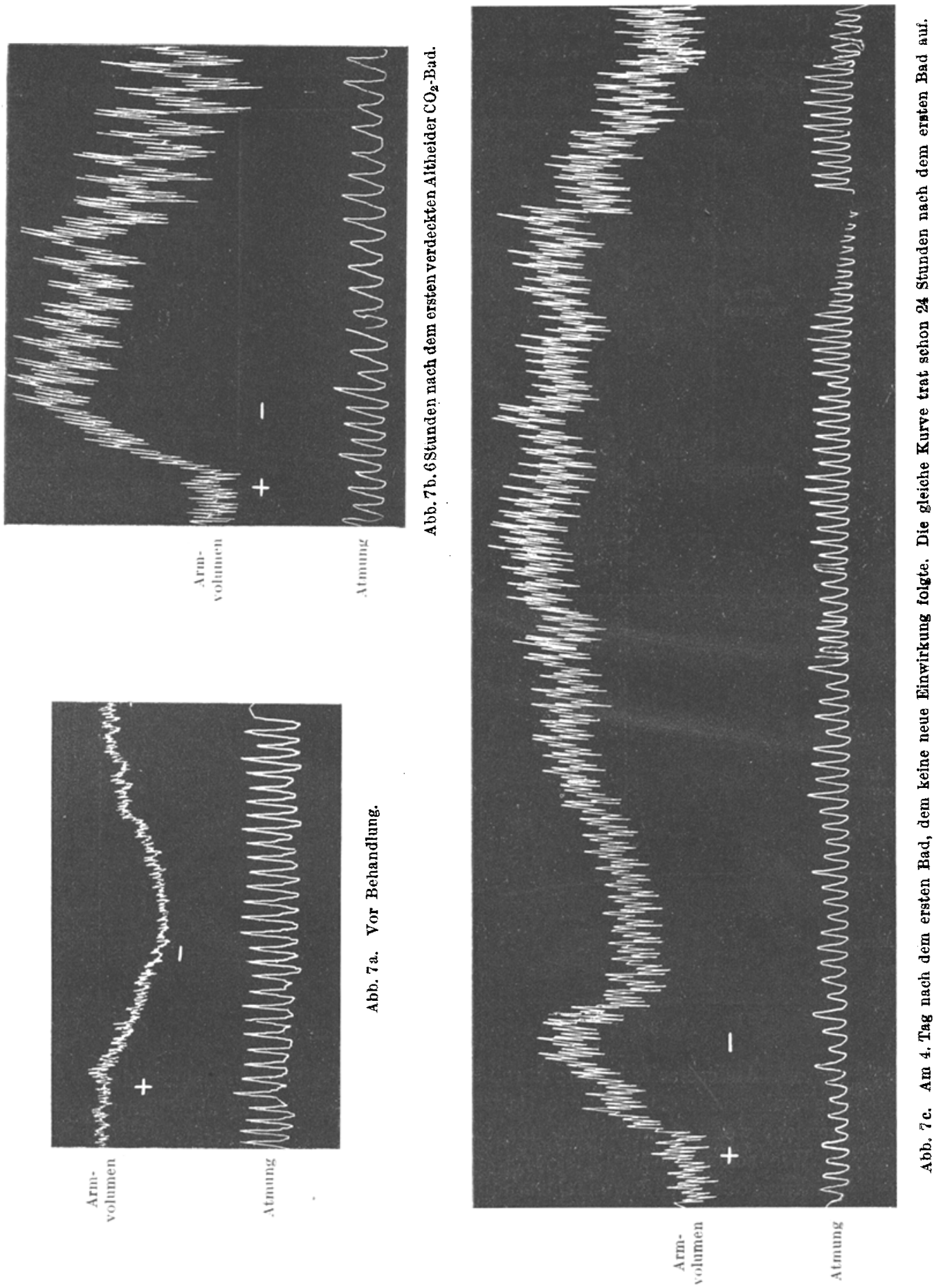
versagt, und ist für uns viel wichtiger, als die schwache anregende Wirkung, die von anderen therapeutischen Maßnahmen besser, als selbst durch die lokale Hochfrequenzbehandlung, geleistet wird. In gewissen seltenen Fällen könnte es vorkommen, daß die anregende Wirkung der Kohlensäurebäder mit ihrer dämpfenden Wirkung sogar verwechselt wird, nämlich wenn es sich um die Beseitigung einer durch Funktionsschwäche besonders des rechten Herzens verursachten

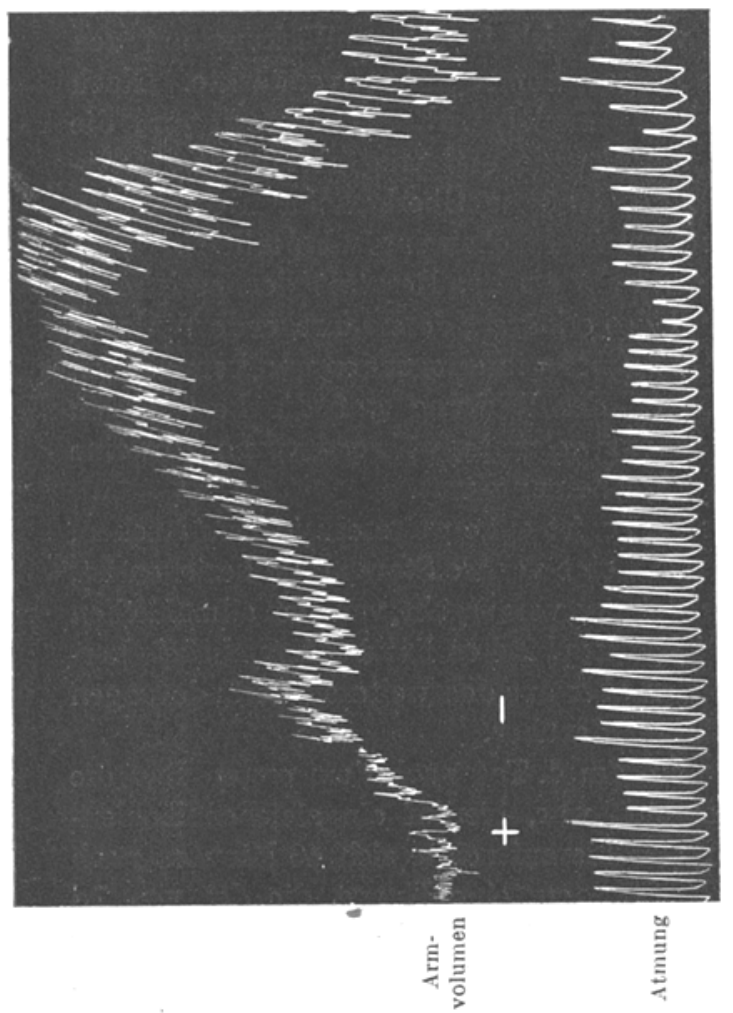
venösen Stauung vermittels der Anregung des gesamten Herzens handelt. Es zeigt dies Abb. 7, die einen Fall von beginnender Aortitis mit starker Erweiterung des rechten und geringer (mit Röntgenuntersuchung kaum nachweisbarer) Vergrößerung des linken Herzens darstellt. Blutdruck 145.

Der Kranke wies vor Beginn der Behandlung regelmäßig die völlig negative Kurve von Abb. 7 a auf. 40 Minuten nach einem verdeckten,natürlichen Bade zeigte sich eine gut ansteigende, aber träge abfallende Kurve, die in gleicher Weise nach 6 Stunden auftrat und in Abb. $7 \mathrm{~b}$ abgebildet ist. Die das Herz anregende Wirkung des Bades war also eine sehr gute, und die dadurch entstehende träge abfallende Kurve deutet darauf hin, daß jetzt zwar eine bessere Arterialisierung des Blutes geschaffen ist, daß aber noch eine beträchtliche venöse Stauung vorhanden ist, die bei der früheren negativen Kurve nicht zum Ausdruck kommen konnte. Immerhin war auch an die Möglichkeit zu denken, daß daneben eine noch latente Hypertrophie des linken Herzens vorhanden war. Es hätte dies durch die Wirkung einer Herzmassage auf die träg abfallende Kurve in früher erwähnter Weise entschieden 
werden können. In diesem Falle entwickelte sich aber, ohne daß irgendein weiterer Eingriff geschah, im Lauf des nächsten Tages die Kurve zu der regelmäßig bei Arbeit auftretenden Form, die in $\mathbf{A b b}$. 7c abgebjldet ist, nämlich $\mathrm{zu}$ einer längere Zeit nachträglich ansteigenden und dann sehr träge abfallenden Kurve. Abb. 7c stammt von einer Aufnahme am vierten Tag nach dem Bade, war aber schon einen Tag nach dem Bad in selber Weise vorhanden. Es ist dieser ganze Vorgang auch deshalb interessant, weil daraus hervorgeht, daß der Reiz, der durch das Kohlensäurebad gesetzt wurde, sich in seiner Wirkung auf den Herzmuskel innerhalb eines Tages immer mehr verstärkte. Nach 6 Stunden genügte die durch das Bad bewirkte Anregung nur, die negative Kurve in eine gut ansteigende und träg abfallende zu verwandeln, und erst nach 24 Stunden trat die Überkorrektion durch den hypertrophischen linken Ventrikel in Erscheinung. Es läßt sich aber auch eine solche Wirkung sehr wohl als das Resultat der peripheren Nervenerregung während des Bades erklären, deren anregende Wirkung infolge der gleichzeitigen Wirkung auf die erregenden und hemmenden Herznerven erst nach Abklingen der Wirkung auf die hemmenden Nerven (Vagus) zur vollen Wirkung gelangte, während vorher nur eine Teilwirkung der Anregung in Erscheinung trat.

Aus einer Kurve, wie die von $7 \mathrm{c}$, ist ohne weiteres nicht zu ersehen, ob der träge Abfall der Kurve auf eine venöse Stauung zu beziehen ist, oder, da ihr eine nachträgliche Steigung vorausgeht, von dem allmählichen Abklingen der Erregung des hypertrophischen linken Herzmuskels herrührt. In diesem Falle ergab sich aber aus den weiteren Veränderungen der Kurve vollkommene Klarheit darüber.

Der Kranke erhielt, nachdem am 4. Tag nach dem ersten Bad die Kurve von $\mathrm{Abb} .7 \mathrm{c}$ aufgenommen war, hierauf ein gleiches Kohlensäurebad, wie 4 Tage vorher, und hierauf zeigte sich 40 Minuten nach dem Bad, sowie auch nach 6 Stunden eine Kurve, die der von $7 \mathrm{~d}$ glich, nur daß dabei der nachträgliche Anstieg noch bedeutend größer war, und 24 Stunden nach dem Bade wurde die Kurve $7 \mathrm{~d}$ aufgenommen. Das Charakteristische in diesen nach dem 2. Bad aufgenommenen Kurven war, daß der nachträgliche Anstieg bedeutend stärker war, als vorher, daß aber der Abfall der Kurven zur Abszisse völlig prompt eintrat, also der träge Abfall wegfiel. Es beweist dies deutlich, daB es sich bei dem trägem Abfall in den Kurven von $A b b .7 b$ und besonders $7 \mathrm{c}$ nur um den Ausdruck einer venösen Stauung handelte, die ja auch schon durch die im Röntgenbilde festgestellte Erweiterung des rechten Herzens in Erscheinung trat und also die Folge einer Schwäche vorzugsweise des rechten Herzens war.

Nach dem ersten Bad war die Anregung des Herzmuskels noch nicht stark genug, die Stauung, die sich in der Erweiterung des rechten 
Herzens und in der trägen Kurve ausdrückte, zu beseitigen, sie genügte nur, die Arterialisierung des Blutes wieder hinreichend zu machen, also die Negativität der Kurve zu beseitigen. Die zweite Anregung durch das wiederholte Bad wirkte auf die schon bedeutend verbesserten Zirkulationsverhältnisse so viel stärker, daß die sich auf dem Röntgenbilde nur undeutlich ausdrückende Hypertrophie des linken Herzens jetzt vollständig ausgenutzt und in Funktion gesetzt wurde, wie der bedeutend höhere nachträgliche Anstieg der Kurve beweist. Diese verstärkte Funktion des ganzen Herzens genügte weiterhin vollständig, die venöse Stauung, die die Folge der früheren Funktionsschwäche des rechten Herzens gewesen war, zu beseitigen, wie der prompte Abfall der früher auf die dreifache Länge ausgedehnten Kurve beweist. Es wäre in diesem Falle sehr falsch, dies Kürzerwerden der vorher viel länger ausgedehnten, nachträglich ansteigenden Kurve etwa auf eine neben der Anregung in Erscheinung tretende hemmende Wirkung der Kohlensäure zu beziehen, wie wir es oben in Abb. 6c eintreten sahen. Bei Abb. 6c war der Anstieg nach dem $\mathrm{Bad}$ geringer als der von $\mathrm{Abb} .6 \mathrm{~b}$, so daß die dämpfende Wirkung des Bades auch dadurch offenbar wurde, bei Abb. 7e und noch mehr in den Kurven unmittelbar nach dem zweiten Bad, die wegen ihrer Größe nicht reproduktionsfähig sind, war der nachträgliche Anstieg um ein Vielfaches größer als jemals nach dem ersten Bade, es kann also eine Dämpfung nicht in Betracht kommen, und gerade die durch den abermaligen Reiz erreichte volle Ausnutzung der vorhandenen und vorher nur nicht ausgenutzten Muskelkräfte des hypertrophierten Herzens erklärt hinreichend das Verschwinden der vorher in der Vergrößerung des rechten Herzens und der träg abfallenden Kurve sich ausdrückenden venösen Stauung infolge ungenügender Herzfunktion. Einen interessanten Gegensatz werden wir später im Falle von Abb. 12 finden, bei dem das wirksame Prinzip bei einer ähnlichen Kurve zweifellos nur die dämpfende Wirkung des Kohlensäurebades ist.

In dem Falle von Abb. 7 konnte übrigens die starke nachträgliche Steigung durch Hochfrequenzbehandlung, wenn auch nicht vollständig, abgedämpft werden.

Wie sehr auch eine nicht vollständige Abdämpfung der sehr häufig durch die Kohlensäurebäder eintretenden übertriebenen Anregung des Herzmuskels vermittels der allgemeinen Hochfrequenzbehandlung von Wert ist, sei auch an dem Falle, der in Abb. 8 illustriert ist, gezeigt, der auch in anderer Bezeichnung lehrreich ist. Es handelte sich dabei um eine Mitralstenose mit Vergrößerung des Herzens nach beiden Seiten und Blutdruck von 150.

Die Kurve vor der Behandlung war die von Abb. 8a, die während der Fußarbeit erst etwas steigt, dann unter die Abszisse sinkt und nach 
dem Ende der Arbeit noch weiter sinkt. Nach leichter Ermüdung des Patienten war die Kurve rein negativ. Fis handelte sich also um eine durch Hypertrophie des linken Herzens völlig ungenügend korrigierte Insuffizienz des Kreislaufs.

Der Patient erhielt darauf in gewissen Zeiträumen zuerst ein künstliches, dann ein natürliches, dann wieder ein künstliches und wieder ein natürliches Kohlensäurebad mit dem Erfolg, daß die Wirkung bei allen Bädern zunächst immer die gleiche war, daß die Wirkung nach den künstlichen Bädern aber jedesmal nach einem Tag wieder völlig verschwunden war, während die Wirkung nach den natürlichen Bädern zuerst 3 Tage und dann mindestens 8 Tage nachweisbar war. Es bestand also in der Dauer der anregenden Wirkung bei den natürlichen (Altheider) Bädern eine bedeutende Überlegenheit gegenüber den abwechselnd mit den natür. lichen gegebenen künstlichen Bädern.

Abb. 8b zeigt die Aufnahme der Kurve 40 Minuten nach dem zu Beginn der Behandlung gegebenen offenen
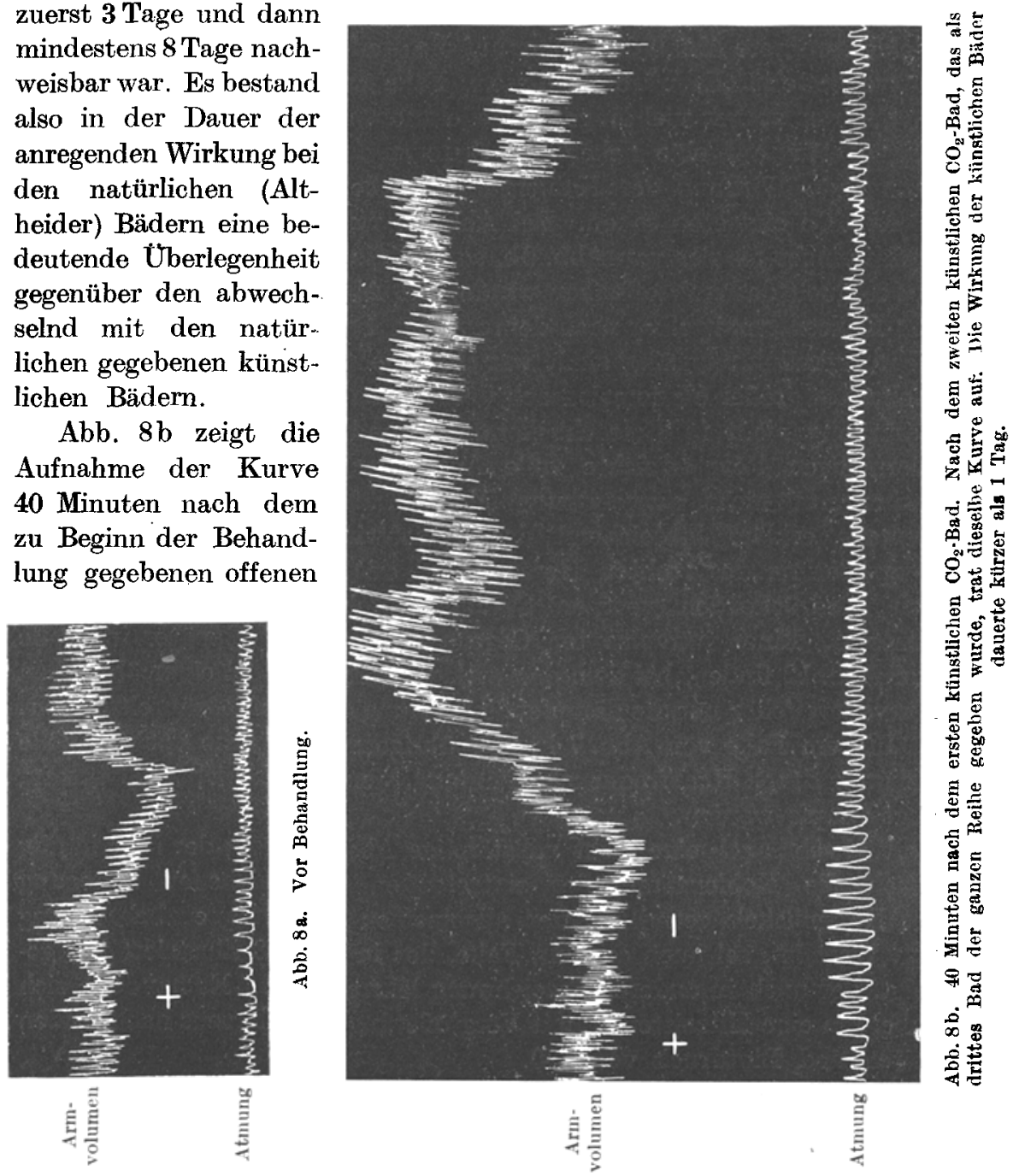


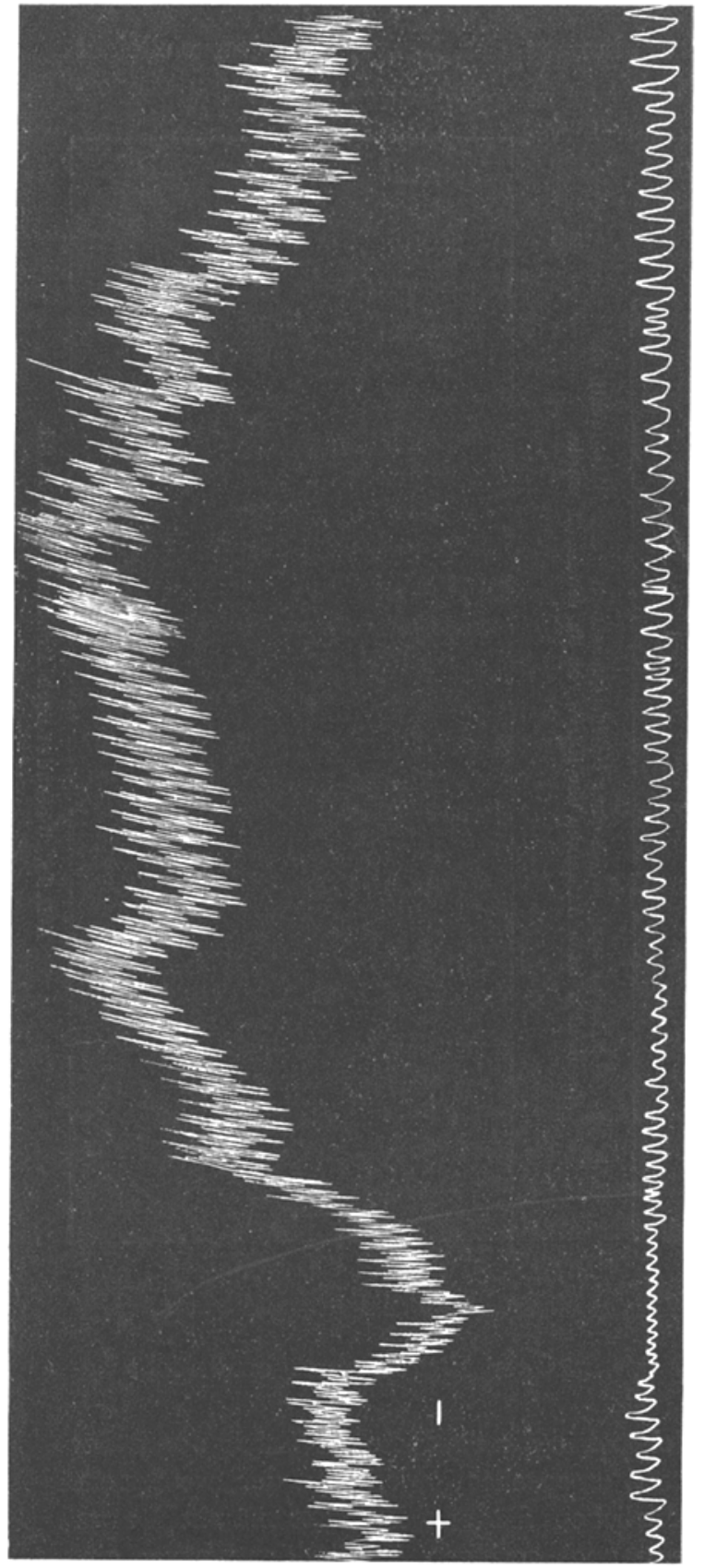

产 ơ künstlichenBad,eine stark und langenachträglich ansteigende Kurve, die schon am nächsten Tag wieder zu der von Abb. 8a zurückgegangen war. Das als drittes Bad verdeckt gegebene künstliche Bad hatte die gleiche Wirkung, aber gleichfalls nur für weniger als 24 Stunden. Das als zweites und viertes Bad gegebene ver-

seckte, natürliche Bad hatte jedesmal eine Kurve wie die of $\mathrm{Abb} .8 \mathrm{c}$ zur Fol造 茞 की 홍 ge. Abb. 8c selbst wurde 3 Tage nach dem Badeaufgenommen. Es ist sehr instruktiv, die Kurven Abb. 8 b und $8 c$, die in einem Zwischenraum von 10 Tagen von dem Patienten aufgenommen wurden und die Wirkung eines künstlichen

und eines natürlichen Bades zeigen, genau in den Einzelheiten zu vergleichen, denn in der dazwischenlie$\underset{\infty}{*}$ genden Zeit war - die Wirkung des $\stackrel{0}{\circ} \quad$ ersten Bades wieder völlig verlorengegangen. 
Bei dieser Betrachtung zeigt sich, daß trotz dieses langen Zwischenraumes alle einzelnen Schwankungen der Kurve, die man vielleicht für zufällige halten könnte, sich in der späteren Kurve genau wiederholen. Die zwei Absätze während des Anstiegs, sowie die des Abstiegs treten mit geringen Variationen wieder ein, woraus zu schließen ist, daß
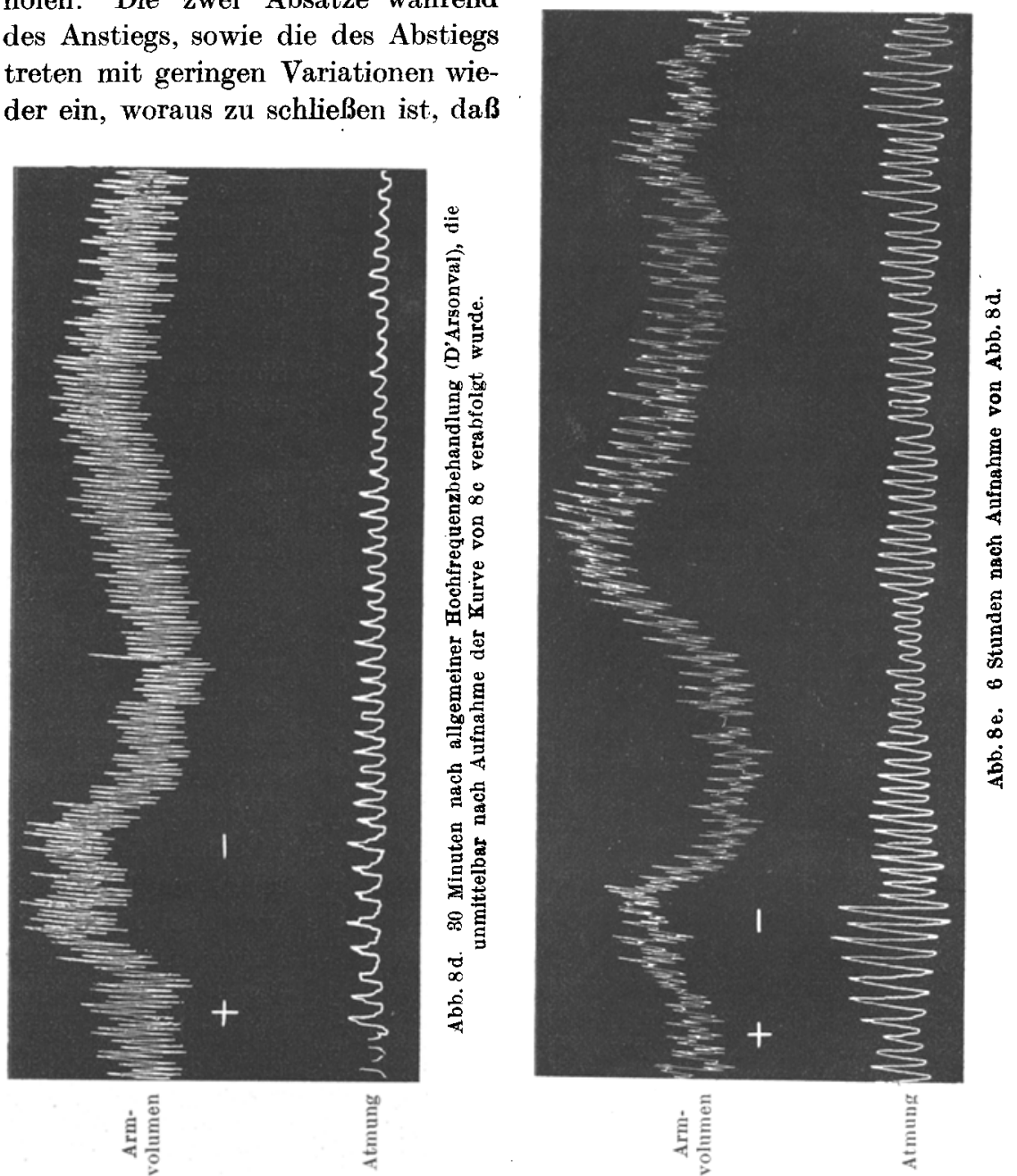

sie alle organisch begründet und in ihren Einzelheiten gewiß nicht bedeutungslos sind.

In therapeutischer Hinsicht ist in diesem Falle der Erfolg der Bäder nur als teilweise befriedigend anzusehen, auch der der wenigstens dauerhafter wirkenden natürlichen Bäder. Es tritt nämlich zwar während der Arbeit ein, wenn auch geringer, Anstieg der Kurven ein, aber der starke und langdauernde nachträgliche Anstieg steht in keinem 
Verhältnis dazu und stellt eine überflüssige Kraftvergeudung dar, wie das oben erörtert wurde.

Es wurde daher eine Abdämpfung mittels allgemeiner Hochfrequenz versucht. Kurze Zeit nach Verabfolgung einer Behandlung mit allgemeiner Hochfrequenz, vor der die gleiche Kurve von $8 \mathrm{c}$ aufgenommen worden war, zeigte sich die Kurve von $\mathrm{Abb}$. 8d, bei der ein guter Anstieg der Kurve während der Muskelarbeit eintrat, und der dann folgende nachträgliche Anstieg zwar noch deutlich bemerkbar, aber so stark abgedämpft war, daß er geringer als der Anstieg während der Arbeit selbst war. Der Erfolg war also nicht so voliständig, wie bei anderen hier illustrierten Fällen, aber immerhin sehr'befriedigend. Wie schon früher erwähnt, jst die Dauer der Wirkung einer solchen Beeinflussung durch Hochfrequenzbehandlung zunächst nicht allzugroß. 6 Stunden nach Aufnahme der Kurve 8d wurde bei demselben Patienten die Kurve 8e aufgenommen, bei der zwar noch die Wirkung der Hochîrequenz zu erkennen ist, bei der aber schon deutlich die allmähliche Rüickbildung zu der Kurvenform von $8 \mathrm{c}$ und 8d deutlich wird, da der nachträgliche Anstieg schon wieder größer ist, als der Anstieg während der Muskelarbeit. Am nächsten Tag war die Wirkung völlig verschwunden. Man muß in solchen Fällen also unbedingt alle Tage eine Behandlung mit Hochfrequenz verabfolgen.

Bei den bisher besprochenen Fällen handelte es sich um Patienten, die vor der Behandlung eine völlig, oder teilweise negative Kurve aufwiesen, also vollständige oder nur ungenügend korrigierte Insuffizienz der Kreislauffunktion besaßen, und bei denen die Anregung der Herztätigkeit durch die Kohlensäurebäder (ganz besonders durch die verdeckten natürlichen Bäder) diesen ungünstigsten Zustand der Funktion des Kreislaufs beseitigte, also zweifellos einen sehr günstigen Einfluß ausübte.

Die dabei eintretende Überkorrektion, die sich in dem nachträglichen Anstieg der Kurve ausdrückte, wurde so lange gern mit in Kauf genommen, als die Kurve die Neigung zeigte, wieder in den früheren Zustand zurückzufallen, wenn die anregende Wirkung abgeklungen war. Wenn der nachträgliche Anstieg einen gewissen Grad überstieg, mußte er durch andere Mittel wieder abgedämpft werden, und zwar am besten durch allgemeine Hochfrequenzbehandlung, weil ein übertrieben hoher und lange dauernder nachträglicher Anstieg der Kurve den Herzmuskel unnötig ermüdet, wie die Fälle mit schlechter Beschaffenheit des Herzmuskels beweisen, bei denen schon bei der ersten Wiederholung der FuBarbeit unmittelbar nach einer solchen übermäßig nachträglich ansteigenden Kurve eine negative Kurve erscheint. Auch in diesen Fällen war aber die anregende Wirkung der Kohlensäurebäder zunächst von größtem Wert. 
Ganz anders liegt die Sache dann, wenn es sich um Fälle handelt, bei denen vor Beginn der Behandlung überhaupt keine Insuffizienz in unserem Sinne, also keine negative Kurve besteht, und wenn auf solche suffiziente Herzen nun die Anregung durch die Kohlensäure in ungehemmter. Weise einwirkt. Es kann dann zu einem zweifellos schädlichen Einfluß der Bäder kommen.

Wie ich oben schon andeutete und später ausführlicher behandle, können auch die Kohlensäurebäder einen dämpfenden Einfluß, neben dem anregenden, aufs Herz ausüben, je nach der Beeinflussungsfähigkeit des Vagus und Accelerans der betreffenden Patienten, aber dieser dämpfende Einfluß kommt aus bestimmten Gründen in der Mehrzahl der Fälle überhaupt nicht zur Geltung, so daß bei ihnen die anregende Wirkung allein in Erscheinung tritt.

Ein solcher Fall ist der von Abb. 9, bei dem es sich um eine Hypertrophie des linken Ventrikels mit beginnender Aortitis und Blutdruck 100 handelte.

Die vor Beginn der Behandlung aufgenommene Kurve ist in Abb. 9a abgebildet und zeigt einen Anstieg während der Muskelarbeit, der bezüglich seiner Höhe und der Schnelligkeit des Anstiegs der ersten Kurve von Abb. 2 auf S. 4 gleicht. Während aber dort der Abfall der Kurve sich ebenso schnell wie der Anstieg vollzog und dadurch die Kurve als die normale eines an viel Muskelarbeit gewöhnten Mannes kennzeichnete, ist der Abstieg bei Abb. 9a ein träg abfallender mit einem kleinen, darauf aufgesetzten Höcker, der sich an allen Kurven wiederholte und also eine Bedeutung haben muß. Diese Form der Kurve deutet darauf hin (und die Wirkung des Bades bestätigte es später vollkommen), daB es sich hier um einen Zustand der Zirkulationsverhältnisse handelt, der das früher auf S. 8 erwähnte wünschenswerte Ziel der Korrektion einer früheren Herzinsuffizienz durch Hypertrophie des linken Ventrikels darstellt. Die früher einmal negative Kurve ist in diesem Falle durch Hypertrophie des linken Herzens in eine positive und nachträglich ansteigende verwandelt worden, und diese hat sich infolge der allmählichen. Besserung der Zirkulationsverhältnisse und des Aufhörens der pathologischen Widerstände in der Peripherie allmählich in eine träg abfallende Kurve umgebildet, indem die weiter bestehende Hypertrophie des linken Herzens, da sie nicht mehr in voller Stärke zur Korrektion der Kreislaufsfunktion nötig war, zum größten Teil außer Funktion gesetzt und ,funktionell latent" wurde. Das langsamere Abklingen des bei der Muskelarbeit erregten hypertrophischen Muskels äußert sich nur noch in dem trägen Abfall der Kurve, und der kleine Höcker während des Abstiegs stellt den Rest des ehemaligen nachträglichen Anstiegs dar, dafür ist aber in diesem Zustand eine ausgiebige Versorgung der arbeitenden Muskeln mit arteriellem Blut 
vorhanden, so daß dieser Zustand zweifellos das bestmögliche Ergebnis dieses Heilungsprozesses darstellt. Die geringen Beschwerden des Patienten, die ihn ins Bad führten, waren sicherlich neurasthenischer Natur, besonders verstärkt durch die Erinnerung an das frühere, schwere Herzleiden.

Dieser Patient erhielt nun ein verdecktes, natürliches Kohlensäurebad, also das bestmögliche Bad dieser Art. Es trat nach dem Bad ein außerordentlich hoher und langdauernder nachträglicher Anstieg der Kurve ein, der ohne dämpfende therapeutische Einwirkung mehrere Tage lang anhielt. Abb. 9b zeigt die Kurve, die 24 Stunden nach dem natürlichen, verdeckten Bad aufgenommen wurde.' Um die Kurve reproduktionsfähig zu machen, wurde die Registriertrommel bei dem

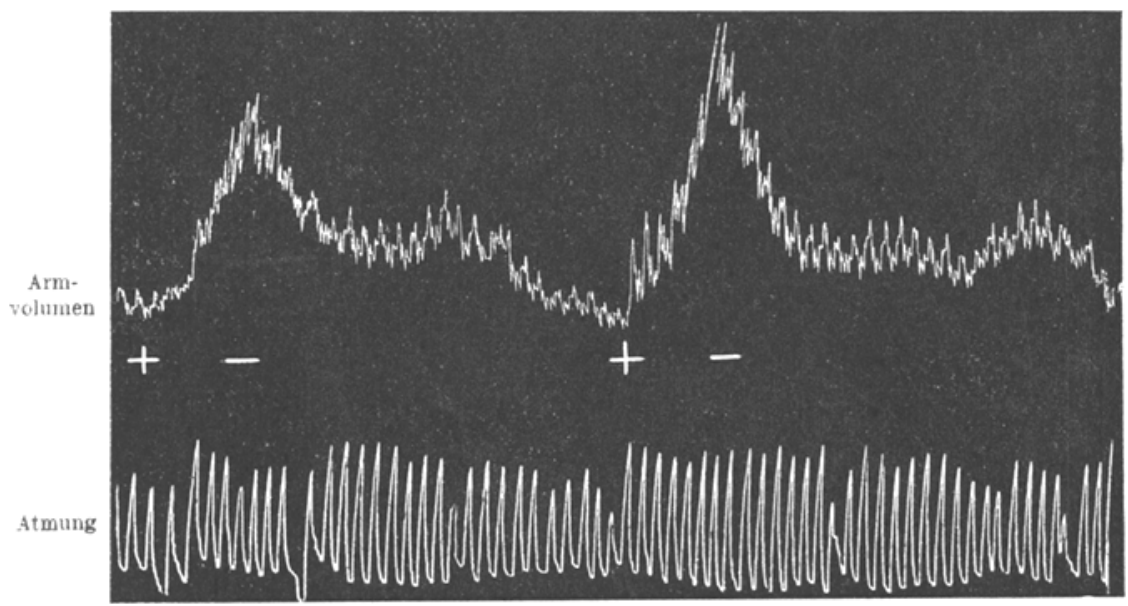

Abb. 9a. Vor Behandlung.

entsprechenden Zeichen der Kurve 2 Minuten lang angehalten, so daß die Kurve in Wirklichkeit die mehr als doppelte Länge der abgebildeten Kurve hatte. (Die volle Umdrehung der Registriertrommel um sich selbst dauert 15 Minuten.)

Dies Ergebnis stellt zweifellos eine beträchtliche Schädigung des Patienten durch das Bad dar, obwohl eine Abdämpfung in diesem Falle von sehr gutem, wenn auch zunächst nicht dauerndem Erfolg war. Nach 8 Minuten allgemeiner Hochfrequenz war die Kurve von $A b b .9 b$ in die von 9c verwandelt, also vollkommen normal geworden. Nur in diesem Falle sah ich übrigens auch eine dämpfende Wirkung des Vierzellenbades (15 MA), wenn sie auch den Erfolg der Hochfrequenz nicht erreichte. In allen anderen Fällen war sie unwirksam, während allgemeine Hochfrequenz gute Wirkung hatte. (Auch anregende Wirkung der 4 Zellenbäder beobachtete ich nicht.) 
Die dämpfende Wirkung der Hochfrequenz war auch hier nach 24 Stunden wieder verschwunden, so daß die übermäßig nachträglich

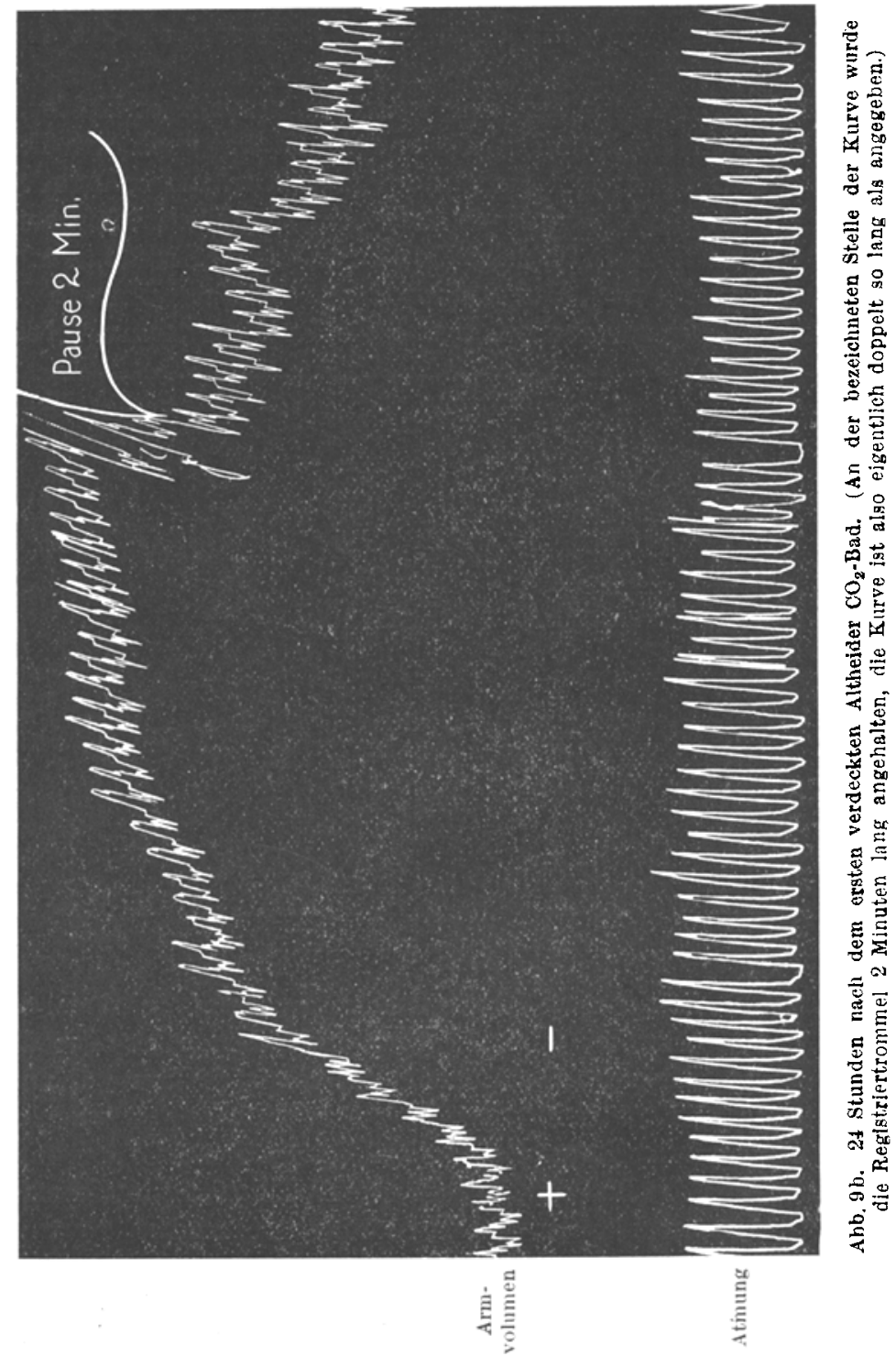

ansteigende Kurve wieder vorhanden war, und die Hochfrequenzbehandlung wiederholt werden mußte.

Es wäre zweifellos für diesen Kranken vorteilhafter gewesen, wenn er kein Kohlensäurebad erhalten hätte, da sein Kreislauf sich im best- 
möglichen Korrektionszustand befand, und das Bad durch die Úberreizung des hypertrophischen Herzmuskels einen sehr schädlichen Einfluß hatte, der nur mühsam durch eine Reihe von Hochfrequenzbehandlungen wieder einigermaßen bis zum früheren Zustand abgedämpft werden konnte.

Dabei handelte es sich in diesem Falle zum Glück um einen Herzmuskel von guter Muskelbeschaffenheit, wie daraus hervorging, daß nach dem Abklingen der übermäßig stark nachträglich ansteigenden Kurve bei abermaliger Fußarbeit immer wieder die gleiche nachträglich ansteigende Kurve erschien, also der Muskel durch die übertriebene, unnötige Anstrengung noch nicht erschöpft wurde. Bei schlechterer Beschaffenheit des Herzmuskels tritt, wie schon erwähnt, in solchen Fällen oft schon bei der ersten Wiederholung der Fußarbeit nach einer derartig langen, nachträglich ansteigenden Kurve als Zeichen der Erschöpfung eine negative Kurve auf, und dann ist natürlich die Abdämpfung der Kurve von um so größerer Bedeutung für den Kranken,

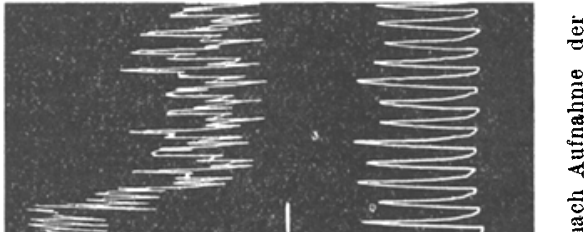

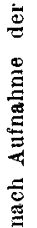

.
muß aber bisweilen mit anderen Anregungsmitteln kombiniert werden. In solchen

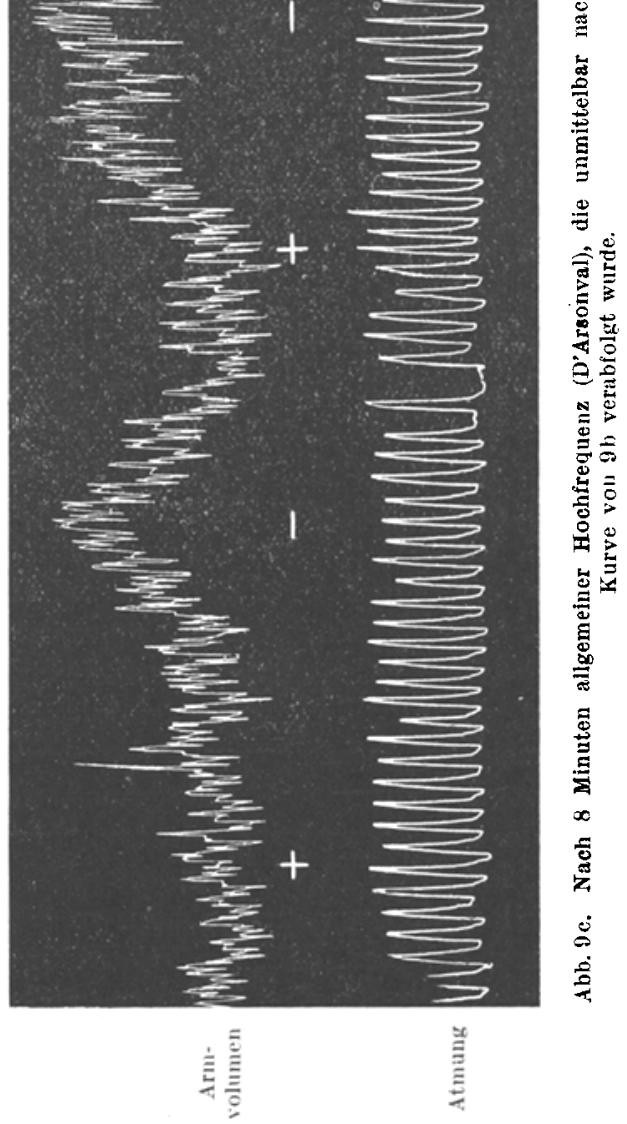
Fällen muß natürlich die Schädigung durch das Bad als weit schlimmer angesehen werden, ganz besonders, wenn bei Mangel einer Kontrolle der Bäderwirkung durch die plethysmographische Arbeitskurve solche schädlich wirkentle Bäder in längerer Aufeinanderfolge gegeben werden, und jede Abdämpfung der schädlichen Überreizung durch andere Behandlungsarten unterbleibt. 
Ich bin überzeugt, daß solche Fälle besonders es sind (außer der oben beschriebenen üblen Wirkung der unverdeckt gegebenen Bäder bei gewissen Herzinsuffizienzen), bei denen man üble Wirkungen und selbst Todesfälle nach mehr oder minder langem Gebrauch von Kohlensäurebädern festgestellt hat. Während man die oben erwähnte Gefahr der Einatmung der Kohlensäure leicht vermeiden kann, indem man prinzipiell nur völlig verdeckte Bäder verabreicht, ist die Vermeidung der Gefahr der eben erörterten Ủberreizung völlig sicher nur bei Kontrolle der Wirkung wenigstens des ersten Probebades durch die plethysmographische Arbeitskurve möglich. In den Fällen, bei denen dies nicht möglich ist, und bei denen eine durch andere Mittel nachweisbare Hypertrophie des linken Herzens an die Möglichkeit einer solchen Überreizung denken läßt, wäre es dringend zı empfehlen, vorsichtshalber jedem Bade eine allgemeine Hochfrequenzbehandlung in oben beschriebener Weise folgen zu lassen. Da allgemeine Hochfrequenz nicht schadet, kann man mit der Verordnung dieser Kombination lieber etwas zu freigebig sein und sie, wenn eine plethysmographische Untersuchung nicht möglich ist, auch in anderen Fällen mit den Bädern versuchsweise kombinieren, bei denen diese die gewünschte gute Wirkung nicht zu haben scheinen. Aber auch das subjektive Empfinden ist dabei durchaus nicht immer maßgebend, da eine zunächst eintretende Anregung des Herzmuskels die Autosuggestion dèr Besserung verstärken und oft vortäuschen kann.

Andererseits kann aber die Hochfrequenz bezüglich der anregenden Wirkung den Erfolg der Bäder keineswegs ersetzen, da die für die Kranken oft sehr notwendige Reizwirkung der Bäder, wie oben erwähnt, um ein Vielfaches stärker und länger dauernd ist als die der allgemeinen Hochfrequenz und auch der etwas stärker anregenden lokalen Hochfrequenz überlegen ist.

Wie es der praktischen Erfahrung entsprach, wenn ich gewisse Fälle feststellte, bei denen die Einwirkung der Kohlensäurebäder zweifellos eine ungünstige war, so fand ich auch in Altheide zwei Herzkranke, bei denen die Kohlensäurebäder überhaupt keine Wirkung hatten, weder im guten noch im schlechten Sinne. Ich berücksichtige dabei natürlich nur die sicherere Wirkung der natürlichen $\mathrm{CO}_{2}$-Bäder.

Ich erwähnte schon, daß ich an mehreren völlig normalen Kurven Gesunder zu Beginn der Untersuchungen feststellte, daß sie durch Kohlensäurebäder nur in ihrer Form gewissermaßen deutlicher akzentuiert, aber sonst nicht beeinflußt wurden. Bei den beiden hier in Frage kommenden Fällen handelte es sich aber um Kurven, die auf bestehende Krankheitszustände allerschwerster Art hinwiesen. Bei dem einen Falle handelte es sich um einen 62 jährigen Mann mit Arteriosclerose, sehr 
leisen Herztönen, Blutdruck 175, mit Verbreiterung der Aorta und außerordentlich starker Verbreiterung des linken Herzens.

Die Kurve war die von Abb. 10, während der Arbeit stark sinkend und nachträglich sinkend und hierauf ziemlich stark nachträglich über die Abszisse ansteigend. Nach mehrmaliger

Wiederholung der kurzdauernden Fußarbeit zeigten sich völlig negative Kurven. Wie ich schon früher kurz erwähnte, beweist ein derartiger Kurvenbefund das Vorhandensein eines sehr schlechten Zustandes der Kreislaufverhältnisse, besonders wenn die Kurve nach kurzem schon in völlig negative Kurve übergeht. Der ziemlich starke nachträgliche Anstieg beweist nämlich, daß alle Korrektionsmöglichkeiten des ungenügenden Kreislaufs durch Vermittlung der Hypertrophie des linken Herzens schon entwickelt und in Funktion sind, aber das trotzdem zunächst eintretende langdauernde Sinken der Kurve zeigt; daß diese Korrektion völlig versagt und unfähig ist, die Negativität der Kurve zu beeinflussen. Erst nach dem Aufhören der Kontraktion der peripheren Gefäße hat der hypertrophischelinkeVentrikel dieKraft,

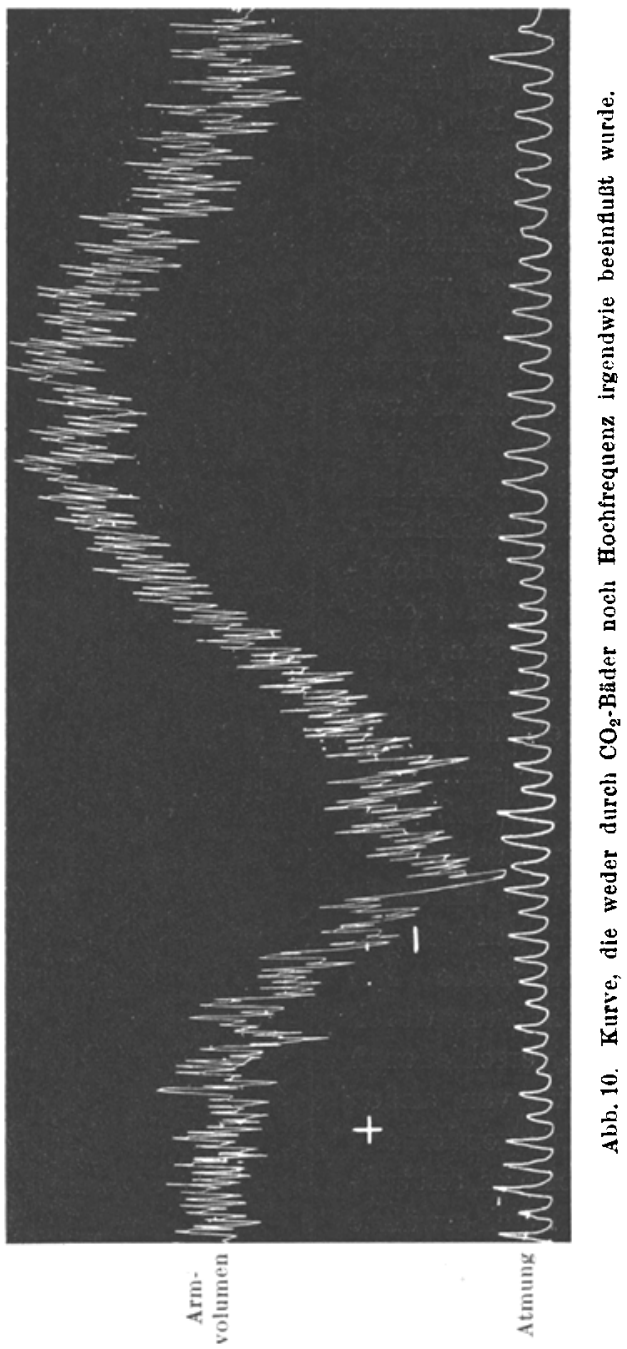
allmählich eine stärkere Blutwelle in die Peripherie zu treiben und dadurch zu beweisen, daß er völlig in Funktion ist, und also keine Besserung der Verhältnisse durch weitere funktionelle Heranziehung der schon vorhandenen starken Hypertrophie des linken Herzens zu erwarten ist. Die Beschaffenheit des hypertrophischen Herzmuskels muß in solchen Fällen also eine sehr minderwertige sein. 
Dieser Patient erhielt mehrere verdeckte, natürlicheKohlensäurebäder und später auch ein künstliches Bad, ohne daß der geringste Einfluß der Bäder auf die Kurve beobachtet werden konnte. Auch-der Blutdruck wurde dadurch nicht verändert. Patient erhielt hierauf mehrere Behandlungen mit Hochfrequenz, gleichfalls ohne jeden Erfolg. Es ist wohl in einem solchen Falle anzunehmen, daß der Herzmuskel nicht mehr imstande war, auf, die reflektorische $\mathrm{Be}$ einflussung durch die verschiedenen Reize von außen in irgendeiner Weise zu antworten. (Ich erwähne noch, daß bei zwei Fällen, die der Kurvenach genau diesem Falle entsprachen, von Kollege Karfunkel durch Auf-

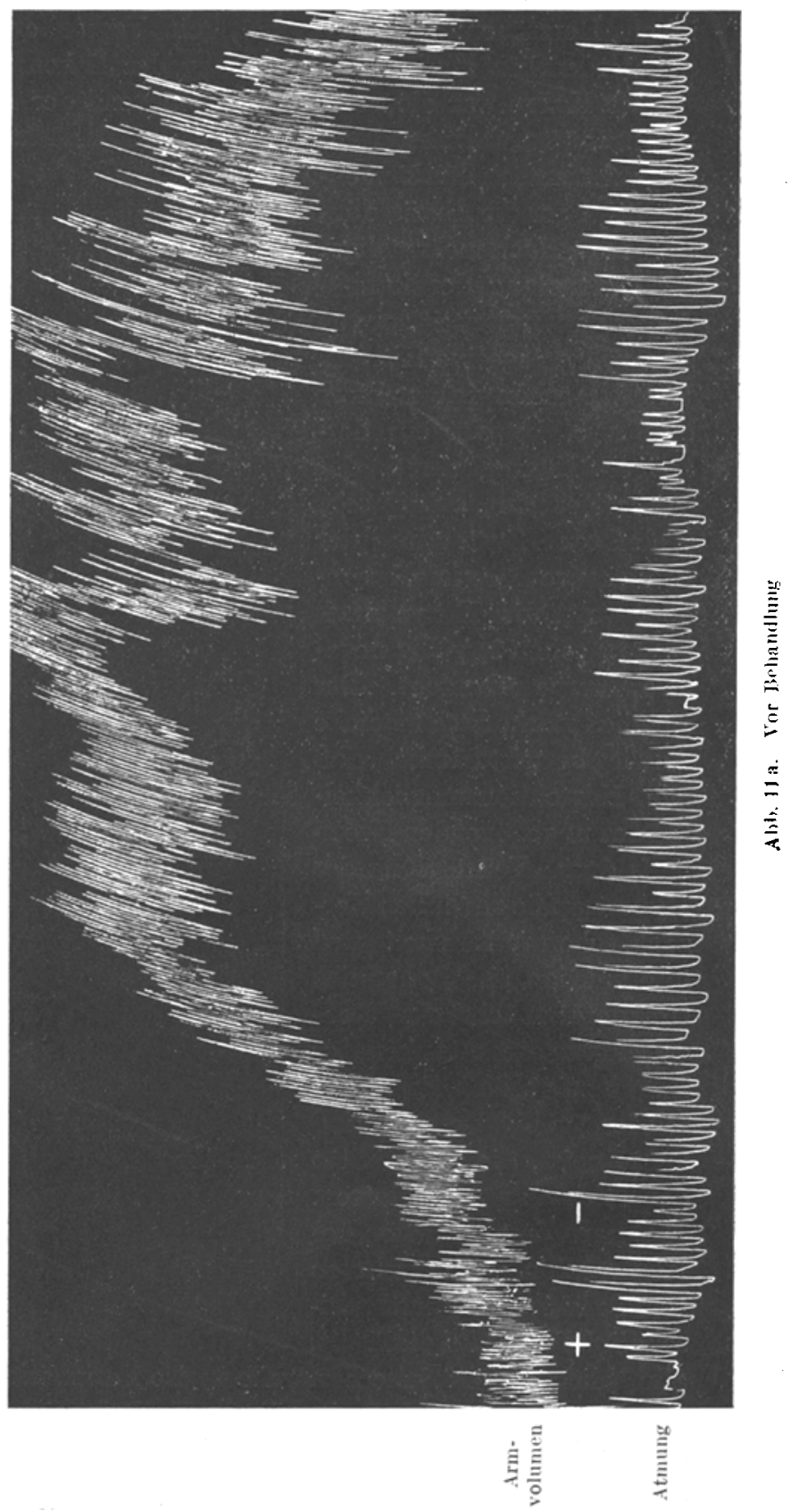
nahme des Elektrokardiogramms eine etwaige Reizleitungsstörung nicht nachgewiesen werden konnte.) 


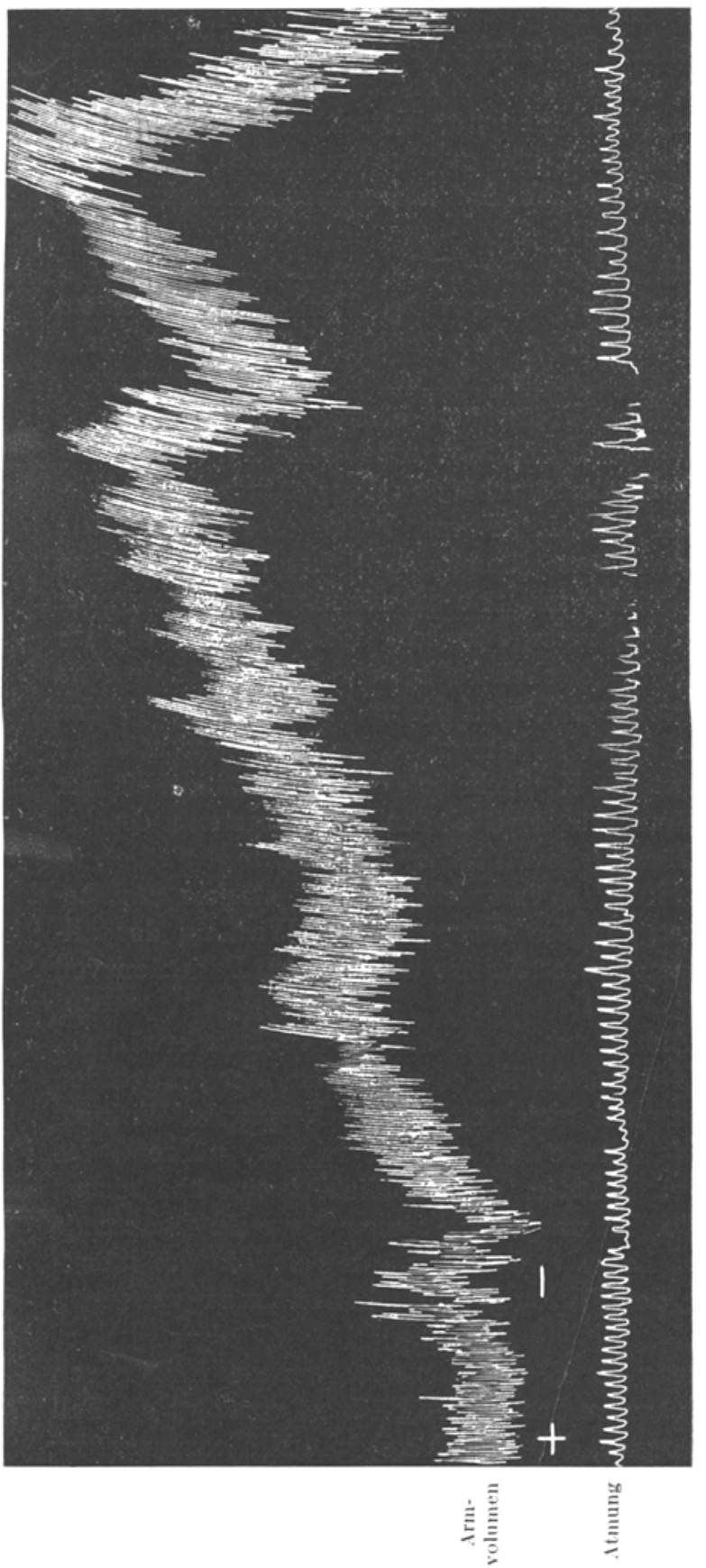

Der andere charakteristische Fall ist durch Abb. 11 a und $b$ illustriert.

Es handelte sich um eine alte Aorteninsuffizienz. Tinkes Herz sehr stark verbreitert, Aorta verbreitert, erster Aortenton unrein, zweiter lautes Geräusch, Blutdruck 125, Puls regelmäBig.Die Kurve zeigte den sehr hohen und langen nachträglichen Anstieg von Abb. 11 a, der auch bei Wiederholung erhalten blieb, was auf eine gute Beschaffenheit des Herzmuskels hinweist.

Auch in diesem Falle blieben Bäder, Hochfrequenz, Vierzellenbad völlig wirkungslos. Abb. $11 \mathrm{~b}$ zeigt die Kurve 6 Stunden nach einem natürlichen, verdeckten Bade. (Auch später änderte sich die Kurve nicht.) Es entspricht dies der schon bekannten Erfahrung, daß alte Aorteninsuffizienzen durch Kohlensäurebäder nicht günstig beeinflußt werden. Inmerhin kam es in 
diesem Falle wenigstens auch nicht zu einer Schädigung durch die Bäder, wie zum Beispiel im Falle von Abb. 9. Sicherlich ist aber auch bei Aorteninsuffizienzen eine solche Schädigung in früheren Stadien, oder bei Zuständen erreichter guter Korrektion der Kreislaufverhältnisse, nicht ausgeschlossen, und es wäre in solchen Fällen besonders wichtig, die Wirkung durch Aufnahme einer Arbeitskurve zu kontrollieren.

Man könnte nach dem Beispiel der Fälle von Abb. 9 und 11 auf den Gedanken kommen, daß es besser wäre, überhaupt bei keinem Falle, bei dem vor der Behandlung eine ansteigende, oder eine nachträglich ansteigende Kurve sich findet, Kohlensäurebäder anzuwenden, weil dann nur eine schädliche Uberreizung eintreten könne. Dies ist indes bei der gehörigen Vorsicht und Kontrolle durch die Kurve deshalb nicht richtig, weil die Kohlensäurebäder außer der anregenden Wirkung auf den Herzmuskel auch in gewissen Fällen eine dämpfende Wirkung ausüben können. Diese dämpfende Wirkung tritt allerdings bei weitem nicht so regelmäßig ein, wie die dämpfende Wirkung der Hochfrequenzbehandlung, sie versagt in sehr vielen Fällen, wie wir aus den besprochenen Kurven ersehen haben, und ich konnte sie etwa nur bei einem Viertel bis zu einem Drittel der nachträglich ansteigenden Kurven beobachten, aber wenn sie einmal wirksam ist, was offenbar von einer besonders günstigen Konstellation der Empfindlichkeit der beiden die Reize dem Herzen übermittelnden Nervensysteme des betreffenden Patienten abhängt (wie ich später noch erörtern werde), so ist diese dämpfende Wirkung außerordentlich viel stärker und besonders viel nachhaltiger, als die entsprechende Wirkung der allgemeinen Hochfrequenz und daher für die betreffenden Patienten von unersetzlichem Werte.

Bei dem Falle von Abb. 6 mußte ich oben schon kurz erwähnen, daß als Wirkung eines natürlichèn Bades sich neben der anregenden Wirkung auf den Herzmuskel gleichzeitig eine dämpfende Wirkung zeigte, so daß der Erfolg gerade der erwünschte war, während das künstliche Bad bei demselben Patienten ausschließlich eine übertrieben anregende Wirkung zeigte. Es war also in diesem Falle die dämpfende Wirkung des natürlichen Bades zweifellos stärker als die des künstlichen, und beide Arten der Wirkung traten bei letzterem nebeneinander auf.

Die dämpfende Wirkung der Bäder kann aber in vielen Fällen auch als einzige Wirkung sichtbar werden. In $\mathrm{Abb} .12$ sei zunächst ein Fall illustriert, aus dem sich ergibt, daß auch künstliche Kohlensäurebäder eine ausgezeichnete und sehr dauerhafte dämpfende Wirkung haben können, und der auch aus anderen Gründen sehr instruktiv ist.

Es handelte sich um einen 45 jährigen Offizier, bei dem bereits 
vor 20 Jahren nach einem Kommando in einer Turnanstalt eine Herzerweiterung festgestellt worden war. Es fand sich bei sonstigem normalen Befund eine starke Vergrößerung des Herzens nach beiden Seiten. Vor der Behandlung wurde regelmäßig die außerordentlich ausgedehnte Kurve von Abb. 12a aufgenommen, die, als einzige der abgebildeten Kurven, in der Reproduktion auf zwei Drittel der Originalgröße verkleinert wurde. Nach gutem Anstieg während der Fußarbeit zeigt die Kurve nach vorübergehender Senkung eine schwache, aber langdanernde nachträgliche Steigung mit trägem Abfall. Die spätere Kurve von $12 \mathrm{~d}$ zeigt denselben Charakter.

Nach einer zu diagnostischen Zwecken vorgenommenen Bauchmassage (Kirchbergsche Saug-Druckmassage) zeigte sich die bedeutend stärker nachträglich ansteigende Kurve von $12 \mathrm{~b}$, die wegen ihres Umfangs nur in ihrem ersten Teile abgebildet ist. Hierauf erhielt der Patient ein verdecktes, künstliches Kohlensäurebad, und nach einer Stunde wurde die völlig normale Kurve von Abb. 12c aufgenommen, was bei der Ausdehnung der vorher aufgenommenen Kurven einen ganz frappanten Erfolg darstellt.

Von Interesse dürfte es sein, diese Kurven mit denen von Abb. 7 oben (S. 26) zu vergleichen. In jenem Falle war durch die anregende Wirkung der Kohlensäure eine negative Kurve zunächst in eine nachträglich ansteigende und träge abfallende Kurve umgewandelt worden (Abb. 7c), die der Kurve von 12a und der entsprechenden von $12 \mathrm{~d}$ sehr ähnlich ist. Wie oben erwähnt, kann man bei solchen Kurven nicht ohne weitere diagnostische Maßnahmen entscheiden, ob der träge Abfall die Folge einer venösen Stauung, oder die des langsamen Abklingens der bei der Muskelarbeit gesteigerten Tätigkeit des hypertrophischen linken Ventrikels ist. Sowohl im Falle von Abb. 7, als im Falle von Abb. 12 wurde durch das Bad dieser träge Abfall vollständig beseitigt, der wichtige Unterschied in der Wirkung ist aber der, daß offenbar in jenem Falle, wie schon oben auf S.28/29 erörtert, das wirksame therapeutische Prinzip dabei die anregende Wirkung der Kohlensäure auf den Herzmuskel war, in diesem aber die dämpfende Wirkung. In jenem Falle wurde nach dem zweiten Bade der nachträgliche Anstieg der Kurve infolge der Anregung des Herzmuskels durch die Kohlensäure um das Mehrfache höher als vorher, so daß das.Verschwinden des trägen Abfalls auf die Beseitigung der venösen Stauung durch die gesteigerte Herzaktion zu beziehen ist. In diesem Falle von Abb. 12 aber hatte eine andersartige Einwirkung, die Bauchmassage, die ausschließlich eine anregende Wirkung hatte, auch eine Verstärkung des nachträglichen Anstiegs zur Folge (Abb. 12 b), aber der träge Abfall blieb dabei vollständig erhalten und glich völlig dem von Abb. 12 a. Da num eine venöse Staunng für den Fall, 


\section{E. Weber: Die Wirkung natürlicher und künstlicher Kohlensäurebäder}
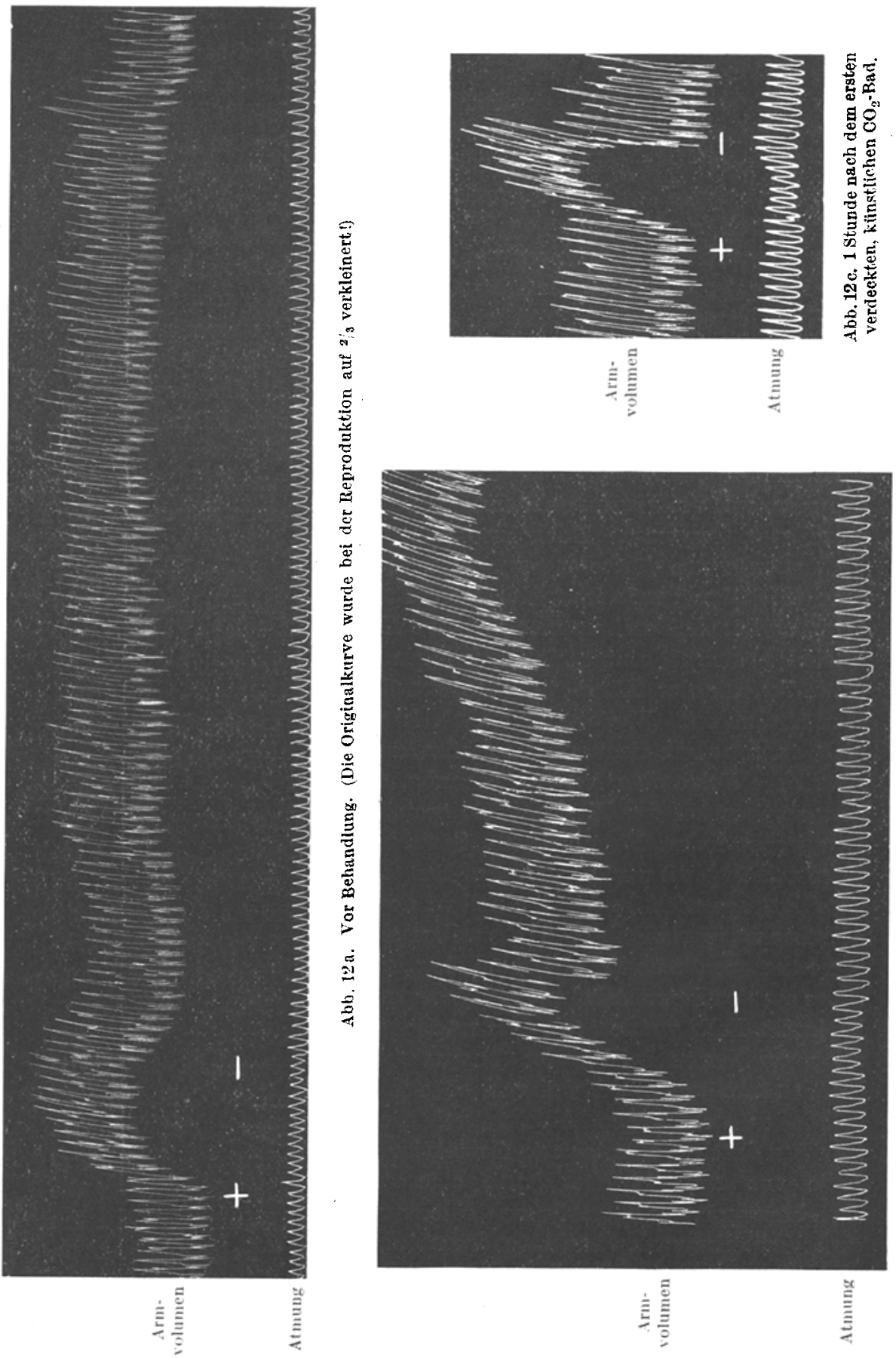

D 

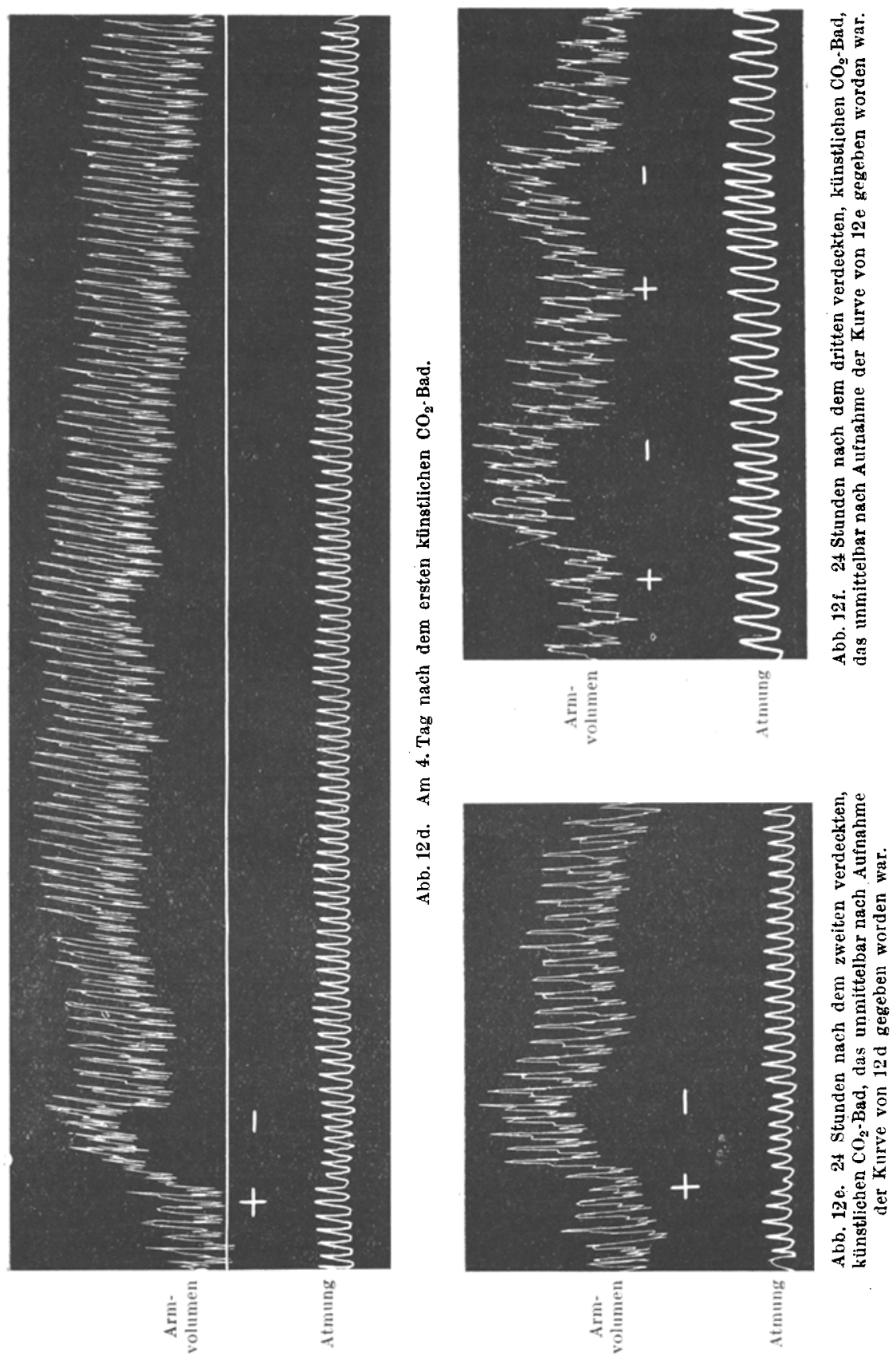
daß sie von einer Funktionsschwäche vorzugsweise des rechten Herzens herrührte, durch die gesteigerte Herzaktion, für den anderen Fall, daß sie von einer Stauung in den Bauchgefäßen herrührte, durch die Bauchmassage hätte beeinflußt werden müssen, so spricht dies Fehlen jeder Wirkung in diesem Falle schon gegen das Vorhandensein einer venösen Stauung und für die Verursachung des trägen Abfalls der Kurve durch die Folgen der Hypertrophie des linken Herzens. Völlig bestätigt wird dies aber durch die Wirkung des kohlensauren Bades, nach dem die Kurve völlig normal wurde, wie Abb. $12 \mathrm{c}$ zeigt. Diese Wirkung läßt sich nur durch die dämpfende Wirkung der Kohlensäure erklären, die durch Vermittlung des Vagus die über-

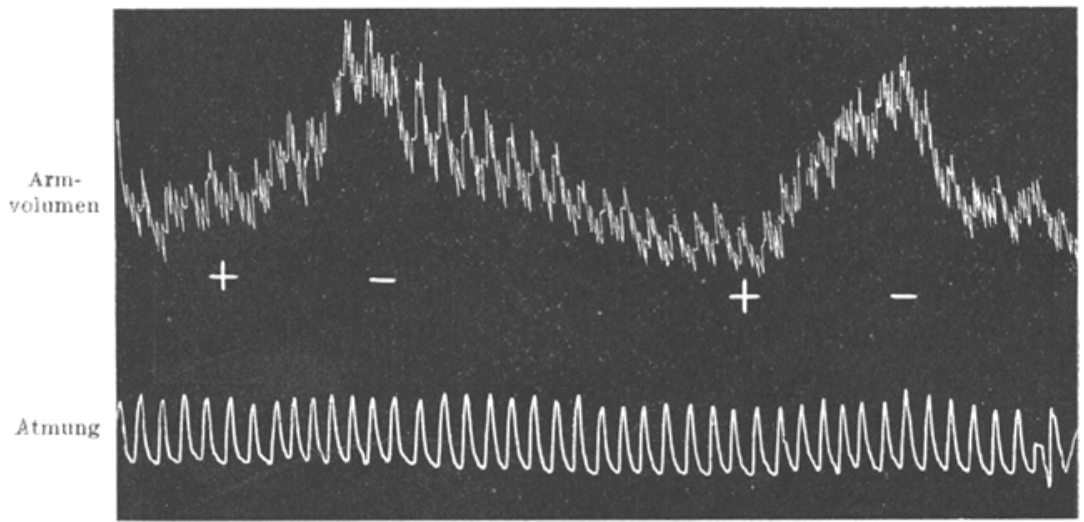

Abb.12g. 1 Woche nach dem dritten künstlichen $\mathrm{CO}_{2}$-Bad, dem keine weitere Einwirkung folgte.

triebene Aktion des hypertrophischen linken Herzens auf das richtige Maß zurückbrachte.

Wie schon erwähnt, ist die dämpfende Wirkung, wenn sie nach Kohlensäurebädern überhaupt eintritt, eine viel dauerhaftere, als die entsprechende Wirkung der allgemeinen Hochfrequenzbehandlung. Im Falle von Abb. 12 hielt die gute Wirkung des ersten Bades, allmählich sich vermindernd, 3 Tage lang an. Am vierten Tage wurde die Kurve von Abb. $12 \mathrm{~d}$ aufgenommen, die wieder nahezu den alten Zustand darstellt, wenn auch nicht vollständig. Das Bad wurde dann wiederholt, und nach 6 Stunden wurde wieder die gleiche normale Kurve, wie die von $\mathrm{Abb} .12 \mathrm{c}$, registriert. Am nächsten Morgen zeigte Patient die Kurve von $\mathrm{Abb} .12 \mathrm{e}$, an der schon wieder eine leichte Neigung zum Charakter der früheren Kurve nicht zu verkennen ist. Diesmal wurde dem $\mathrm{Pa}$ tienten sofort, also am Tage nach dem zweiten Bad, ein drittes künstliches $\mathrm{CO}_{2}$-Bad (alle diese Bäder wurden im Lazarett in Berlin verabfolgt) gegeben. Nach 24 Stunden wurde die Kurve von Abb. $12 f$ 
aufgenommen, und diesmal war die Wirkung schon eine bedeutend nachhaltigere, denn noch eine volle Woche nach dem dritten Bade. dem bis dahin kein anderes folgte, zeigte der Patient die als fast völlig normal anzusehende Kurve von Abb. 12g. Der Erfolg ist also als ein geradezu idealer zu betrachten, und, wie in allen Fällen, entsprach auch das Befinden des Kranken der Kurve. Ich wage hierbei nicht zu entscheiden, ob die kurze Aufeinanderfolge des zweiten und dritten Bades an der verstärkten Wirkung einen Anteil hatten, in einem anderen Falle von negativer Kurve sah ich von' zwei unmittelbar aufeinanderfolgenden Bädern eine ungünstigere Wirkung eintreten, als bei Bädern in längeren Intervallen, so daß offenbar auch hierin individuelle Verschiedenheiten bestehen, die durch die Aufnahme der Arbeitskurve festgestellt werden müßten.

Jedenfalls zeigt dieser Fall, daß die dämpfende Wirkung der Kohlensäurebäder in gewissen Fällen auch durch künstliche Bäder in sehr schöner Weise erreicht werden kann. Wie sich aber früher bei Besprechung der anregenden Wirkung der Kohlensäure herausstellte, daß die Einatmung der Kohlensäure bei unverdeckt verabfolgten Bädern die gute Wirkung verhindern kann, so konnte ich das gleiche auch von der dämpfenden Wirkung beobachten. Tch wähle als Beispiel zunächst noch einen Fall der Wirkung künstlicher Bäder.

Abb. 13 betrifft einen Fall von typischer Mitralinsuffizienz, der die nachträglich schwach ansteigende Kurve von Abb. 13a zeigte. Ich hatte damals noch keine Erfahrung über die Nachteile der unverdeckt verabfolgten Kohlensäurebäder und ließ den Patienten daher zunächst in verschiedenen Zeiträumen unverdeckte, künstliche Bäder nehmen. Der Erfolg war ein überraschend ungleicher. Während das erste Bad eine für einen halben Tag normale Kurve zur Folge hatte, fehlte diese Wirkung bei den nächsten Bädern, oder wurde sogar zu einer schädlichen Wirkung durch Vergrößerung der Überkorrektion. Erst als ich den Patienten auf Rat von Herrn Kollegen Tobias völlig verdeckte Bäder nehmen ließ, war der Erfolg ein regelmäßiger, wie ihn die Kurve 13 b zeigt. (Sauerstoffbäder schienen nicht völlig gleichwertig in der Wirkung zu sein.) Da immerhin der Erfolg auch der verdeckten Bäder nicht sehr dauerhaft erschien, und die Abdämpfung der Kurve in diesem Falle von allgemeiner Hochfrequenz und Kondensatorstrom in fast gleicher Weise geleistet wurde, wie die Veränderung der Kurve $13 \mathrm{c}$ zu der von $13 \mathrm{~d}$ durch solche Behandlung beweist (wenn auch zunächst nur für einen halben Tag wirkend), ließ ich eine Dauerbehandlung mit allgemeiner Hochfrequenz folgen. Nach achtmaliger Behandlung blieb die Kurve schon 24 Stunden nach Behandlung normal, die Behandlung mußte aber aus äußeren Gründen plötzlich abgebrochen werden. Hierauf kam Patient 4 Monate später wieder zur 
Untersuchung, nachdem er unmittelbar vorher ca. 6 Wochen lang in einem Badeorte mit natürlichen Kohlensäurequellen sich aufgehalten hatte und dort 20 Bäder, allerdings unverdeckt, erhalten hatte. Der

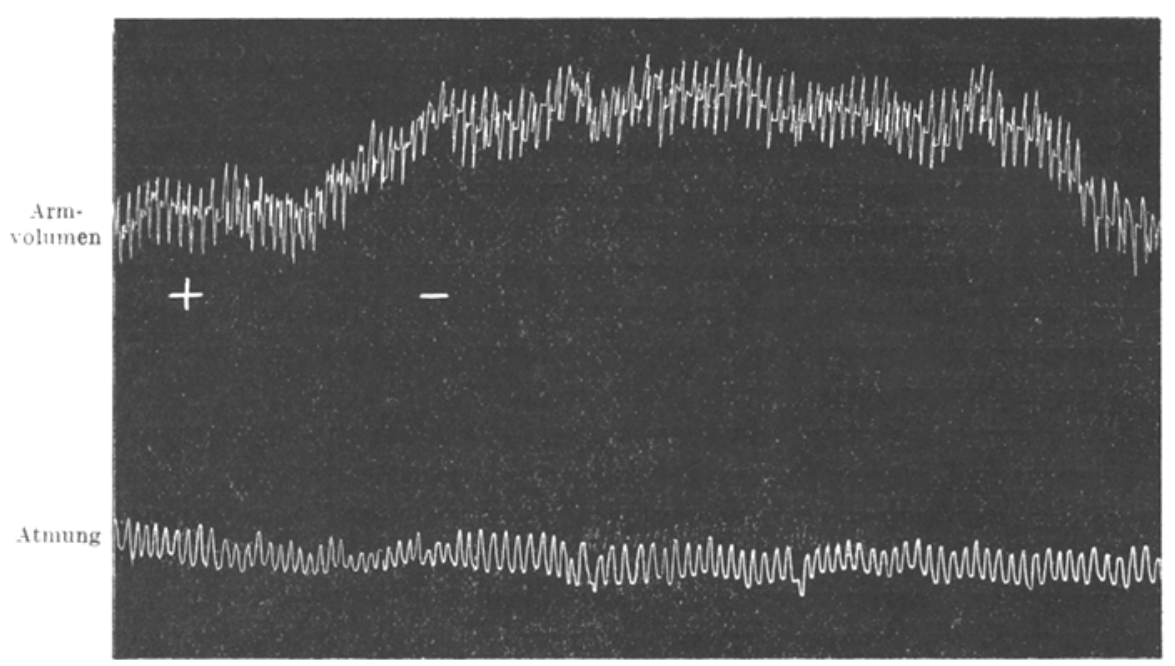

Abb. 13a. Vor Behandlung.

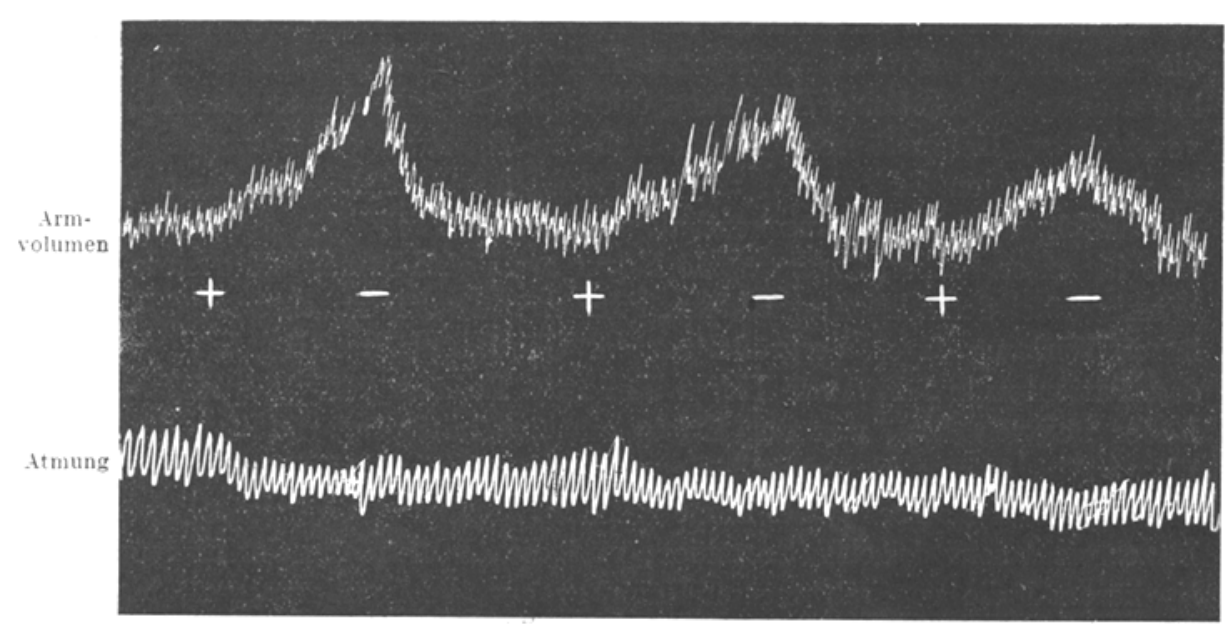

Abb. 13b. I Stunde nach verdecktem, künstlichem $\mathrm{CO}_{2}$-Bad.

Patient zeigte jetzt jedesmal zunächst überaus lange nachträglich ansteigende und dann bei Wiederholung der Fußarbeit dauernd negative Kurven, und sein Befinden war dementsprechend schlecht. Er war vor dem Weggang von mir darüber informiert wórden, daß unverdeckte Kohlensäurebäder für ihn ungünstig seien. Der Erfolg der 
trotzdem an ihm mit unverdeckten $\mathrm{CO}_{2}$-Bädern vorgenommenen Behandlung zeigte, daß auch die unverdeckten natürlichen Bäder die ungünstigste Wirkung auf seinen Zustand hatten. Nach den früheren Erfahrungen an diesem Patienten, bei dem ich niemals eine negative,

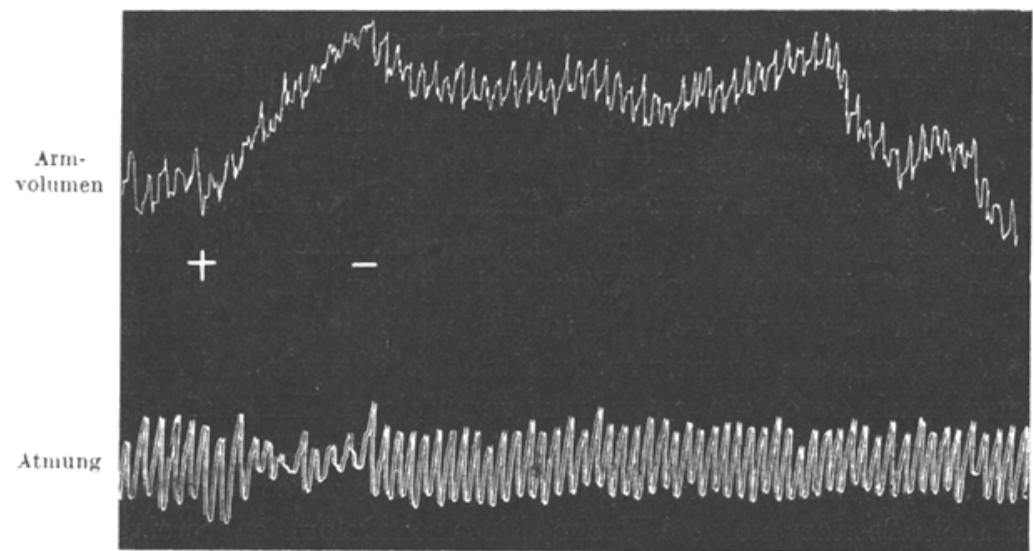

. Abb. 13c. Nach Verschwinden der Wirkung des Bades.

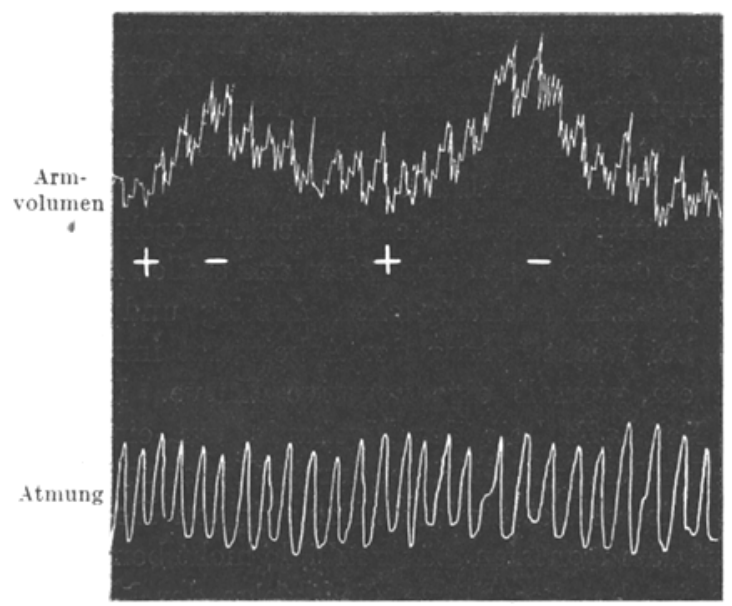

Abb. 13d. Nach allgemeiner Hochfrequenzbehandlung (D'Arsonval) unmittelbar nach Aufnahme der Kurve $13 \mathrm{~d}$. Kondensatorstrom wirkte in diesem Fall ebenso.

sondern nur übertrieben nachträglich ansteigende Kurven als üble Wirkung der offenen Bäder gesehen hatte, war die Umbildung in eine negative Kurve nach den 20 offenen Bädern nur dadurch zu erklären, daß infolge dauernder Uberreizung des hypertrophischen linken Ventrikels durch die unverdeckt verabfolgten Kohlensäurebäder und durch Herbeiführung der davon abhängigen übertrieben 
starken und übermäßig lange nachträglich fortwirkenden Arbeit des Herzens bei jeder geringen Muskelarbeit eine derartige Erschöpfung des Herzmuskels eingetreten war, daß er schon bei geringer Anstrengung nicht mehr zur hinreichenden Arterialisierung des Blutes genügte. Ich erwähnte schon früher, daß bei schlechter Beschaffenheit des Herzmuskels die mit einem sehr lange dauernden nachträglichen Anstieg verbundene unnötige Anstrengung des Herzens dieses so erschöpfen kann, daß kurze Zeit darauf bei wiederholter Fußarbeit eine völlig negative Kurve eintreten kann. In diesem Falle war nun einige Monate vorher der Herzmuskel zweifellos von guter Beschaffenheit gewesen, denn selbst in den schlechtesten Stadien des Befindens war jedesmal bei Wiederholung der Fußarbeit wieder eine, bisweilen langdauernde, nachträgliche Steigung der Kurve eingetreten. Es war die zwanzigmal wiederholte übertriebene Anregung des Herzmuskels durch die unverdeckt verabfolgten Kohlensäurebäder, nach denen der Kranke zudem jedesmal einen ansteigenden Weg zurückzulegen hatte, notwendig, um diesen Herzmuskel genau so zu erschöpfen, wie wern sein Besitzer mehrere Wochen hindurch Dolomitenbesteigungen ausgeführt hätte.

Als letzten bespreche ich einen Fall von besonders schnell eintretender, nachhaltig dämpfender Wirkung der natürlichen (Altheider) Kohlensäurebäder, bei dem die künstlichen Kohlensäurebäder überhaupt keine Dämpfung herbeiführten. Es handelte sich um eine beginnende Arteriosclerose mit steilgestelltem, kleinen Herzen, verbreiterteim Aortenband und Blutdruck 142.

Vor der Behandlung wurde bei dem Patienten regelmäßig die Kurve von Abb. 14a aufgenommen, die einen hohen und steilen Anstieg während der Arbeit mit starkem nachträglichen Anstieg und trägem Abfall aufweist. Auch bei Wiederholung der Arbeit trat immer wieder eine ähnliche Kurve ein, niemals eine negative Kurve. Es handelt sich also bei guter Beschaffenheit des Myokards um eine starke Uberkorrektion der Kreislaufverhältnisse durch Hypertrophie des linken Ventrikels, die, wie es bei steilgestellten, kleinen Herzen häufig der Fall ist, sich auf dem frontalen Röntgenbilde nicht bemerkbar machte. Charakteristisch ist bei der Kurve die infolge der Muskelarbeit eintretende Vergrößerung der Atmungsschwankungen.

Patient erhielt nun ein unverdecktes, natürliches (Altheider) Kohlensäurebad, und hierauf wurde sowohl nach 40 Minuten als nach 6 Stunden die Kurve von 14b aufgenommen. Der übertrieben hohe und steile Anstieg während der Arbeit war durch das Bad völlig auf die Norm zurückgeführt, der nachträgliche Anstieg völlig fortgefallen; und nur ein etwas träger Abfall der Kurve deutete noch den früheren pathologisehen Charakter der Kurve an. Auch die Vergrößerung der Atmungsschwan- 
kungen und Volumpulse infolge der Arbeit blieb aus und wurde nur am absteigenden Teil der zweiten Kurve von $14 \mathrm{~b}$ angedeutet, der infolgedessen auch träger abfiel, denn die Vergrößerung der Volumpulse und Atmungsschwankungen (deren Fehlen nichts bedeutet) ist ein Ausdruck für die nachträgliche Verstärkung der Herzaktion. (Wie früher erwähnt, dürfen die Pulsgrößen bei diesen Versuchen ohne weiteres nur während desselben Versuchs verglichen werden und an verschiedenen Tagen nur bei Einhaltung bestimmter Vorsichtsmaßregeln.) Bei Abb.14a betrug der Unterschied der Pulsgröße vor und nach der Muskelarbeit

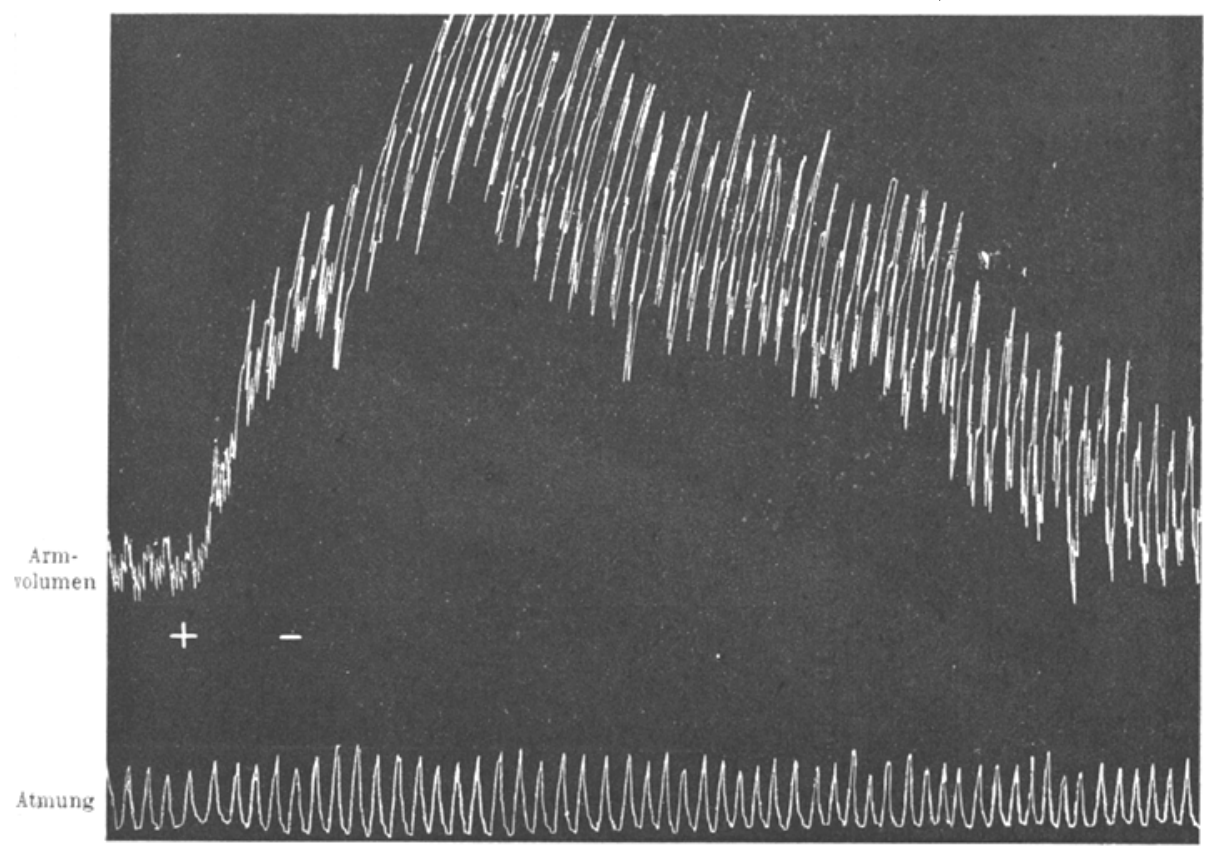

Abb. 14a. Vor Behandlung.

ein Mehrfaches, und der träge Abfall der Kurve wurde nur durch das allmähliche Abklingen der gesteigerten Herzaktion verursacht. In $A b b .14 b$ war die Kurve bei der ersten Arbeitsausführung völlig normal, es fehlte auch jede über das Normale hinausgehende Volumpulsvergrößerung nach der Arbeit. Bei der unmittelbar darauffolgenden Wiederholung der Arbeit auf derselben Abbildung sehen wir, daß infolge der Kumulation der Anstrengung die durch die Intention der Arbeit gesetzte Anregung des Herzmuskels bereits wieder eine geringe pathologische, nachträgliche Erregung des Herzmuskels herbeiführte, die zu dem trägen Abfall der Kurve führte, der schon fast eine geringe nachträgliche Steigung andeutet. Aus den Einzelheiten dieser Kurven, 
E. Weber: Die Wirkung natürlicher und künstlicher Kohlensäurebäder
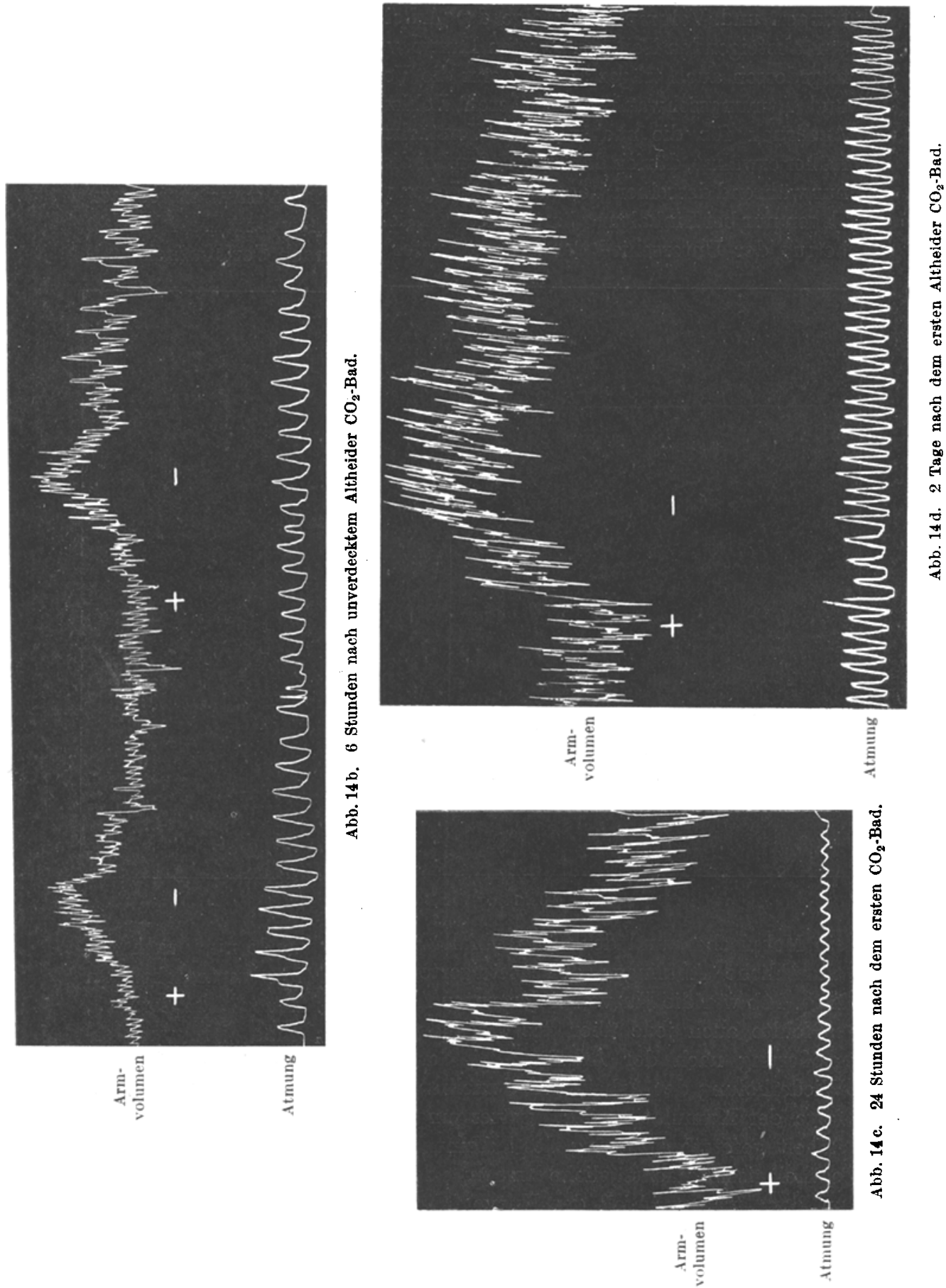

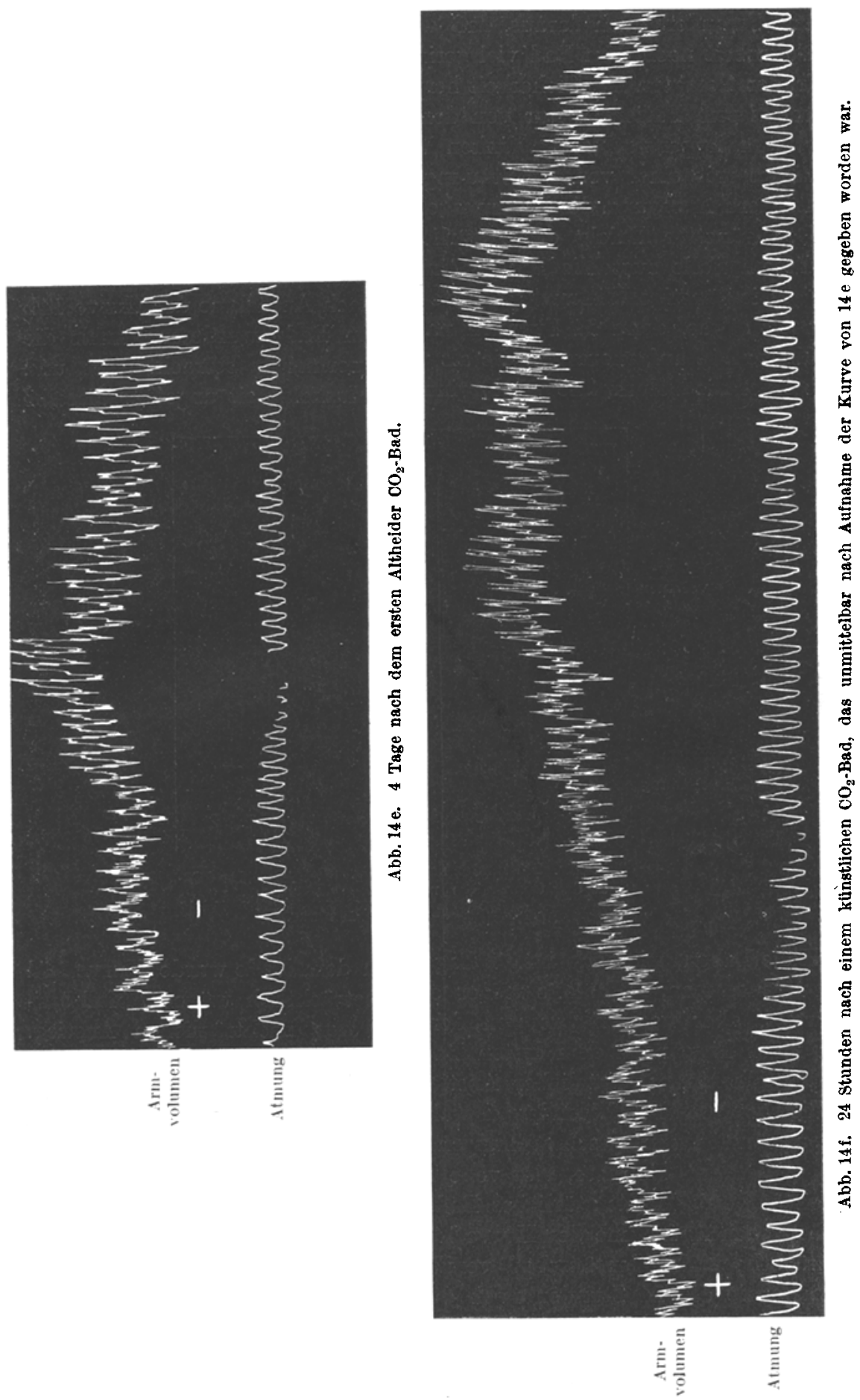
und besonders auch daraus, daß der Anstieg der Kurven während der Fußarbeit nach dem Bad viel geringer war als vorher, geht nach dem früher Gesagten mit Sicherheit hervor, daß der träge Abfall der Kurven bei diesem Patienten nur von dem allmählichen Abklingen des überreizten hypertrophischen linken Ventrikels herrührte und durchaus nichts mit einer venösen Stauung zu tun hatte, die etwa durch eine stärkere Anregung des Herzmuskels infolge des Bades beseitigt wäre. Der günstige Erfolg des natürlichen Kohlensäurebades bestand in diesem Falle ausschließlich in einer dämpfenden Wirkung.

Die günstige Wirkung steigerte sich nach Aufnahme der Kurve 14b noch etwas, denn 24 Stunden nach dem Bade wurde mehrmals die Kurve $14 \mathrm{c}$ aufgenommen, die als völlig normal $\mathrm{zu}$ betrachten ist, und bei der die Volumpulse vor Beginn der Muskelarbeit ungefähr dieselbe

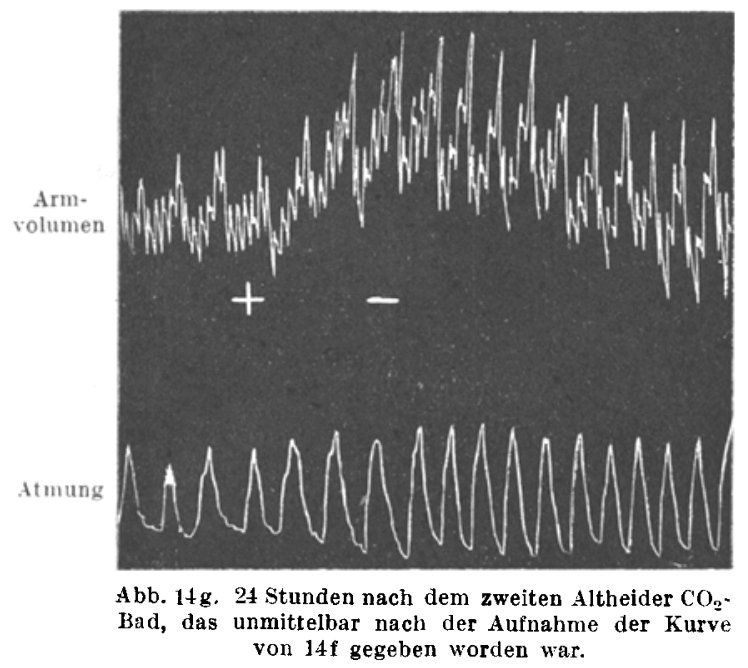

Höhe haben, wie nach ihr. 2 Tage nach dem Bade wurde Kurve 14d aufgenommen, die bereits wieder einen beträchtlich trägen Abfall aufweist, aber noch nichts von dem früheren nachträglichen Anstieg. Erst 4 Tage nach dem ersten Bade zeigte sich in Kurve 14e wieder deutlich ein nachträglicher Anstieg der Kurve und gleichzeitig auch die für diesen Fall besonders charakteristische Vergrößerung der Volumpulse und Atmungsschwankungen nach der Muskelarbeit.

Während die erste, vier volle Tage dauernde, gute Wirkung durch ein unverdecktes, natürliches Bad erreicht war, wurde nun, unmittelbar nach Aufnahme der Kurve 14e, dem Patienten ein unverdecktes künstliches Kohlensäurebad verabfolgt. Der Erfolg blieb vollständig aus, wie die 24 Stunden nach dem Bade aufgenommene Kurve 14f 
zeigt. Man könnte eher an eine Schädigung durch das künstliche Bad denken, denn der nachträgliche Anstieg ist ein bedeutend längerer als in Abb. 14a. Unmittelbar nach Aufnahme dieser Kurve erhielt Patient wieder ein natürliches Bad, und zwar diesmal gleichfalls ein verdecktes $\mathrm{Bad}$, worauf bei der Untersuchung nach 40 Minuten, wie auch nach 24 Stunden die fast normale, nur schwach träg abfallende Kurve von Abb. 14g aufgenommen wurde. Ein später auf Wunsch des Patienten genommenes unverdecktes künstliches Bad hatte die gleiche negative Wirkung wie das verdeckte künstliche Bad, und die gute Wirkung des ersten Bades wurde hierauf durch ein natürliches Bad wieder von neuem herbeigeführt.

Die Uberlegenheit der natürlichen Bäder auch bezüglich der dämpfenden Wirkung der Kohlensäure war also in diesem Falle sehr hervorstechend, während wir aus den zwei vorher besprochenen Fällen sahen, daß in anderen Fällen sehr wohl auch durch künstliche Bäder diese Wirkung erzielt werden kann, bisweilen allerdings nur bei Benutzung völlig verdeckter Bäder. Daß die Empfindlichkeit gegen die Einatmung der Kohlensäure bei unverdeckten, Bädern eine ganz individuelle und durchaus nicht in allen Fällen vorhanden ist (was vielleicht auch von diagnostischer Bedeutung ist), war schon durch die früher besprochenen Versuche festgestellt. Jedenfalls geht aus diesen Beispielen hervor, daß die dämpfende Wirkung der Kohlensäurebäder, wenn sie überhaupt eintritt, eine unvergleichlich wertvollere, weil nachhaltigere Wirkung darstellt, als die allgemeine Hochfrequenzbehandlung. Dauerte doch die gute' Wirkung des ersten Bades im Falle von Abb. 14 vier Tage und die des dritten Bades im Falle von Abb. 12 eine Woche. Da aber diese dämpfende Wirkung leider in der Mehrzahl der Fälle, in der sie gebraucht wird, versagt, und an Stelle dessen sogar eine schädliche Reizwirkung eintreten kann, ist es dringend nötig, diese Wirkung, ganz besonders bei Anwendung künstlicher Bäder, durch die plethysmographische Arbeitskurve zu kontrollieren.

Die praktischen Folgerungen, die sich aus allen hier besprochenen Untersuchungen ergeben, sind so zahlreich, daß ich zum Schluß nur die Hauptpunkte nochmals kurz zusammenfassen kann.

Schon aus den wenigen hier näher erörterten Fällen geht wohl deutlich hervor, daß bei annähernd gleichartigem sonstigem klinischem Befund bisweilen die tatsächliche Funktionsfähigkeit des Kreislaufs der Patienten, wie sie sich aus der Aufnahme der plethysmographischen Arbeitskurve ergibt, eine unerwartet verschiedenartige sein kann. Besonders scheint die Größe des Herzens und des Blutdrucks dafür durchaus nicht immer maßgebend zu sein. Von welchem praktischen Nutzen allein das diagnostische Resultat meiner Funktionsprüfung bisweilen ist, zeigen unter anderem Fälle wie der von Abb. 9 (S. 36), bei denen 
schon nach dem Ergebnis der Aufnahme der ersten Arbeitskurve von jedem Versuch einer Behandlung Abstand genommen werden müßte, da die bestmögliche Korrektion der Funktion des Kreislaufs schon erreicht ist und durch jede Behandlung nur geschadet wird. Ferner ist die für die Art der Behandlung maßgebende Unterscheidung, ob funktionelle Insuffizienz oder funktionelle Utberkorrektion des Kreislaufs vorliegt, wie ich gezeigt habe, sehr oft nur mit Hilfe meiner Untersuchungsmethode sicher zu erreichen. Dazu kommt nun die individuell außerordentlich verschiedenartige Wirkung der einzelnen, und gerade der wirksamsten, therapeutischen Maßnahmen, die von der individuellen Beschaffenheit des Herzmuskels und der Empfindlichkeit der das Herz reflektorisch beeinflussenden Nervensysteme abhängt, so daß wohl gesagt werden darf, daß eine völlige Sicherheit über die Notwendigkeit und den guten Erfolg einer bestimmten Behandlungsart, ferner über den Zeitpunkt, wenn die Behandlung abgebrochen werden kann, oder durch eine andere Art der Behandlung ersetzt werden oder mit ihr kombiniert werden muB, nur durch eine Reihe von Aufnahmen der plethysmographischen Arbeitskurve erreicht werden kann, deren tberlegenheit in dieser Hinsicht (bei richtiger Ausführung der allerdings schwierigen Technik) über alle anderen Untersuchungsmethoden jeder nähere Kenner der Methode zugeben muß.

Immerhin ergaben sich auch eine Reihe von praktischen Folgerungen über die Benutzung der Kohlensäurebäder und der allgemeinen Hochfrequenzbehandlung, die auch bei Unmöglichkeit, meine Untersuchungsmethode anzuwenden, und dann gerade um so sorgfältiger, beachtet werden müßten. Zunächst dürften überhaupt keine Kohlensäurebäder mehr anders verabfolgt werden, als bei völliger Verdeckung der Wannen und sonstiger (auf S. 15 erörterten) Sorge dafür, daß die Kranken die Kohlensäure nicht einatmen, was bisher noch an den meisten Stellen versäumt wird.

Ferner sollte prinzipiell bei fehlender Untersuchung mittels der plethysmographischen Arbeitskurve jedes Kohlensäurebad nach einigen Stunden von einer allgemeinen Hochfrequenzbehandlung gefolgt sein; noch sicherer wäre es vielleicht, auch an den Zwischentagen Hochfrequenz zu verabreichen, um Schädigung durch Uberreizung des Herzmuskels zu vermeiden oder wenigstens abzuschwächen.

Da die volle Wirkung der Kohlensäurebäder bisweilen noch nicht nach 6 Stunden, sondern erst nach 24 Stunden bei den Kranken eintritt, dürfte wohl eine länger als bisher übliche vollständige Ruhe nach den Bädern, nämlich für die Dauer des ganzen Tages, empfehlenswert sein. Bei der meist überaus starken und langdauernden Wirkung: schon der $\mathrm{CO}_{2}$-Bäder von $32^{\circ}$ dürfte es wohl genügen, alle 2 Tage ein Bad von ca. 10 Minuten Dauer nehmen zu lassen, obwohl scheinbar 
auch darin individuelle Unterschiede bestehen, die nur durch Aufnahme der Arbeitskurve mit Sicherheit nachgewiesen werden können.

Weitere allgemeingültige Ratschläge lassen sich bei Nichtanwendung der plethysmographischen Untersuchungen schwer geben. Bei völligen Insuffizienzen des Kreislaufs mit negativer Kurve, bei denen Hypertrophie des linken Herzens noch nicht entwickelt, oder bereits vorhandene Hypertrophie ,funktionell latent" ist, stellen Kohlensäurebäder neben den Medikamenten im allgemeinen wohl das stärkste und nachhaltigste Anregungsmittel des Herzmuskels dar, ganz besonders die natürlichen Bäder, die in vieler Hinsicht den künstlichen überlegen sind. Aber auch künstliche Kohlensäurebäder können eine schöne und dauerhafte anregende und auch dämpfende Wirkung haben, nur ist bei ihnen eine Kontrolle der Wirkung durch die Kurven ganz besonders dringlich, da ihre Wirkung öfter versagt und selbst ungünstig sein kann, als bei natürlichen Bädern.

Die größte Vorsicht sollte man bezüglich Anwendung von Kohlensäurebädern, auch natürlichen Bädern, bei Kranken mit sehr stark entwickelter, alter Hypertrophie des linken Ventrikels (auch bei Aorteninsuffizienz) beobachten, bei denen von vornherein keine negative Kurve, sondern Uberkorrektion vorliegt, denn die dämpfende Wirkung auch der natürlichen Bäder tritt nur bei einer Minderzahl dieser Fälle ein, bedeutet allerdings bei ihrem Eintreten wohl die beste und nachhaltigste Heilmethode für solche Kranke. Bei solchen Fällen kann man augenscheinlich die Kontrolle durch die plethysmographische Arbeitskurve am wenigsten entbehren. -

Zum Schluß komme ich zur zusammenhängenden Besprechung der Vorstellungen, die man sich von der Wirkungsweise der verschiedenen therapeutischen Einwirkungen auf die pathologisch veränderte Kreislauffunktion, wie sie durch die Kurven nachgewiesen wird, machen könnte, die ich schon oben an verschiedenen Stellen kurz andeuten mußte.

Daß zur Erklärung dieser Wirkung die durch die Kohlensäurebäder herbeigeführte Erweiterung der peripheren Blutgefäße keinesfalls herbeigezogen werden kann, erörterte ich schon auf S. 15. Bei denselben Kranken, bei denen Kohlensäurebäder charakteristische Veränderungen der Arbeitskurven herbeiführten, blieben kräftige Solbäder, die gleichfalls eine starke Hyperämie der Haut herbeiführen, völlig wirkungslos. (Bei allgemeiner Hochfrequenzbehandlung zeigte ein mit Kollegen Boh $\mathrm{n}$ vorgenommener vorläufiger Versuch überhaupt keine Veränderung der peripheren Gefäßweite.)

Bei den Bädern handelt es sich zweifellos um eine spezifische Einwirkung der Kohlensäure auf Nervenendigungen in der Haut, von der die Erregung reflektorisch zum Herzen weitergeleitet wird. Die sehr 
häufig außerordentlich schnell nach dem Bade eintretende Wirkung auf den Kreislauf, wie sie durch die Kurven nachgewiesen werden kann, erklärt sich am besten durch eine derartige Vermittlung der Wirkung.

Man könnte weiterhin im Zweifel sein, ob durch den Reiz reflektorisch der Herzmuskel unmittelbar beeinflußt wird, oder erst durch Vermittlung der Coronargefäße, bei deren reflektorischer Erweiterung der Herzmuskel infolge der besseren Ernährung aktionsfähiger werden würde, oder ob beides gleichzeitig geschieht. Anzunehmen, daß allein die Wirkung auf die Coronargefäße die Ursache des ganzen Vorgangs ist, ist nicht nur zur Erklärung völlig unnötig, sondern es spricht sogar Verschiedenes dagegen. Wenn wir die Verstärkung der Herzaktion nur durch die vorhergehende reflektorische Erweiterung der Coronargefäße erklären wollen, müßten wir die in vielen Fällen infolge der Bäder eintretende erwünschte Abschwächung der Herzaktion durch vorhergehende reflektorische Verengerung der Coronargefäße erklären. Nun ist aber nach E. Edens (Die Digitalisbehandlung, Berlin 1916, S. 16ff.) die Blutversorgung des hypertrophischen Herzmuskels im Verhältnis eine schlechtere, als die des normalen Herzmuskels, und es ist daher unwahrscheinlich, daß eine noch weitere Verminderung der Blutversorgung des hypertrophischen Herzmuskels, wie sie bei Verengerung der Coronargefäße eintreten würde, anstatt zur Insuffizienz des Herzmuskels mit negativer Kurve, zu völlig normaler und hinreichender Herzaktion mit normaler Kurve führt, also nur gerade die überflüssige Ưberkorrektion beseitigt, wie dies bei der dämpfenden Wirkung der Bäder der Fall ist.

Wollte man annehmen, daß in solchen Fällen gerade nur so viel Verminderung der Durchblutung des Herzmuskels stattgefunden hat, als zur Erreichung der normalen Verhältnisse nötig war, so müßte man auch annehmen, daß die vorher vorhandene Utberkorrektion, die durch die starke und.zu langdauernde Tätigkeit des hypertrophischen Herzmuskels bewirkt war, und die sich in der nachträglich ansteigenden Kurve ausdrückte, durch eine übertrieben starke Blutversorgung des Herzmuskels verursacht worden wäre. Hiergegen spricht aber nicht nur die obige Annahme von Edens, sondern auch der Umstand, daß solche nachträglich ansteigende Kurven bei fortschreitender Ermüdung des Patienten an Höhe und Länge des nachträglichen Anstiegs meist immer weiter zumehmen, so daß die Arbeitsleistung des Herzens dann oft das Zehnund Mehrfache der normalerweise hinreichenden Arbeitsleistung beträgt (die ja sofort nach der dämpfenden Wirkung des Bades tatsächlich eintritt), und es ist physiologisch nicht vorstellbar, daß ein hypertrophischer Herzmuskel vor einer.therapeutischen Maßnahme eine das normale Maß um mehr als das Zehnfache übersteigende Blutversorgung erhalten kann, während er unmittelbar danach die normale Menge erhält. 
Diese ganze Annahme, daß in diesen Fällen die reflektorksthe Beeinflussung der Coronargefäße die alleinige Ursache der Änckexung der Herzaktion ist, ist auch völlig unnötig, denn es ist uns ôf ś genaueste bekannt, daß durch direkte Nervenvermittlung dỉese sämtlichen Veränderungen der Herzfunktion eintreten können. Durch Vermittlung des Accelerans werden bekanntlich dem Herzmuskel die Aktion verstärkende und durch den Vagus die Aktion hemmende Reize übermittelt, wobei von besonderer Wichtigkeit hier wohl die Reize sind, infolge deren die Stärke der einzelnen Kontraktionen des Herzmuskels sich vergrößert oder vermindert.

(Nach Meinungsaustausch mit E. Edens halte ich es aber für sehr wohl möglich, daß gleichzeitig mit der Beeinflussung der Herzmuskulatur eine entsprechende Beeinflussung der Coronargefäße einhergeht. Es würde dies auch anderen, früheren Untersuchungen von mir entsprechen, nach denen bei elektrischer Reizung der motorischen Zone der Hirnrinde an den Gliedern, deren Muskeln in engster Beziehung zu den gereizten Hirnrindenstellen stehen, auch gleichzeitig Gefäßerweiterung eintritt.)

Meiner Ủberzeugung nach beeinflussen nicht nur die Kohlensäurebäder auf diesem Wege reflektorisch den Herzmuskel, sondern auch die allgemeine und lokale Hochfrequenzbehandlung, die tiefe Bauchmassage, die Herzmassage, die Medikamente und andere therapeutisch schnell wirkende Maßnahmen, wobei natürlich andere nebenher gehende Wirkungen nicht ausgeschlossen sind.

Die Verschiedenartigkeit der Wirkungen ist meines Erachtens begründet einerseits in der verschiedenen Qualität der therapeutisch wirkenden Reize, von denen manche, wie die allgemeine Hochfrequenz, prinzipiell stärker auf den Vagus, und andere, wie die Kohlensäurebäder, stärker auf den Accelerans wirken, andererseits aber in der individuell verschiedenen Aufnahmefähigkeit der beiden für die Vermittlung der therapeutischen Reize in Frage kommenden Nervensysteme der einzelnen Patienten.

Alle die erwähnten therapeutischen Maßnahmen wirken offenbar gleichzeitig auf beide Nervensysteme, so daß das endguiltige Resultat von dem Ausgleich der beiden entgegengesetzten Wirkungen und dem schließlichen Sieg der einen abhängt. So erklärt es sich auch ungezwungen, daß in manchen Fällen die eine bestimmte Wirkung der Kohlensäurebäder (und ähnlich auch bei anderen therapeutischen Maßnahmen) sofort eintritt, in anderen Fällen erst nach 6 oder nach 24 Stunden, und daß die Wirkung sich allmählich stejgern kann. In den ersten Fällen war das eine der beiden gleichzeitig reflektorisch beeinflußten Nervensysteme bedeutend reizempfindlicher als das andere, so daß die betreffencle Wirkung am Herzen und auf der Kurve 
sofort in Ersicheinung trat, in den anderen Fällen war die Empfindlichkeit der beiden Systeme eine gleichartigere, so daß zunächst die beiden einander entgegengesetzten Wirkungen sich teilweise aufhoben, und erst allmählich die Wirkung des einen, stärker und nachhaltiger beeinflußten Nervensystems, die Oberhand bezüglich der endgültigen Herzwirkung gewann, was wir dann an der Kurve erkennen.

Worin die Ưberlegenheit der natürlichen Kohlensäurebäder über die (nach meinen Untersuchungen) besten Arten der künstlichen Bäder beruht, kann ich vorläufig noch nicht entscheiden, ebensowenig, wie ich etwas Sicheres darüber aussagen kann, ob alle natürlichen Kohlensäurebäder die gleiche Uberlegenheit besitzen, wie die von mir untersuchten Althèider Bäder. Daß bei bestimmten Kranken trotz gleichmäßiger Abdeckung beider Bäderarten regelmäßig die anregende, wie auch in anderen Fällen die dämpfende Wirkung, ausschließlich bei natürlichen (Altheider) Bädern eintrat und bei künstlichen Bädern auch nicht in vermindertem Grade nachzuweisen war, könnte vielleicht daran denken lassen, daß bei den natürlichen Bädern Stoffe mit einwirken, die in den künstlichen Bädern fehlen. Daß dies aber nicht der Fall sein kann, geht aus der völlig gleichartigen, vorzüglichen Wirkung der künstlichen Bäder in vielen anderen Fällen hervor. Anscheinend ist es doch nur die verschiedene physikalische Art der Einwirkung der Kohlensäure, die bei ganz bestimmter Konstellation der Empfindlichkeit der beiden, für die reflektorische Utbermittlung der Reize auf den Herzmuskel in Betracht kommenden Nervensysteme, die Wirkung nur in rem einen Falle zustande kommen läßt. Weitere Untersuchungen dieser Art werden sicherlich zu größerer Klarheit auch hierüber führen.

Die bei vielen Patienten von mir nachgewiesene Schädigung durch die Einatmung der Kohlensäure, die durch völlige Abdeckung der Bäder und die dazugehörigen Vorsichtsmaßregeln verhindert werden kann, ist keinesfalls dadurch zu erklären, daß etwa die durch die Einatmung ins Blut übergegangene Kohlensäure in der Weise, wie ich das eingangs ausgeführt habe, einen schädlichen Einfluß auf die von diesem Blut umspülten Gefäßzentren im Gehirn ausübt, dessen Folge die Umkehrung der von den Gefäßzentren zu den Blutgefäßen während der Muskelarbeit ausgesandten Reize ist. Dafür ist die Menge der eingeatmeten Kohlensäure zu gering und die Dauer des schädlichen Einflusses, der sich über mehrere Tage nach dem Bade erstrecken kann, viel zu groß. Auch hierbei handelt es sich zweifellos um eine reflektorische Einwirkung der eingeatmeten Kohlensäure, die den bei den betreffenden Patienten besonders empfindlichen Vagus zu stark erregt und durch seine Vermittlung eine Abschwächung der Herzaktion, besonders der Kraft der einzelnen Herzkontraktionen, herbeiführt. Da es sich in diesen Fällen um Patienten handelt, deren Kreislauffunktion schon 
vorher so geschädigt ist, daß eine hinreichende Arterialisierung des Blutes nicht, oder kaum noch durch den Kreislauf geschafft werden kann, so genügt diese weitere Herabsetzung der Herzaktion vollkommen dazu, die Arterialisierung des Blutes so weit zu verschlechtern, daß die erwähnte Schädigung der Gefäßzentren im Gehirn eintritt, deren Folgen sich durch eine negative Kurve ausdrücken.

In derselben Weise èrklärt sich z. B. auch das Eintreten von negativen Kurven bei zu starker Herzmassage, oder anderen therapeutischen Eingriffen, die das bei diesen Kranken besonders empfindliche autonome System zu stark erregen.

Wohl nur durch die Veränderung des Erregungszustandes des autonomen Systems läßt sich auch die durch meine Kurven außerordentlich häufig nachgewiesene, eigenartige Erscheinung erklären, daß die Überkorrektion einer pathologisch veränderten Funktion des Kreislaufs durch Hypertrophie des linken Herzens zeitweilig völlig verschwinden, also die Funktion der durch die Hypertrophie geschaffenen neuen Muskelmasse des Herzens völlig funktionell latent werden, oder vielleicht von vornherein funktionell latent bleiben kann. Ich nenne sie latent deshalb, weil sie durch gewisse thera peutische Reize wieder in Funktion gesetzt werden kann. Wir sahen, daß in jedem der Fälle von Abb. 3, 4, 5, 6, 7, 8 eine völlig, oder teilweise negative Kurve vorhanden war, die durch die entsprechenden therapeutischen Einwirkungen in allen Fällen in eine nachträglich ansteigende Kurve umgewandelt wurde, die den Beweis dafür darstellt, daß nach der Behandlung in jedem dieser Fälle eine Hypertrophie des linken Herzens funktionell wirksam war, die wieder ihrerseits durch andere, dämpfende therapeutische Maßnahmen zu normaler Kurve umgewandelt werden konnte.

In allen diesen Fällen war die Hypertrophie des linken Herzens auch durch das Röntgenbild nachzuweisen (obwohl das durchaus nicht immer der Fall zu sein braucht), es hatte also bereits in einem früheren Stadium der Krankheit eine Selbsthilfe des Organismus durch Entwicklung von Hypertrophie des linken Herzens stattgefunden, die, wie wir aus dem Erfolg der Behandlung sehen, bei genügender Ausnutzung völlig genügte, die Insuffizienz des Kreislaufs in jedem einzelnen Falle zu korrigieren, ja sogar eine Utberkorrektion zu schaffen, und trotzdem lag vor Beginn der Behandlung in jedem dieser Fälle infolge Nichtausnutzung der funktionsfähigen mechanischen Mittel Insuffizienz des Kreislaufs vor.

Nach den oben entwickelten Anschauungen erklärt sich dieses ungezwungen dadurch, daß bei diesen Patienten nicht das wünschenswerte Verhältnis der Erregbarkeit der beiden Nervensysteme vorhanden war, durch deren Vermittlung die Aktion des Herzmuskels reflektorisch beeinflußt wird, sei es, daß die Erregbarkeit des Accelerans vermindert, 
oder die des Vagus gesteigert war. Dieses anormale Verhalten der beiden Nervensysteme kann sich im Laufe der Krankheit entwickelt haben, sehr wohl ist es auch denkbar, daß es dauernd vorhanden gewesen ist, was an eine gewisse Prädisposition solcher Menschen für Herzmuskelinsuffizienz denken lassen könnte. In jedem Falle sahen wir bei diesen Patienten nach Zuführung von Reizen, die besonders stark erregend auf den Accelerans wirken, wie z. B. die Kohlensäurebäder, die vorher unausgenutzte, latente Funktion des hypertrophischen Anteils des linken Ventrikels in Funktion treten und die gewünschte Korrektion, ja sogar zunächst Überkorrektion des Kreislaufs eintreten. Daß in entsprechender Weise die Dämpfung einer Überkorrektion, die sich in nachträglich ansteigender Kurve ausdrückt, durch reflektorische Erregung des Vagus zu erklären sein wird, wurde schon oben erörtert, und die Kohlensäurebäder wirken offenbar deshalb nur in der Minderzahl der Fälle, in denen es erwünšcht wäre, bei Uberkorrektion dämpfend (dann aber auch sehr anhaltend), weil diese Art der therapeutischen Maßnahmen vorzugsweise auf den Accelerans wirkt und offenbar nur bei besonders günstigem Verhältnis der Erregbarkeit der beiden das Herz beeinflussenden Nervensysteme zum dämpfenden Enderfolg führt.

Die günstigen Dauerwirkungen nach thera peutischen Maßnahmen, wie ich sie besonders auch nach Kohlensäurebädern an Hand meiner Kurven beobachtet habe, sprechen nicht gegen diese Erklärung der Wirkung gewisser therapeutischer Maßnahmen durch reflektorische Beeinflussung des Herzmuskels. Man könnte an eine Art von Bahnung denken, die durch die ungewohnten, starken Reize an den nervösen Verbindungen bewirkt wird und den später wieder allein wirkenden normalen Reizen eine leichtere Einwirkungsmöglichkeit schafft. (Ich bin auch bei anderen Untersuchungen auf derartige Dauerwirkungen starker Nervenreize gestoßen.)

Diese theoretischen Erwägungen werden wesentlich dadurch gestützt, daß ich in ihrer natürlichen Weiterführung zu der medikamentösen Beeinflussung der Nerven überging, deren verschiedener Erregbarkeitszustand nach oben Gesagtem von so maßgebendem Einfluß auf die Wirkung der verschiedenen therapeutischen Maßnahmen bei Herzkranken zu sein scheint, und daß sich tatsächlich nachweisen ließ, daß dadurch in gewissen Fällen die Wirkung der gleichen Maßnahmen am gleichen Patient völlig verändert werden kann.

(Ưber diese neueren Untersuchungen werde ich mit meinem Mitarbeiter später berichten.)

Die praktische Bedeutung dieser letzten Erörterungen liegt offenbar darin, daß aus ihnen hervorgeht, daß es sich bei der Wirkung der therapeutischen Maßnahmen, wie z. B. der Kohlensäurebäder, bei Herzkranken keineswegs nur um ein Aufpeitschen der Herzmuskulatur 
handelt, bei dem keine neuen Kräfte dem Herzen zugeführt werden, wie man bisher annahm.

Vielmehr zeigen meine Untersuchungen, daß bei vielen Herzkranken die längst entwickelten und funktionsfähigen Hilfskräfte des Herzmuskels infolge bestimmter Hemmungen nicht, oder nicht genügend ausgenutzt werden, also latent bleiben, und erst durch gewisse Reize hinreichend zur Mitarbeit an der Herzfunktion herangezogen werden.

Es werden also auf diese Weise tatsächlich der Kreislaufsfunktion durch die wirksamen therapeutischen Maßnahmen neue, vorher unbenutzte Kräfte zugeführt, ohne die ja auch in vielen Fällen eine Dauerwirkung sich kaum erklären lassen würde. - 